Cochrane Database of Systematic Reviews

\title{
Perioperative nutrition for the treatment of bladder cancer by radical cystectomy (Review)
}

Burden S, Billson HA, Lal S, Owen KA, Muneer A

Burden S, Billson HA, Lal S, Owen KA, Muneer A.

Perioperative nutrition for the treatment of bladder cancer by radical cystectomy.

Cochrane Database of Systematic Reviews 2019, Issue 5. Art. No.: CD010127.

DOI: 10.1002/14651858.CD010127.pub2.

www.cochranelibrary.com 
TABLE OF CONTENTS

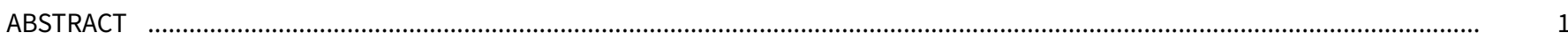

PLAIN LANGUAGE SUMMARY

SUMMARY OF FINDINGS

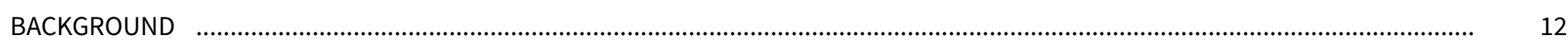

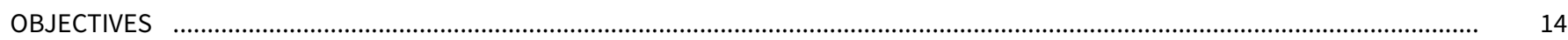

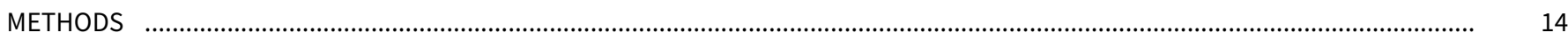

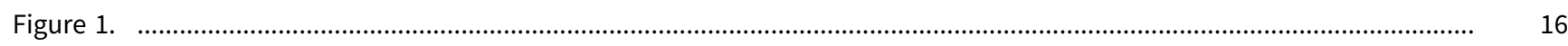

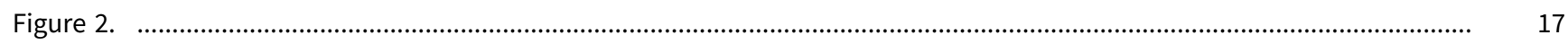

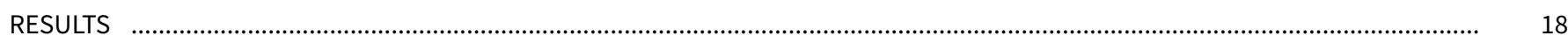

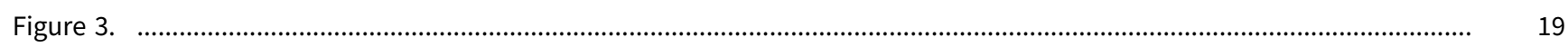

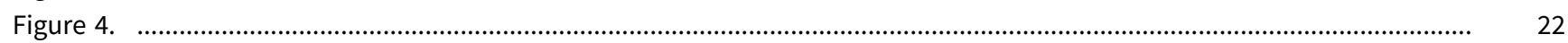

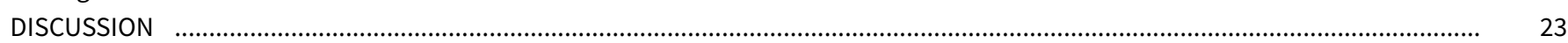

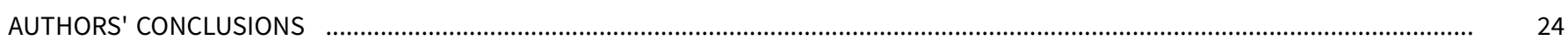

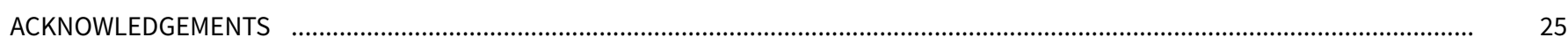

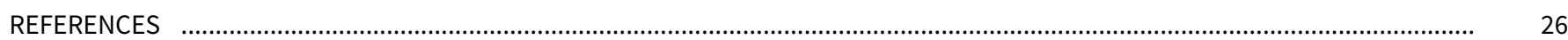

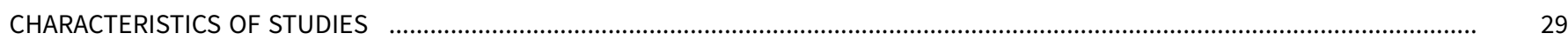

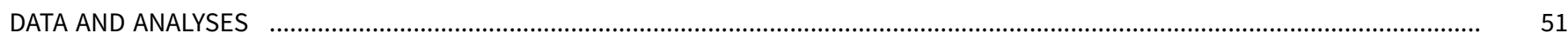

Analysis 1.1. Comparison 1 Postoperative parenteral nutrition compared to standard care, Outcome 1 Complications. ........... 51

Analysis 1.2. Comparison 1 Postoperative parenteral nutrition compared to standard care, Outcome 2 Mortality. .................... 52

Analysis 2.1. Comparison 2 Immunonutrition compared to standard oral nutritional supplements, Outcome 1 Complications 52 at 90 days.

Analysis 2.2. Comparison 2 Immunonutrition compared to standard oral nutritional supplements, Outcome 2 Complications at 30 days.

Analysis 2.3. Comparison 2 Immunonutrition compared to standard oral nutritional supplements, Outcome 3 Length of hospital stay.

Analysis 3.1. Comparison 3 Preoperative oral nutritional support compared to normal diet, Outcome 1 Complications. ..........

Analysis 4.1. Comparison 4 Early postoperative feeding compared to standard postoperative management, Outcome 1 Complications.

Analysis 4.2. Comparison 4 Early postoperative feeding compared to standard postoperative management, Outcome 2 Mortality.

Analysis 5.1. Comparison 5 Amino acid solution, alone or in combination with dextrose, compared to dextrose solution, Outcome 1 Complications.

Analysis 5.2. Comparison 5 Amino acid solution, alone or in combination with dextrose, compared to dextrose solution, Outcome 2 Length of hospital stay.

Analysis 5.3. Comparison 5 Amino acid solution, alone or in combination with dextrose, compared to dextrose solution, Outcome 3 Mortality.

Analysis 6.1. Comparison 6 Perioperative oral nutritional supplements compared to oral multivitamin and mineral supplement, Outcome 1 Complications.

Analysis 6.2. Comparison 6 Perioperative oral nutritional supplements compared to oral multivitamin and mineral supplement, Outcome 2 Length of hospital stay.

Analysis 6.3. Comparison 6 Perioperative oral nutritional supplements compared to oral multivitamin and mineral supplement, Outcome 3 Mortality.

ADDITIONAL TABLES

APPENDICES

CONTRIBUTIONS OF AUTHORS

DECLARATIONS OF INTEREST

SOURCES OF SUPPORT

DIFFERENCES BETWEEN PROTOCOL AND REVIEW

NOTES

INDEX TERMS 
[Intervention Review]

\section{Perioperative nutrition for the treatment of bladder cancer by radical cystectomy}

Sorrel Burden¹, Hazel A Billson², Simon Lal ${ }^{3}$, Kellie A Owen², Asif Muneer4

1School of Health Sciences, The University of Manchester, and Manchester Academic Health Science Centre, Manchester, UK. 2Dietetic Department, Platt 2 Rehabilitation, Manchester Royal Infirmary, Manchester, UK. 3 Intestinal Failure Unit, Salford Royal Foundation Trust, Salford, UK. ${ }^{4}$ Department of Urology and NIHR Biomedical Research Centre, University College London Hospital, London, UK

Contact: Sorrel Burden, School of Health Sciences, The University of Manchester, and Manchester Academic Health Science Centre, Manchester, M13 9PL, UK. Sorrel.burden@manchester.ac.uk.

Editorial group: Cochrane Urology Group.

Publication status and date: New, published in Issue 5, 2019.

Citation: Burden S, Billson HA, Lal S, Owen KA, Muneer A. Perioperative nutrition for the treatment of bladder cancer by radical cystectomy. Cochrane Database of Systematic Reviews 2019, Issue 5. Art. No.: CD010127. DOI: 10.1002/14651858.CD010127.pub2.

Copyright @ 2019 The Cochrane Collaboration. Published by John Wiley \& Sons, Ltd.

\section{A B S T R A C T}

\section{Background}

Radical cystectomy (RC) is the primary surgical treatment for muscle-invasive urothelial carcinoma of the bladder. This major operation is typically associated with an extended hospital stay, a prolonged recovery period and potentially major complications. Nutritional interventions are beneficial in some people with other types of cancer and may be of value in this setting too.

\section{Objectives}

To assess the effects of perioperative nutrition in people undergoing radical cystectomy for the treatment of bladder cancer.

\section{Search methods}

We performed a comprehensive search using multiple databases (Evidence Based Medicine Reviews, MEDLINE, Embase, AMED, CINAHL), trials registries, other sources of grey literature, and conference proceedings published up to 22 February 2019, with no restrictions on the language or status of publication.

\section{Selection criteria}

We included parallel-group randomised controlled trials (RCTs) of adults undergoing RC for bladder cancer. The intervention was any perioperative nutrition support.

\section{Data collection and analysis}

Two review authors independently assessed studies for inclusion, extracted data, and assessed risk of bias and the quality of evidence using GRADE. Primary outcomes were postoperative complications at 90 days and length of hospital stay. The secondary outcome was mortality up to 90 days after surgery. When 90-day outcome data were not available, we reported 30-day data.

\section{Main results}

The search identified eight trials including 500 participants. Six trials were conducted in the USA and two in Europe.

1. Parenteral nutrition (PN) versus oral nutrition: based on one study with 157 participants, PN may increase postoperative complications within 30 days (risk ratio (RR) 1.40, 95\% confidence interval (CI) 1.07 to 1.82; low-quality evidence). We downgraded the quality of evidence for serious study limitations (unclear risk of selection, performance and selective reporting bias) and serious 
imprecision. This corresponds to 198 more complications per 1000 participants ( $95 \% \mathrm{Cl} 35$ more to 405 more). Length of hospital stay may be similar (mean difference (MD) 0.5 days higher, $\mathrm{Cl}$ not reported; low-quality evidence).

2. Immuno-enhancing nutrition versus standard nutrition: based on one study including 29 participants, immuno-enhancing nutrition may reduce 90 -day postoperative complications ( $\mathrm{RR} 0.31,95 \% \mathrm{Cl} 0.08$ to 1.23 ; low-quality evidence). These findings correspond to 322 fewer complications per 1000 participants ( $95 \%$ Cl 429 fewer to 107 more). Length of hospital stay may be similar (MD 0.20 days, 95\% Cl 1.69 lower to 2.09 higher; low-quality evidence). We downgraded the quality of evidence of both outcomes for very serious imprecision.

3. Preoperative oral nutritional support versus normal diet: based on one study including 28 participants, we are very uncertain if preoperative oral supplements reduces postoperative complications. We downgraded quality for serious study limitations (unclear risk of selection, performance, attrition and selective reporting bias) and very serious imprecision. The study did not report on length of hospital stay.

4. Early postoperative feeding versus standard postoperative management: based on one study with 102 participants, early postoperative feeding may increase postoperative complications (very low-quality evidence) but we are very uncertain of this finding. We downgraded the quality of evidence for serious study limitations (unclear risk of selection and performance bias) and very serious imprecision. Length of hospital stay may be similar (MD 0.95 days less, $\mathrm{Cl}$ not reported; low-quality evidence). We downgraded the quality of evidence for serious study limitations (unclear risk of selection and performance bias) and serious imprecision.

5. Amino acid with dextrose versus dextrose: based on two studies with 104 participants, we are very uncertain whether amino acids reduce postoperative complications (very low-quality evidence). We are also very uncertain whether length of hospital stay is similar (very low-quality evidence). We downgraded the quality of evidence for both outcomes for serious study limitations (unclear and high risk of selection bias; unclear risk of performance, detection and selective reporting bias), serious indirectness related to the patient population and very serious imprecision.

6. Branch chain amino acids versus dextrose only: based on one study including 19 participants, we are very uncertain whether complication rates are similar (very low-quality evidence). We downgraded the quality of evidence for serious study limitations (unclear risk of selection, performance, detection, attrition and selective reporting bias), serious indirectness related to the patient population and very serious imprecision. The study did not report on length of hospital stay.

7. Perioperative oral nutritional supplements versus oral multivitamin and mineral supplement: based on one study with 61 participants, oral supplements compared to a multivitamin and mineral supplement may slightly decrease postoperative complications (low-quality evidence). These findings correspond to 135 fewer occurrences per 1000 participants ( $95 \% \mathrm{Cl} 256$ fewer to 65 more). Length of hospital stay may be similar (low-quality evidence). We downgraded the quality of evidence of both outcomes for study limitations and imprecision.

\section{Authors' conclusions}

Based on few, small and dated studies, with serious methodological limitations, we found limited evidence for a benefit of perioperative nutrition interventions. We rated the quality of evidence as low or very low, which underscores the urgent need for high-quality research studies to better inform nutritional support interventions for people undergoing surgery for bladder cancer.

\section{PLAIN LANGUAGE SUMMARY}

\section{Nutrition support for people having an operation for bladder cancer}

\section{Review objective}

To assess the effects of perioperative nutrition in participants undergoing an operation for treating bladder cancer.

\section{Background}

Some people with advanced bladder cancer require an operation called a radical cystectomy to remove their bladder, which has a risk of complications after surgery.

Some people who have bladder cancer may have difficulties with eating before or after the operation and may lose weight and be malnourished. In this review, we wanted to see if providing additional nutrition is of benefit compared to waiting for people to eat ordinary food.

\section{Study characteristics}

The evidence is current up to 22 February 2019. There were eight studies conducted including 500 people in hospital. There were seven different ways in which nutrition was given.

\section{Key results}


1. Feeding into a vein versus oral nutrition: based on one study that included 157 people, we found that feeding into a vein may increase complications after surgery. However, there may be little or no difference in length of hospital stay.

2. Immuno-enhancing nutrition versus standard supplements: immuno-enhancing nutrition has high levels of nutrients that are thought to improve the immune function and was given in one study that included 29 people. We found that this form of nutrition may decrease complications 90 days after surgery, but may have little effect on length of hospital stay.

3. Preoperative oral nutrition support versus diet: based on one study that included 28 people, we are uncertain if oral supplements before surgery improve complications after surgery. Length of hospital stay was not reported.

4. Early postoperative feeding versus standard care: based on one study that included 102 people, early postoperative feeding may increase postoperative complications after surgery, but we are very uncertain of this finding. Length of hospital stay may be similar.

5. Amino acids versus dextrose: amino acids are the building blocks of proteins and dextrose is sugary water. From two studies that included 104 people, we are uncertain whether complications may be reduced. Length of hospital stay may be similar.

6. Branch chain versus dextrose: branch chain are a type of amino acid. From one study that included 19 people, we are very uncertain whether complication rates are similar. Length of hospital stay was not reported.

7. Perioperative oral nutritional supplements versus multivitamin and mineral supplement: from one study that included 61 people, oral supplements compared to a multivitamin and mineral supplement may slightly decrease postoperative complications. Length of hospital stay may be similar.

\section{Certainty of the evidence}

The certainty of the evidence for all outcomes in this review was low or very low, meaning that the true effect may be very different or is likely very different from what we found. 


\section{SUMMARY OF FINDINGS}

Summary of findings for the main comparison. Postoperative parenteral nutrition compared to oral nutrition alone for the treatment of bladder cancer by radical cystectomy

Postoperative parenteral nutrition compared to oral nutrition alone for the treatment of bladder cancer by radical cystectomy

Participants: people with bladder cancer who have had a radical cystectomy

Settings: University Hospital Bern, Switzerland

Interventions: parenteral nutrition

Control: oral nutrition with Ringer's lactate solution

\begin{tabular}{|c|c|c|c|c|c|}
\hline \multirow[t]{2}{*}{ Outcomes } & \multirow{2}{*}{$\begin{array}{l}\text { № of participants } \\
\text { (studies) }\end{array}$} & \multirow{2}{*}{$\begin{array}{l}\text { Certainty of the } \\
\text { evidence } \\
\text { (GRADE) }\end{array}$} & \multirow{2}{*}{$\begin{array}{l}\text { Relative effect } \\
(95 \% \mathrm{CI})\end{array}$} & \multicolumn{2}{|c|}{ Anticipated absolute effects* $(95 \% \mathrm{Cl})$} \\
\hline & & & & $\begin{array}{l}\text { Risk with oral nutrition } \\
\text { alone }\end{array}$ & $\begin{array}{l}\text { Risk difference with postoperative parenter- } \\
\text { al nutrition }\end{array}$ \\
\hline \multirow{2}{*}{$\begin{array}{l}\text { Complications } \\
\text { Follow-up: } 30 \text { days }\end{array}$} & \multirow{2}{*}{$\begin{array}{l}157 \\
(1 \mathrm{RCT})\end{array}$} & \multirow{2}{*}{$\begin{array}{l}\oplus \oplus \ominus \ominus \\
\text { Low }^{a, b}\end{array}$} & \multirow{2}{*}{$\begin{array}{l}\text { RR } 1.40 \\
\text { (1.07 to } 1.82)\end{array}$} & \multicolumn{2}{|l|}{ Study population } \\
\hline & & & & 494 per 1000 & $\begin{array}{l}198 \text { more per } 1000 \\
\text { (35 more to } 405 \text { more) }\end{array}$ \\
\hline $\begin{array}{l}\text { Length of hospital } \\
\text { stay }\end{array}$ & $\begin{array}{l}157 \\
(1 \mathrm{RCT})\end{array}$ & $\begin{array}{l}\oplus \oplus \ominus \ominus \\
\text { Lowa,c }\end{array}$ & - & $\begin{array}{l}\text { The mean length of hospital } \\
\text { stay was } 15.5 \text { days }\end{array}$ & $\begin{array}{l}\text { MD } 0.5 \text { days more } \\
\text { (not reported) }\end{array}$ \\
\hline \multirow{2}{*}{$\begin{array}{l}\text { Mortality } \\
\text { Follow-up: } 30 \text { days }\end{array}$} & \multirow{2}{*}{$\begin{array}{l}157 \\
(1 \mathrm{RCT})\end{array}$} & \multirow{2}{*}{$\begin{array}{l}\oplus \ominus \ominus \ominus \\
\text { Very low }{ }^{a, d}\end{array}$} & \multirow{2}{*}{$\begin{array}{l}\text { RR } 1.12 \\
(0.07 \text { to } 17.62)\end{array}$} & \multicolumn{2}{|l|}{ Study population } \\
\hline & & & & 12 per 1000 & $\begin{array}{l}1 \text { more per } 1000 \\
\text { (11 fewer to } 200 \text { more) }\end{array}$ \\
\hline
\end{tabular}

${ }^{\star}$ The risk in the intervention group (and its $95 \%$ confidence interval) is based on the assumed risk in the comparison group and the relative effect of the intervention (and its $95 \% \mathrm{Cl})$.

Cl: confidence interval; RCT: randomised controlled trial; RR: risk ratio.

\section{GRADE Working Group grades of evidence}

High certainty: we are very confident that the true effect lies close to that of the estimate of the effect.

Moderate certainty: we are moderately confident in the effect estimate: the true effect is likely to be close to the estimate of the effect, but there is a possibility that it is substantially different.

Low certainty: our confidence in the effect estimate is limited: the true effect may be substantially different from the estimate of the effect.

Very low certainty: we have very little confidence in the effect estimate: the true effect is likely to be substantially different from the estimate of effect. 


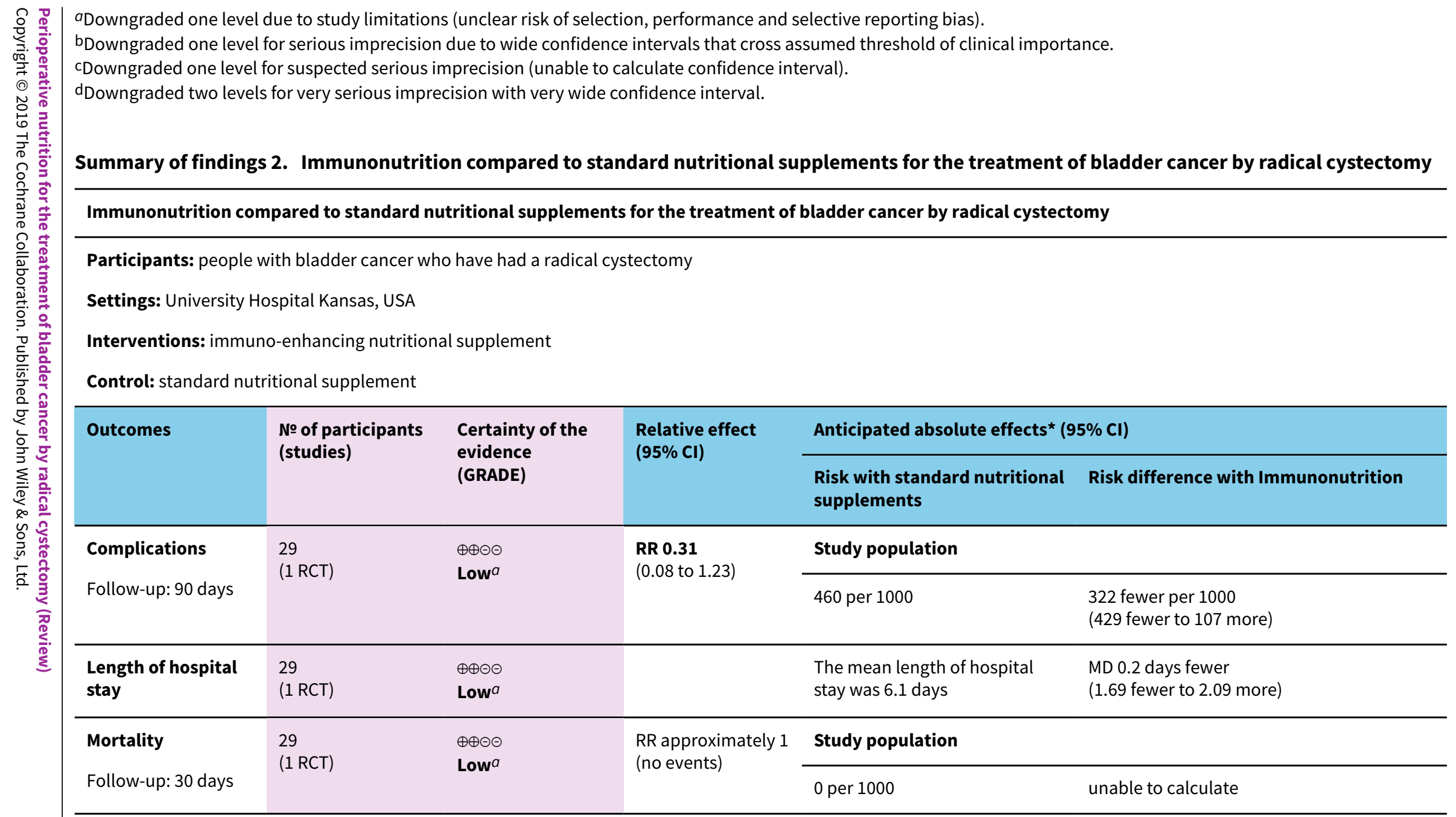

${ }^{*}$ The risk in the intervention group (and its $95 \%$ confidence interval) is based on the assumed risk in the comparison group and the relative effect of the intervention (and its $95 \% \mathrm{Cl})$.

Cl: confidence interval; RCT: randomised controlled trial; RR: risk ratio.

\section{GRADE Working Group grades of evidence}

High certainty: we are very confident that the true effect lies close to that of the estimate of the effect.

Moderate certainty: we are moderately confident in the effect estimate: the true effect is likely to be close to the estimate of the effect, but there is a possibility that it is substantially different.

Low certainty: our confidence in the effect estimate is limited: the true effect may be substantially different from the estimate of the effect. 


\begin{tabular}{|c|c|c|c|c|c|}
\hline \multicolumn{6}{|c|}{ Summary of findings 3. Preoperative oral nutritional support compared to normal diet for the treatment of bladder cancer by radical cystectomy } \\
\hline \multicolumn{6}{|c|}{ Preoperative oral nutritional support compared to normal diet for the treatment of bladder cancer by radical cystectomy } \\
\hline \multicolumn{6}{|c|}{$\begin{array}{l}\text { Participants: people with bladder cancer who have had a radical cystectomy } \\
\text { Settings: Hospital, Turin, Italy } \\
\text { Interventions: oral nutritional supplements } \\
\text { Control: normal diet }\end{array}$} \\
\hline \multirow[t]{2}{*}{ Outcomes } & \multirow{2}{*}{$\begin{array}{l}\text { № of participants } \\
\text { (studies) }\end{array}$} & \multirow{2}{*}{$\begin{array}{l}\text { Certainty of the } \\
\text { evidence } \\
\text { (GRADE) }\end{array}$} & \multirow{2}{*}{$\begin{array}{l}\text { Relative effect } \\
(95 \% \mathrm{Cl})\end{array}$} & \multicolumn{2}{|c|}{ Anticipated absolute effects* $(95 \% \mathrm{Cl})$} \\
\hline & & & & $\begin{array}{l}\text { Risk with normal di- } \\
\text { et }\end{array}$ & $\begin{array}{l}\text { Risk difference with Preoperative oral nu- } \\
\text { tritional support }\end{array}$ \\
\hline \multirow{2}{*}{$\begin{array}{l}\text { Complications } \\
\text { Follow-up: } 30 \text { days }\end{array}$} & \multirow{2}{*}{$\begin{array}{l}28 \\
(1 \mathrm{RCT})\end{array}$} & \multirow{2}{*}{$\begin{array}{l}\oplus \ominus \odot \odot \\
\text { Very low } a, b\end{array}$} & \multirow{2}{*}{$\begin{array}{l}\text { RR } 0.89 \\
(0.18 \text { to } 4.51)\end{array}$} & \multicolumn{2}{|l|}{ Study population } \\
\hline & & & & 188 per 1000 & $\begin{array}{l}21 \text { fewer per } 1000 \\
\text { (154 fewer to } 658 \text { more) }\end{array}$ \\
\hline $\begin{array}{l}\text { Length of hospital stay - } \\
\text { not measured }\end{array}$ & - & - & - & - & - \\
\hline \multirow{2}{*}{$\begin{array}{l}\text { Mortality } \\
\text { Follow-up: } 30 \text { days }\end{array}$} & \multirow{2}{*}{$\begin{array}{l}28 \\
(1 \mathrm{RCT})\end{array}$} & \multirow{2}{*}{$\begin{array}{l}\oplus \ominus \odot \ominus \\
\text { Very low }\end{array}$} & \multirow{2}{*}{$\begin{array}{l}\text { RR approximately } 1 \\
\text { (no events) }\end{array}$} & \multicolumn{2}{|l|}{ Study population } \\
\hline & & & & 0 per 1000 & Unable to calculate \\
\hline
\end{tabular}

*The risk in the intervention group (and its 95\% confidence interval) is based on the assumed risk in the comparison group and the relative effect of the intervention (and its $95 \% \mathrm{Cl})$.

Cl: confidence interval; RCT: randomised controlled trial; RR: risk ratio.

\section{GRADE Working Group grades of evidence}

High certainty: we are very confident that the true effect lies close to that of the estimate of the effect.

Moderate certainty: we are moderately confident in the effect estimate: the true effect is likely to be close to the estimate of the effect, but there is a possibility that it is substantially different.

Low certainty: our confidence in the effect estimate is limited: the true effect may be substantially different from the estimate of the effect. 


\begin{tabular}{|c|c|c|c|c|c|}
\hline \multicolumn{6}{|c|}{$\begin{array}{l}\text { aDowngraded one level due to study limitations (unclear risk of selection, performance, attrition and selective reporting bias). } \\
\text { bDowngraded two levels for very serious imprecision with very wide confidence interval. } \\
\text { Summary of findings } 4 \text {. Early postoperative feeding compared to standard management for the treatment of bladder cancer by radical cystectomy }\end{array}$} \\
\hline \multicolumn{6}{|c|}{ Early postoperative feeding compared to standard management for the treatment of bladder cancer by radical cystectomy } \\
\hline \multicolumn{6}{|c|}{$\begin{array}{l}\text { Settings: } 2 \text { hospitals, USA } \\
\text { Interventions: early enteral feeding after surgery } \\
\text { Control: standard care }\end{array}$} \\
\hline \multirow[t]{2}{*}{ Outcomes } & \multirow{2}{*}{$\begin{array}{l}\text { № of participants } \\
\text { (studies) }\end{array}$} & \multirow{2}{*}{$\begin{array}{l}\text { Certainty of the } \\
\text { evidence } \\
\text { (GRADE) }\end{array}$} & \multirow{2}{*}{$\begin{array}{l}\text { Relative effect } \\
(95 \% \mathrm{Cl})\end{array}$} & \multicolumn{2}{|c|}{ Anticipated absolute effects* $(95 \% \mathrm{Cl})$} \\
\hline & & & & $\begin{array}{l}\text { Risk with standard manage- } \\
\text { ment }\end{array}$ & $\begin{array}{l}\text { Risk difference with early postoperative } \\
\text { feeding }\end{array}$ \\
\hline Complications & \multirow{2}{*}{$\begin{array}{l}102 \\
(1 \mathrm{RCT})\end{array}$} & \multirow{2}{*}{$\begin{array}{l}\oplus \oplus \ominus \ominus \\
\text { Very low }{ }^{a, b}\end{array}$} & \multirow{2}{*}{$\begin{array}{l}\text { RR } 1.14 \\
(0.85 \text { to } 1.53)\end{array}$} & \multicolumn{2}{|l|}{ Study population } \\
\hline Follow-up: 30 days & & & & 596 per 1000 & $\begin{array}{l}83 \text { more per } 1000 \\
\text { ( } 89 \text { fewer to } 316 \text { more) }\end{array}$ \\
\hline $\begin{array}{l}\text { Length of hospital } \\
\text { stay }\end{array}$ & $\begin{array}{l}102 \\
(1 \mathrm{RCT})\end{array}$ & $\begin{array}{l}\oplus \oplus \ominus \ominus \\
\text { Lowa,c }\end{array}$ & - & $\begin{array}{l}\text { The mean length of hospital } \\
\text { stay was } 9.7 \text { days }\end{array}$ & MD 0.95 days fewer (unable to calculate $\mathrm{Cl}$ ) \\
\hline \multirow{2}{*}{$\begin{array}{l}\text { Mortality } \\
\text { Follow-up: } 30 \text { days }\end{array}$} & \multirow{2}{*}{$\begin{array}{l}102 \\
(1 \mathrm{RCT})\end{array}$} & \multirow{2}{*}{$\begin{array}{l}\oplus \oplus \ominus \ominus \\
\text { Lowa,c }\end{array}$} & \multirow{2}{*}{$\begin{array}{l}\text { RR } \mathbf{0 . 5 2} \\
(0.10 \text { to } 2.71)\end{array}$} & Study population & \\
\hline & & & & 38 per 1000 & $\begin{array}{l}19 \text { fewer per } 1000 \\
\text { ( } 35 \text { fewer to } 72 \text { more) }\end{array}$ \\
\hline
\end{tabular}

${ }^{\star}$ The risk in the intervention group (and its $95 \%$ confidence interval) is based on the assumed risk in the comparison group and the relative effect of the intervention (and its $95 \% \mathrm{Cl}$ ).

Cl: confidence interval; $\mathbf{R C T}$ : randomised controlled trial; RR: risk ratio.

\section{GRADE Working Group grades of evidence}

High certainty: we are very confident that the true effect lies close to that of the estimate of the effect.

Moderate certainty: we are moderately confident in the effect estimate: the true effect is likely to be close to the estimate of the effect, but there is a possibility that it is substantially different. 


\begin{tabular}{|c|c|c|c|c|c|}
\hline \multicolumn{6}{|c|}{$\begin{array}{l}\text { Low certainty: our confidence in the effect estimate is limited: the true effect may be substantially different from the } \\
\text { Very low certainty: we have very little confidence in the effect estimate: the true effect is likely to be substantially diff }\end{array}$} \\
\hline \multicolumn{6}{|c|}{$\begin{array}{l}\text { aDowngraded one level for study limitations (unclear risk of selection and performance bias). } \\
\text { bDowngraded two levels for very serious imprecision with very wide confidence interval. } \\
\text { cDowngraded one level for serious imprecision (unable to calculate confidence interval). }\end{array}$} \\
\hline \multicolumn{6}{|c|}{ Amino acid solution, alone or in combination with dextrose compared to dextrose solution for the treatment of bladder cancer by radical cystectomy } \\
\hline $\begin{array}{l}\text { Participants: peopl } \\
\text { Settings: hospital, } \\
\text { Interventions: ami } \\
\text { Control: dextrose }\end{array}$ & $\begin{array}{l}\text { with bladder cancer } \\
\text { SA } \\
\text { acid solutions }\end{array}$ & ho have had a radic & ystectomy & & \\
\hline \multirow[t]{2}{*}{ Outcomes } & \multirow{2}{*}{$\begin{array}{l}\text { № of participants } \\
\text { (studies) }\end{array}$} & \multirow{2}{*}{$\begin{array}{l}\text { Certainty of the } \\
\text { evidence } \\
\text { (GRADE) }\end{array}$} & \multirow{2}{*}{$\begin{array}{l}\text { Relative effect } \\
(95 \% \mathrm{Cl})\end{array}$} & \multicolumn{2}{|c|}{ Anticipated absolute effects* $(95 \% \mathrm{Cl})$} \\
\hline & & & & $\begin{array}{l}\text { Risk with dextrose solu- } \\
\text { tion }\end{array}$ & $\begin{array}{l}\text { Risk difference with amino acid solution, } \\
\text { alone or in combination with dextrose }\end{array}$ \\
\hline \multirow{2}{*}{$\begin{array}{l}\text { Complications } \\
\text { Follow-up: } 30 \text { days }\end{array}$} & \multirow{2}{*}{$\begin{array}{l}104 \\
(2 \text { RCTs })\end{array}$} & \multirow{2}{*}{$\begin{array}{l}\oplus \odot \Theta \Theta \\
\text { Very lowa,b,c }\end{array}$} & \multirow{2}{*}{$\begin{array}{l}\text { RR } 0.77 \\
(0.32 \text { to } 1.82)\end{array}$} & \multicolumn{2}{|l|}{ Study population } \\
\hline & & & & 200 per 1000 & $\begin{array}{l}46 \text { fewer per } 1000 \\
\text { (136 fewer to } 164 \text { more) }\end{array}$ \\
\hline $\begin{array}{l}\text { Length of hospital } \\
\text { stay }\end{array}$ & $\begin{array}{l}44 \\
(1 \mathrm{RCT})\end{array}$ & $\begin{array}{l}\oplus \ominus \ominus \ominus \\
\text { Very lowa,b,c }\end{array}$ & - & $\begin{array}{l}\text { The mean length of hospital } \\
\text { stay was } 32 \text { days }\end{array}$ & MD 0.5 days fewer \\
\hline \multirow{2}{*}{$\begin{array}{l}\text { Mortality } \\
\text { Follow-up: } 30 \text { days }\end{array}$} & \multirow{2}{*}{$\begin{array}{l}60 \\
(1 \mathrm{RCT})\end{array}$} & \multirow{2}{*}{$\begin{array}{l}\oplus \ominus \odot \odot \\
\text { Very low }{ }^{a, b, c}\end{array}$} & \multirow{2}{*}{$\begin{array}{l}\text { RR approximately } 1 \\
\text { (no events) }\end{array}$} & Study population & \\
\hline & & & & 0 per 1000 & Unable to calculate \\
\hline
\end{tabular}

${ }^{\star}$ The risk in the intervention group (and its $95 \%$ confidence interval) is based on the assumed risk in the comparison group and the relative effect of the intervention (and its $95 \% \mathrm{Cl})$.

Cl: confidence interval; RCT: randomised controlled trial; RR: risk ratio.

\section{GRADE Working Group grades of evidence}

High certainty: we are very confident that the true effect lies close to that of the estimate of the effect. 
Moderate certainty: we are moderately confident in the effect estimate: the true effect is likely to be close to the estimate of the effect, but there is a possibility that it is substantially different.

Low certainty: our confidence in the effect estimate is limited: the true effect may be substantially different from the estimate of the effect.

Very low certainty: we have very little confidence in the effect estimate: the true effect is likely to be substantially different from the estimate of effect.

aDowngraded one level due to study limitations (unclear and high risk of selection bias; unclear risk of performance, detection and selective reporting bias).

bDowngraded one level due to serious indirectness related to patient population.

cDowngraded two levels due to very serious imprecision with very wide confidence intervals.

\section{Summary of findings 6. Branch chain amino acids compared to dextrose for the treatment of bladder cancer by radical cystectomy}

Branch chain amino acids compared to dextrose for the treatment of bladder cancer by radical cystectomy

Participants: people with bladder cancer who have had a radical cystectomy

Settings: hospital, USA

Interventions: branch chain amino acids

Control: dextrose

\begin{tabular}{|c|c|c|c|c|c|}
\hline \multirow[t]{2}{*}{ Outcomes } & \multirow{2}{*}{$\begin{array}{l}\text { № of participants } \\
\text { (studies) }\end{array}$} & \multirow{2}{*}{$\begin{array}{l}\text { Certainty of the } \\
\text { evidence } \\
\text { (GRADE) }\end{array}$} & \multirow{2}{*}{$\begin{array}{l}\text { Relative effect } \\
(95 \% \mathrm{CI})\end{array}$} & \multicolumn{2}{|c|}{ Anticipated absolute effects ${ }^{\star}(95 \% \mathrm{Cl})$} \\
\hline & & & & Risk with dextrose & $\begin{array}{l}\text { Risk difference with branch } \\
\text { chain amino acids }\end{array}$ \\
\hline \multirow{2}{*}{$\begin{array}{l}\text { Complications } \\
\text { Follow-up: } 30 \text { days }\end{array}$} & \multirow{2}{*}{$\begin{array}{l}19 \\
(1 \mathrm{RCT})\end{array}$} & \multirow{2}{*}{$\begin{array}{l}\oplus \odot \odot \odot \\
\text { Very low } a, b, c\end{array}$} & \multirow{2}{*}{$\begin{array}{l}\text { RR approximately } 1 \\
\text { (no events) }\end{array}$} & \multicolumn{2}{|l|}{ Study population } \\
\hline & & & & 0 per 1000 & Unable to calculate \\
\hline Mortality - not assessed & - & - & - & - & - \\
\hline
\end{tabular}

${ }^{\star}$ The risk in the intervention group (and its $95 \%$ confidence interval) is based on the assumed risk in the comparison group and the relative effect of the intervention (and its $95 \% \mathrm{Cl})$.

Cl: confidence interval; $\mathbf{R C T}$ : randomised controlled trial; RR: risk ratio.

\section{GRADE Working Group grades of evidence}

High certainty: we are very confident that the true effect lies close to that of the estimate of the effect.

Moderate certainty: we are moderately confident in the effect estimate: the true effect is likely to be close to the estimate of the effect, but there is a possibility that it is substantially different.

Low certainty: our confidence in the effect estimate is limited: the true effect may be substantially different from the estimate of the effect. 


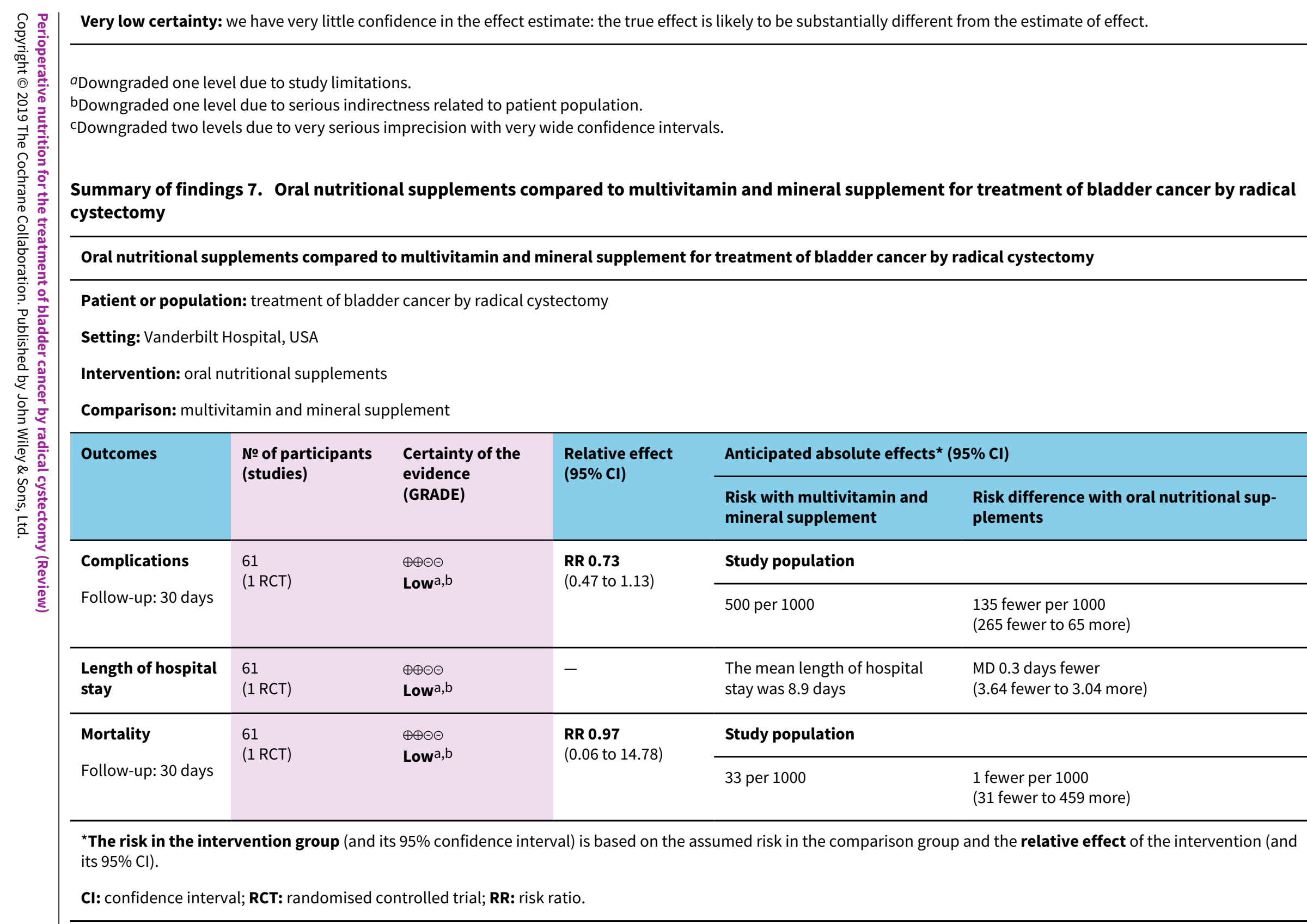

\section{GRADE Working Group grades of evidence}

$\checkmark$ High certainty: we are very confident that the true effect lies close to that of the estimate of the effect. 


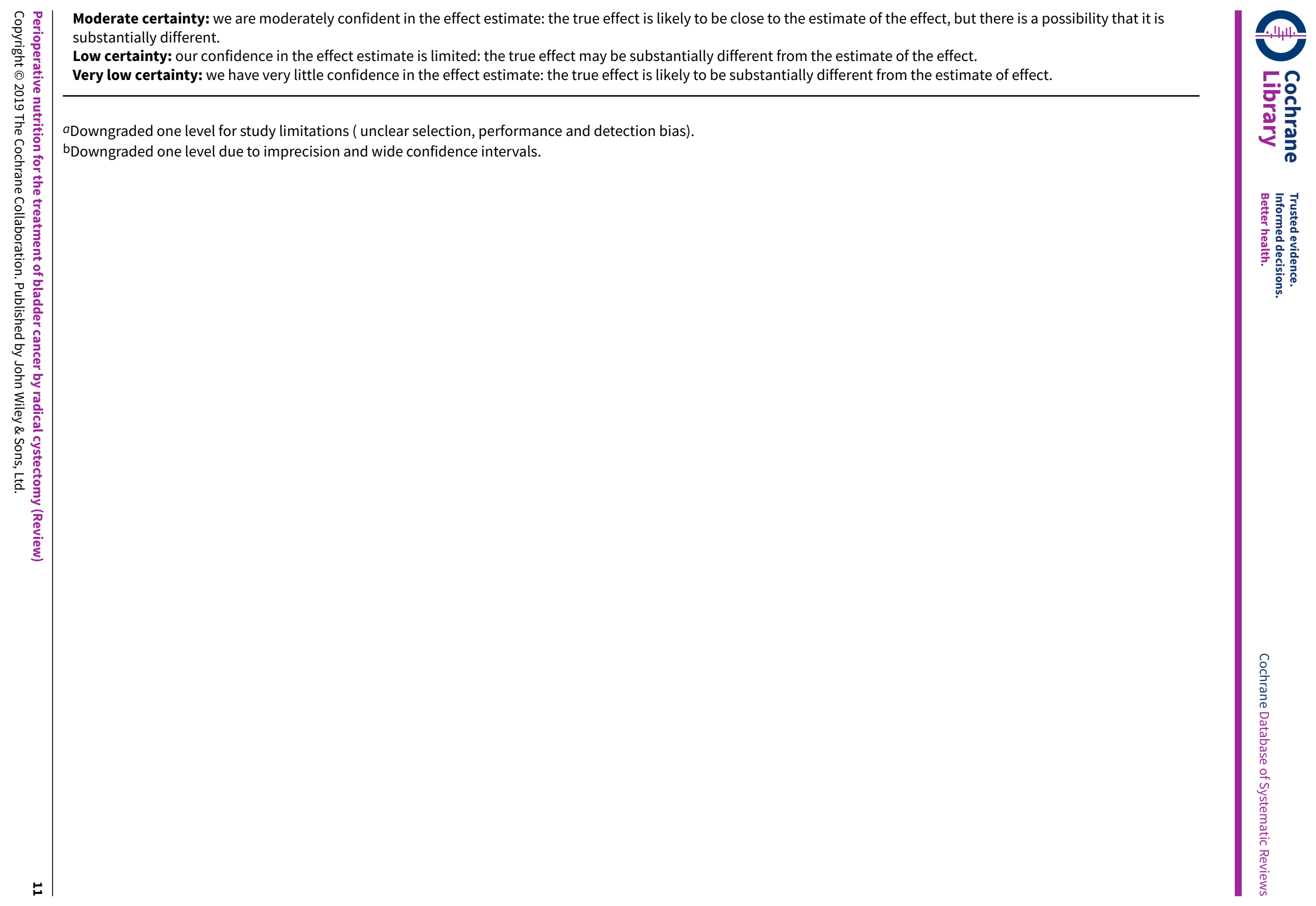




\section{B A C K G R O U N D}

\section{Description of the condition}

The worldwide incidence of bladder cancer is reported to be 5.3 per 100,000 people (age-standardised rate), and the condition is significantly more prevalent in men $(9.0$ per 100,000$)$ than in women (2.2 per 100,000) (GLOBOCAN 2012).

When bladder cancer is diagnosed, the majority of people ( $70 \%$ to $75 \%$ ) have superficial bladder cancer where malignant changes are located on the bladder surface (the urothelium) and limited by the lamina propria (fibrous layer beneath the urothelium) (de Braud 2002; Tobias 2010). The standard treatment for this is transurethral resection of bladder tumour, which involves the removal of the abnormal tissue endoscopically; this may be followed by the instillation of a chemotherapy agent directly into the bladder to reduce the recurrence rate. The most common histological subtype is transitional cell carcinoma. People then require regular follow-up inspections of the bladder by cystoscopy to detect any recurrence of the tumour.

Where bladder cancer has invaded beyond the lamina propria and into the bladder wall muscle layers, it is termed muscle-invasive bladder cancer. This may be found at initial presentation or may result from cancer progression in about $10 \%$ to $25 \%$ of cases previously diagnosed with non-invasive bladder cancer (de Braud 2002). The bladder tumour tissue can invade into muscle and in more extensive cases can also infiltrate into adjacent organs such as the prostate, uterus and vagina, or become fixed to the pelvic side wall. Invasive bladder cancer is associated with a greatly increased mortality rate in comparison to non-invasive bladder cancer. One of the management options is surgery, which in advanced cases is combined with neoadjuvant chemotherapy. The surgical operation is termed a radical (or total) cystectomy (RC); RC may also be indicated for people who have widespread non-muscle invasive, but high-grade tumour associated with carcinoma-in-situ.

$\mathrm{RC}$ is a major surgical procedure consisting of the removal of the bladder, together with the prostate and seminal vesicles in men, or the bladder and urethra, together with the anterior vaginal wall and uterus in women. Additionally, the pelvic lymph nodes are removed (pelvic lymphadenectomy). In the absence of the bladder, urine must be surgically diverted; this is most commonly achieved using a small loop of ileum (small bowel) into which the ureters are connected and then opens onto the abdominal wall as a stoma (a urostomy) with urine collected in a stoma bag. It may be possible to reconstruct a neobladder using a segment from the small or large bowel (bladder reconstruction) so that urine can be voided through the usual route via the urethra if this is retained, or via a catheterisable stoma made from the appendix or small bowel which acts as a channel between the neobladder and skin surface. An alternative treatment is the implanting of the ureters into the sigmoid colon (large bowel) or the rectum.

Although the mortality rate for cystectomy is now relatively low (1.5\% in Shabsigh 2009 and 3\% in Stein 2003), complications have been identified in up to $64 \%$ of people, including $13 \%$ major complications within 90 days of surgery (Shabsigh 2009). Possible complications include wound infections, intestinal obstruction, haemorrhage, cardiopulmonary complications and rectal injury.
Bladder cancer predominately occurs in older people. In the UK from 2005 to 2007, RC was undertaken in 4070 people with a mean age of 67 years (median age 68 years) with many over 70 years (SWPHO 2011). People with bladder cancer may have significant nutritional issues, older people have an increased likelihood of malnutrition compared to younger adults, and this may be due to the presence of comorbidities, poorer access to food, decreased appetite and food intake. When people have cancer, additional causes of malnutrition and weight loss can include inadequate dietary intake due to tumour-induced anorexia; catabolic tumour effects; abnormal metabolism of nutrients; reduced food intake secondary to the adverse effects of radiotherapy or chemotherapy; and diminished intake due to pain, anxiety or depression (Henry 2011). Sarcopenia, which is a loss of muscle mass, is now being considered as a possible factor contributing to the risk of complications and survival in RC (Smith 2014).

Nutritional requirements are liable to increase secondary to the disease process and surgical interventions. In one study of body composition in 11 people undergoing RC where nutritional support was not provided, there was evidence of protein depletion at baseline. Significant loss of protein was noted in almost half of the group 14 days after the procedure and protein loss was associated with postoperative complications; total body protein was not fully regained six months after RC (Mathur 2007). In a separate study, people who were given dextrose infusions post-RC were calculated to have mean nitrogen losses of $6.6 \mathrm{~g}$ per day, which was significantly higher than among people who were tube fed into the jejunum (Daly 1987).

Nutritional status is an important factor in determining postoperative outcomes in RC (Villa 2017), and several methods have been used to evaluate the incidence of malnutrition in people with bladder cancer. A 'Nutrition Risk Screening 2002' tool (combining assessment of weight loss, decreased food intake and disease severity) was used in a prospective assessment, $24 \%$ of people with urological cancers (including $40 \%$ with bladder cancer) had a high nutrition risk score (Karl 2009). In a survey of 277 urologists in the UK, the proportion of inadequately nourished people admitted for RC was estimated to be 23\% (Barrass 2006). Although there is a high incidence of obesity in people undergoing RC in the US (26\%) (Shabsigh 2009), the presence of excess weight may mask evidence of significant weight loss; therefore, better assessment techniques are required which will identify malnutrition in populations with a high incidence of people who are overweight or obese.

Current guidelines recommend the use of nutritional screening for people in hospitals for the purpose of identifying those at risk of malnutrition (Kondrup 2003; Mueller 2011; NICE 2006; Weimann 2017). The identification of people who are malnourished or at risk of malnutrition should be linked to further nutrition assessment, and the implementation of an appropriate nutrition care plan, which may include nutrition support.

Other Cochrane Reviews have examined perioperative feeding issues and found mixed results. In gastrointestinal surgery, there were reduced complications postoperatively with immunoenhancing nutrition (Burden 2012a), and in women with ovarian cancer in the perioperative period there was very limited evidence to direct clinical practice (Billson 2013). There has also been a systematic review in people after radiotherapy, which included studies on participants after surgical intervention for bladder 
cancer (Lawrie 2018). However, this review examined late effects after treatment.

\section{Description of the intervention}

The role of nutrition in the perioperative treatment of bladder cancer by RC encompasses several themes, including the identification of malnutrition in people undergoing RC and the provision of appropriate nutrition support; the use of preoperative nutrition as part of enhanced recovery or Enhanced Recovery After Surgery (ERAS) programmes; the appropriate timing and source of nutrition introduced postoperatively; and the use of nutrition support to manage adverse effects resulting from surgery involving the gastrointestinal tract.

In this context, nutrition support is the supply of nutrients to people other than the standard provision of nourishment, with the intention to improve or maintain nutrient intake. Nutrition support may be provided as supplementary food or drink, fortified food, oral nutrition supplements, formulations that are given by tube into the gastrointestinal tract (enteral feeds) or feeds which are given by infusion directly into a vein referred to as parenteral nutrition (PN). Nutrition support may compensate in part or in full for inadequate food consumption. In addition, nutrition support may be given at any stage during the perioperative period during which RC is undertaken with the intention to prevent or treat malnutrition. It is important that the risk of adverse effects associated with the provision of nutrition support is considered. Risks associated with nutrition support interventions could range from minor effects such as nausea to life-threatening effects including PN catheterrelated bloodstream infections.

\section{How the intervention might work}

Malnutrition has been linked to complications following RC. Thirteen out of 33 (39\%) people undergoing RC in one US series were described as malnourished. Malnutrition was associated with significantly increased perioperative morbidity, mortality and days in intensive care, compared with well-nourished counterparts (Mohler 1987). In a more recent report of 538 people undergoing RC, $19 \%$ met the study criteria for nutritional deficiency and the results showed that they were at a greater risk of death within 90 days of the surgery (hazard ratio $2.91,95 \%$ confidence interval $(\mathrm{CI}) 1.36$ to $6.23 ; P \leq 0.01$ ) and less likely to be alive three years later, compared to those judged to be well nourished (Gregg 2011).

When the complexity of case mix and risk factors for RC were examined in a prospective study of 2538 people, preoperative factors associated with mortality and prolonged length of hospital stay were old age, American Association of Anesthetists (ASA) score of 3 or more, dependent functional status and low serum albumin. While it was noted that some factors could not be altered, it was felt that preoperative nutritional supplementation may be beneficial. Since there was significant weight loss greater than $10 \%$ in the previous six months in $5.4 \%$ of people and which was associated with increased mortality at 30 days (odds ratio (OR) $2.7,95 \% \mathrm{Cl} 1.1$ to 6.4 ) and at 90 days (OR $2.9,95 \% \mathrm{Cl} 1.5$ to 5.4 ), this factor may also be amenable to preoperative nutrition intervention (Hollenbeck 2006).

The use of nutrition supplements preoperatively for carbohydrate loading may be indicated for people undergoing RC in ERAS programmes. The role of ERAS protocols in RC, including the use of carbohydrate drinks two hours prior to surgery, has been reviewed (Melnyk 2011). These programmes have the purpose of facilitating recovery from surgery by adherence to standard protocols with the aim of reducing postoperative complications and hospital stay.

Postoperatively, there is no current consensus on the appropriate provision of nutrition. In a UK survey, the majority $(60 \%)$ of urologists employed a traditional strategy of bowel rest and feeding orally after bowel recovery; a minority used PN (18.5\%) or enteral nutrition (6.5\%) routinely, although a larger proportion $(29 \%)$ considered that enteral nutrition was the "optimal" feeding regimen (Barrass 2006).

Postcystectomy, PN is often used because of the delayed return of bowel function resulting from postoperative ileus. This is one of the most frequent postoperative complications resulting in increased length of hospital stay, with a documented incidence of $10 \%$ to $20 \%$ (Hollenbeck 2006). In a review of complications occurring within 90 days post-RC in 1142 people, gastrointestinal complications were the most frequently reported (29\%) with ileus as the most common problem; this was defined as any inability to tolerate solid food five days after surgery; the need for a nasogastric tube; or need to stop oral intake due to abdominal distension, nausea or vomiting.

In early studies, the use of PN postoperatively was associated with a significantly reduced length of hospital stay compared with people only given $5 \%$ dextrose. This may have been due to a decreased rate in the return of postoperative physical activity in people on dextrose (Askanazi 1986). People who were considered to be malnourished appeared to benefit from perioperative PN, had fewer complications and a shorter hospital stay than the nutritionally 'at risk' control group. However, there were small numbers of malnourished people in the study (Chin 1983). A metaanalysis in 2001 reviewed 27 randomised controlled trials (RCT) and concluded that there may be a reduction in complication rates but not death rates for people receiving PN (Heyland 2001).

More recently, a variety of nutrition strategies have been employed on multimodal programmes for people undergoing RC (Azhar 2016; Maffezzini 2006). When a multimodal programme was introduced for people undergoing RC, the use of early oral nutrition was one of the factors associated with reduced postoperative pain, more rapid mobilisation and a shorter time to defecation compared to PN (Brodner 2001). However, adherence to all aspects of multimodal programmes has been questioned (Rattray 2018). There is also an interest within oncology surgery for prehabilitation where nutrition can form part of multimodal treatments preoperatively (Jensen 2018). Some studies have shown that the use of preoperative oral supplementation improves some clinical outcomes in participants with cancer (Burden 2017). An alternative programme included the early introduction of liquids and introduction of a regular diet on day four postoperatively, irrespective of flatus or bowel movements; this was only delayed if the patient had nausea or vomiting. Mean time to achieving a clear liquid diet intake was two days and to regular diet was 4.2 days with mean discharge at 5.1 days. Surgical techniques employed to minimise the manipulation and dissection of the small bowel plus limited incisions may have reduced the chance of postoperative bowel oedema and ileus. However, the authors indicated that early institution of an oral diet has had the greatest impact on early discharge (Pruthi 2003). There was a significantly reduced hospital stay in Bristol (UK), where clear fluids were introduced in recovery and light diet was permitted 
from day two postoperatively, or nasogastric feeding from day five if foods were not tolerated (Arumainayagam 2008).

\section{Why it is important to do this review}

Bladder cancer is associated with significant morbidity and mortality rates. Malnutrition may be associated with a poorer outcome but the evidence base for nutritional intervention is limited. It was noted that the evidence related to benefits of nutrition support in people undergoing RC was equivocal and that randomised trials are needed to assess the effect of perioperative nutrition in this patient group (Thurairaja 2005). Results from questionnaires completed by urologists performing cystectomies in the UK indicated a diversity in practice, not all based on clinical guidelines (Barrass 2006). It has been suggested that there is a need to demonstrate the best indices of preoperative nutritional status, and whether nutritional intervention can alter the poorer prognosis for people who are nutritionally deficient undergoing RC (Gregg 2011). Current guidelines for nutrition in surgery support the integration of nutritional support in to perioperative management for patients (Weimann 2017). In undertaking this review using Cochrane guidelines to investigate the use of perioperative nutrition in this group we aimed to produce a methodologically rigorous systematic review including a comprehensive literature search, with a focus on patient-important outcomes and rating of the quality of evidence using GRADE. We expect that this review will contribute to raising awareness of the need to consider nutritional issues as part of the supportive care for people undergoing RC.

\section{O B J E C T IVES}

To assess the effects of perioperative nutrition in participants undergoing radical cystectomy for the treatment of bladder cancer.

\section{ME T HO D S}

\section{Criteria for considering studies for this review}

\section{Types of studies}

Randomised controlled trials (RCTs) and quasi-RCTs.

\section{Types of participants}

Adults undergoing RC for bladder cancer. Where trials also included participants undergoing other types of procedures, we only included studies where more than $95 \%$ of participants were undergoing a surgical treatment of cancer and where at least $65 \%$ of the participants were undergoing RC. The diagnosis and definition of bladder cancer is described in current guidelines (NICE 2015).

\section{Types of interventions}

Nutritional interventions were provided at any stage in the perioperative period during which RC was undertaken as a treatment for bladder cancer. Nutritional interventions could have been one or more of the following: additional food or drink, fortified foods, oral supplements, and enteral or parenteral feeds. Nutritional products could have been supplementary to the usual food and drink or could have been the sole source of nourishment. Trials may have examined the provision of nutrition support in comparison with not providing nutrition support or may have compared alternative types of nutrition support. Studies where a nutritional intervention was only one factor in a package of care being evaluated were excluded.
Comparisons which included any nutritional interventions versus standard or usual care.

If a trial included multiple arms, we included any arm that met the inclusion criteria in the review.

\section{Minimum duration of intervention and follow-up}

We defined trial duration according to the number of days over which the intervention had been given and included trials in the analysis where the interventions had been given for any time period. We included follow-up data on the specified outcomes up to 90 days postoperatively. When only 30 -day data were available, we reported those figures.

\section{Types of outcome measures}

\section{Primary outcomes}

- Complications up to 90 days after surgery (e.g. sepsis, wound breakdown, paralytic ileus or infections).

- Length of hospital stay.

For length of hospital stay we considered a difference of one day as clinically important.

\section{Secondary outcomes}

- Mortality reported up to 90 days after surgery.

\section{Search methods for identification of studies}

We performed a comprehensive search for studies, with no restrictions based on language of publication or publication status.

\section{Electronic searches}

We searched the following electronic databases to 22 June 2018.

- Evidence Based Medicine Reviews (via Ovid; from 1991; for the search strategy, see Appendix 1).

- MEDLINE (via Ovid; from 1946; see Appendix 2).

- Embase (via Ovid; from 1974; see Appendix 3).

- AMED (via Ovid; from 1985; see Appendix 4).

- CINAHL (via EBSCO; from 1937; see Appendix 5).

We searched the following trials registers to June 2018.

- metaRegister of Controlled Trials (mRCT; www.controlledtrials.com/mrct/active; see Appendix 6).

- National Cancer Institute (NCl; www.cancer.gov/clinicaltrials; see Appendix 7).

- ClinicalTrials.gov (www.clinicaltrials.gov; see Appendix 8).

- World Health Organization International Clinical Trials Registry Platform (WHO ICTRP; www.who-int/ictrp/; see Appendix 9).

We searched meeting abstracts through the following websites to June 2017.

- Zetoc (zetoc.mimas.ac.uk; see Appendix 10).

- OCLC WorldCat Dissertations and Theses (WorldCatDissertations; see Appendix 11).

We carried out translations when needed. 


\section{Searching other resources}

Where we identified ongoing trials, we attempted to contact principal investigators to request relevant data. The citation lists of included studies were handsearched to identify any further relevant trials. We handsearched reference lists of relevant systematic reviews.

\section{Data collection and analysis}

\section{Selection of studies}

Groups of two review authors (from HAB, SB and KO) independently assessed the titles and abstracts retrieved by the searches to determine relevance and eligibility. We obtained the full-text article where there was insufficient information in the abstract and title. Two review authors (HAB, SB) working independently or one of these authors and a clinically trained translator, reviewed relevant records in full text, mapped records to studies and classified studies as included or excluded studies in accordance with the criteria in the Cochrane Handbook for Systematic Reviews of Interventions (Higgins 2011). Diversity of opinion was resolved by discussion. Reasons for exclusion of studies were documented. In studies where there were multiple reports of the same cohort, all the manuscripts reporting the outcomes were included. Where the same outcomes were reported, we included the latest study with the longest follow-up.

\section{Data extraction and management}

Two review authors ( $\mathrm{HAB}$ and $\mathrm{SB}$ ) independently undertook data extraction using a piloted and modified data collection form. They resolved discrepancies between themselves or, where translation was required, one of these review authors worked with a translator. We extracted the following information.

- Year of publication, country of origin and source of funding.

- Participant details, number of participants, age, inclusion and exclusion criteria.

- Cancer diagnosis, including staging if indicated, type of surgery used.

- Details of nutritional intervention (including type of food, drink, formulation, route of intervention, duration of intervention and quantity delivered).

- Details of primary and secondary outcomes, including the time points when these were collected and reported.
For dichotomous outcomes, we extracted the number of participants in each treatment arm who experienced the outcome of interest, and the number of participants assessed at endpoint.

For continuous outcomes, we extracted the final value and standard deviation of the outcome of interest, and the number of participants assessed at endpoint in each treatment arm at the end of follow-up.

We extracted both unadjusted and adjusted statistics, if reported.

Where possible, we extracted data relevant to an intention-to-treat analysis, in which participants were analysed in the groups to which they were assigned.

\section{Assessment of risk of bias in included studies}

We assessed the risk of bias in included studies using Cochrane's 'Risk of bias' tool (Higgins 2011). This included assessment of the following.

- Selection bias:

- random sequence generation;

- allocation concealment.

- Performance bias:

- blinding of participants and personnel (patients and treatment providers), we evaluated the risk of bias separately for each outcome according to whether susceptible to performance bias.

- Detection bias:

- blinding of outcome assessment, we evaluated the risk of bias separately for each outcome, and grouped outcomes according to whether measured subjectively or objectively.

- Attrition bias:

- incomplete outcome data. We assessed attrition bias (incomplete outcome data) and reporting bias (selective reporting) on a per-outcome basis.

- Reporting bias:

- selective reporting.

- Other possible sources of bias.

Two review authors (HAB, SB) independently applied the 'Risk of bias' tool and resolved differences by discussion. Results of the assessment were summarised in the 'Risk of bias' summary (Figure 1) and 'Risk of bias' graph (Figure 2). 
Figure 1. Risk of bias summary: review authors' judgements about each risk of bias item for each included study.

\begin{tabular}{|c|c|c|c|c|c|c|c|c|c|c|c|c|}
\hline & 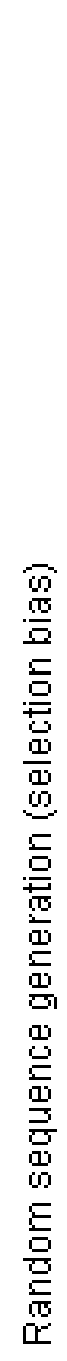 & 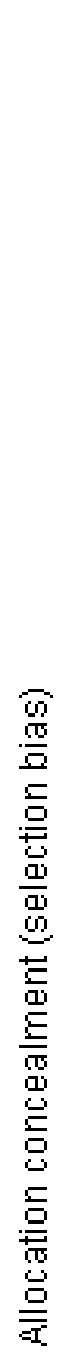 & 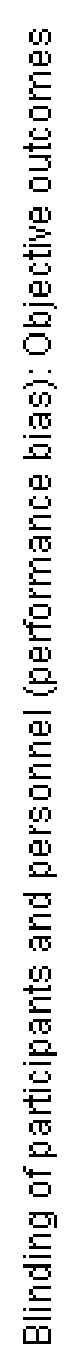 & 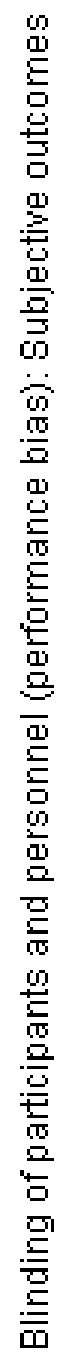 & 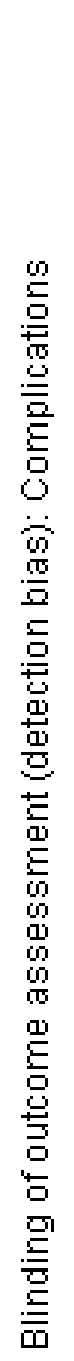 & 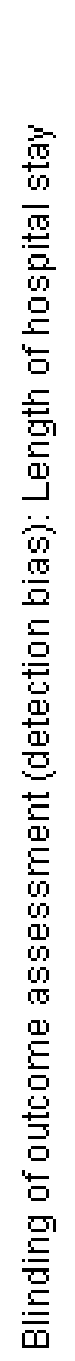 & 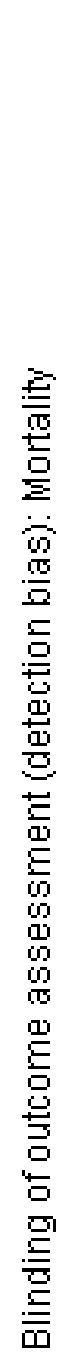 & 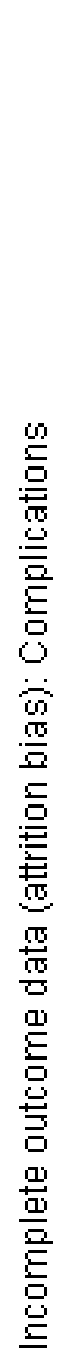 & 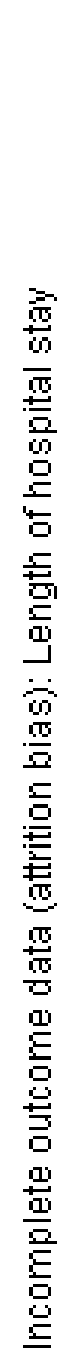 & 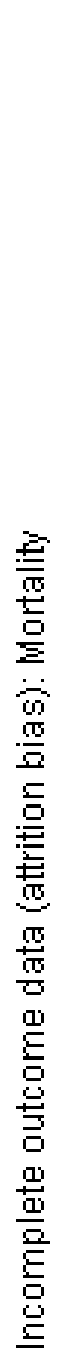 & 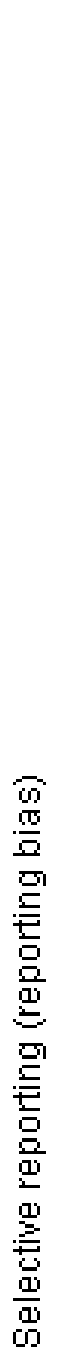 & 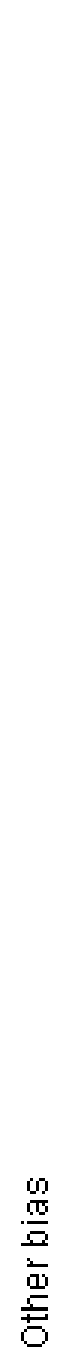 \\
\hline Bonau 1984 & $?$ & $?$ & + & $?$ & $?$ & $?$ & + & $?$ & $?$ & + & $?$ & + \\
\hline Daly 1982 & $?$ & $?$ & $\oplus$ & ? & $?$ & + & $\oplus$ & $\oplus$ & + & + & $?$ & + \\
\hline Deibert 2016 & + & $?$ & + & $?$ & $?$ & + & + & + & + & $\oplus$ & + & \\
\hline Hamilton-Reeves 2016 & + & + & + & + & + & + & 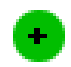 & + & + & $\oplus$ & + & \\
\hline Hensle 1978 & & & + & $?$ & ? & + & + & + & + & + & $?$ & + \\
\hline Ritch 2018 & $?$ & $?$ & + & $?$ & $?$ & + & + & + & + & $\oplus$ & + & + \\
\hline Roth 2013 & + & $?$ & + & $?$ & + & + & + & + & + & + & $?$ & + \\
\hline Rovera 1989 & $?$ & $?$ & + & $?$ & $?$ & + & + & + & $?$ & + & $?$ & + \\
\hline
\end{tabular}


Figure 2. Risk of bias graph: review authors' judgements about each risk of bias item presented as percentages across all included studies.

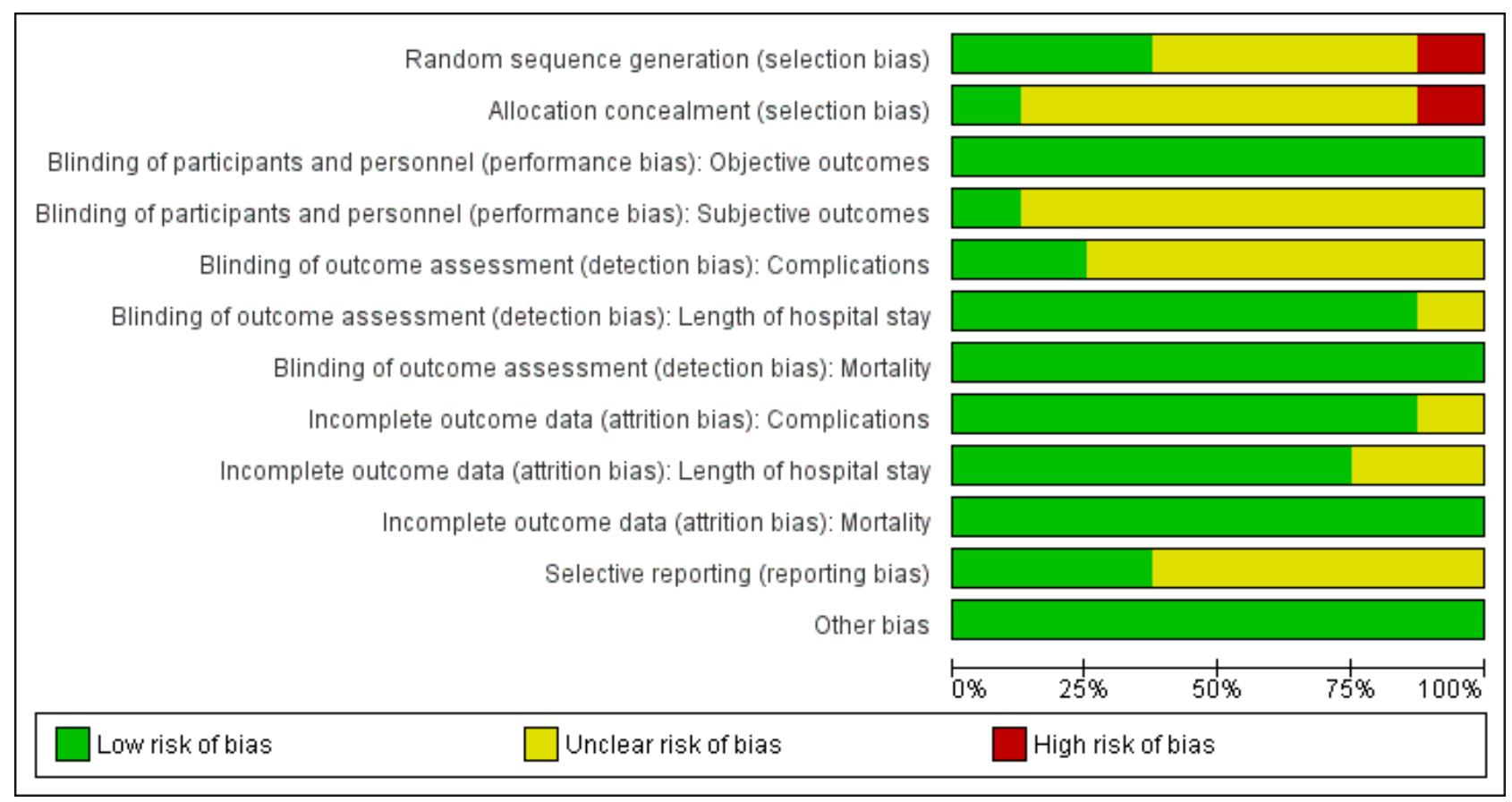

For selection bias (random sequence generation and allocation concealment) and reporting bias (selective reporting), we evaluated risk of bias at a trial level.

For performance bias (blinding of participants and personnel) and detection bias (blinding of outcome assessment), we evaluated the risk of bias separately for each outcome, and grouped outcomes according to whether they were measured subjectively or objectively.

We defined the following endpoints as subjective outcomes for performance bias (blinding of participants and personnel):

- complications;

- length of hospital stay.

We defined the following endpoint as an objective outcome for performance bias (blinding of participants and personnel):

- mortality.

The endpoint classed as subjective for detection bias (blinding of outcome assessment) was:

\section{- complications.}

The endpoints defined as objective for detection bias (blinding of outcome assessment) were:

- mortality;

- length of hospital stay.

Attrition bias (incomplete outcome data) was assessed on an outcome-specific basis.

\section{Measures of treatment effect}

For measures of the effect of treatment: for dichotomous outcomes, we used the risk ratio (RR) with $95 \%$ confidence interval $(\mathrm{CI})$, and for continuous outcomes, the mean difference (MD) with $95 \% \mathrm{Cl}$.

\section{Unit of analysis issues}

We planned to consider trials that were cluster-randomised on an individual basis to determine whether they should be included with unit of analysis issues examined by two review authors (Higgins 2011), but none were included.

If there were multiple interventions in the same study, we planned to combine these and compare to the control if appropriate, but this issue was not relevant in the included studies.

\section{Dealing with missing data}

In studies with missing data, we planned to contact the study authors to seek relevant information; however, this was not practical due to the historic nature of several of the studies. No missing outcome data was imputed, participants were analysed according to the intention-to-treat principle.

\section{Assessment of heterogeneity}

We assessed heterogeneity between studies by visual inspection of forest plots, with the presence of heterogeneity being indicated by poor overlap between the $\mathrm{Cls}$ of individual studies, depicted by horizontal lines. The percent of heterogeneity between trials which could not be ascribed to sampling variation (Higgins 2003), was assessed by a formal statistical test of the significance of the heterogeneity using 12 statistic (Deeks 2001). Subgroup analyses were planned to attempt to determine possible reasons for any identified heterogeneity; however, this was not appropriate with the included studies. 


\section{Assessment of reporting biases}

We searched multiple sources (see Search methods for identification of studies). Consideration was made about whether trials were undertaken and reported according to the trial protocol if this was available. It was planned that publication bias would be assessed using a funnel plot as detailed in the Cochrane Handbook for Systematic Reviews of Interventions (Sterne 2011); however, an insufficient number of trials were identified.

\section{Data synthesis}

The results of clinically similar studies were pooled in metaanalyses. For the meta-analysis of the quantitative data, we used the random-effects model. Statistical analyses were conducted according to the guidelines in the Cochrane Handbook for Systematic Reviews of Interventions (Higgins 2011). For dichotomous outcomes, we used the Mantel-Haenszel method and for continuous outcomes the inverse variance method. Review Manager software was used to perform analyses (Review Manager 2014). If there was significant heterogeneity between the studies, meta-analysis would not have been undertaken but possible causes of heterogeneity would have been examined. Clinically heterogeneous trials were presented individually in a descriptive analysis.

\section{Subgroup analysis and investigation of heterogeneity}

There was a lack of suitable data, therefore subgroup analyses were not undertaken. The planned subgroup analyses were:

- malnourished participants versus non-malnourished participants;

- type of nutrition intervention;

- comparing trials conducted before 1990 versus subsequently (since then there have been significant developments in artificial feeding and nutrition support).

In the interpretation of any heterogeneity, we considered baseline characteristics including factors of age (less than 70 years and 70 years and older), cancer staging, type of nutrition intervention (oral, enteral, parenteral) and length of follow-up (one month, three months).

\section{Sensitivity analysis}

If six or more studies had been suitable for meta-analysis in this review, we planned to conduct sensitivity analyses by repeating the analysis with the following adjustments: exclusion of trials with unclear or incomplete reporting of complications and trials with incomplete follow-up. Additionally, sensitivity analysis were planned excluding studies judged 'high' or 'unclear' risk of bias.

\section{'Summary of findings' tables}

The overall certainty of the evidence for each outcome was rated according to the GRADE approach taking into account five criteria related both to internal validity (risk of bias, inconsistency, imprecision, publication bias) and external validity (directness of results) (Guyatt 2008). For each comparison, two review authors ( $\mathrm{SB}, \mathrm{HB})$ independently rated the quality of the evidence for each outcome as 'high', 'moderate', 'low', or 'very low', and resolved discrepancies by discussion. We used GRADEpro GDT to prepare summaries of the evidence for the primary outcomes in 'Summary of findings' tables for each comparison, in accordance with Cochrane guidance (Schünemann 2011).

\section{RESULTS}

\section{Description of studies}

See Characteristics of included studies, Characteristics of excluded studies, and Characteristics of ongoing studies table.

\section{Results of the search}

See Figure 3. The searches and updated searches run on the electronic databases to 22 February 2019 identified 5514 titles; after scanning titles and reviewing abstracts, we obtained 16 full reports describing relevant studies plus a further study in a conference abstract and one study from an ongoing trial. Translation of four reports was undertaken. Of the 18 studies, eight met the inclusion criteria for this review and 10 studies were excluded. There were no quasi-RCTs. 
Figure 3. Study flow diagram.

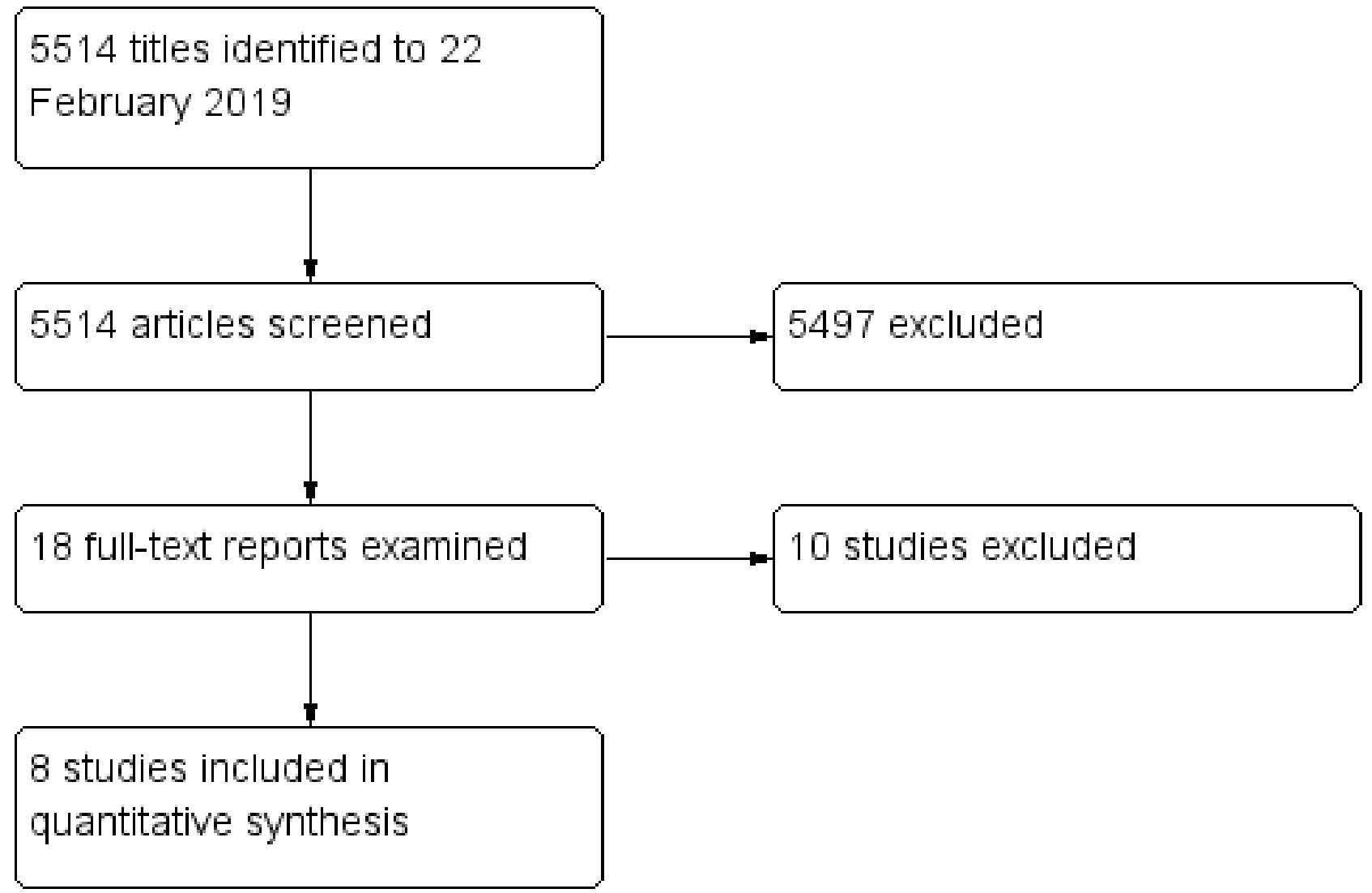

\section{Included studies}

See Characteristics of included studies table.

In the eight studies which met the inclusion criteria there were 500 trial participants, all were undergoing RC and all studies were conducted in a hospital setting (Bonau 1984; Daly 1982; Deibert 2016; Hamilton-Reeves 2016; Hensle 1978; Ritch 2018; Roth 2013; Rovera 1989). In the studies that reported gender, there were 341 men and 82 women (Bonau 1984; Deibert 2016: Hamilton-Reeves 2016; Ritch 2018; Roth 2013; Rovera 1989); two studies recruited only men (Bonau 1984; Hamilton-Reeves 2016). Six studies described the age of the participants who had group mean or median ages between 61 and 69 years or were included in a range of ages from 30 to 84 years (Bonau 1984; Daly 1982; Hamilton-Reeves 2016; Ritch 2018; Roth 2013; Rovera 1989). One study received supported from Abbott Laboratories (Bonau 1984); one study from an educational grant from McGaw Laboratories (Hensle 1978); one study from the American Cancer Society, Nestle Healthcare and travel funding (Hamilton-Reeves 2016); one study from Vanderbilt CTSA, NIH National Centre and Abbott Nutrition Award (Ritch 2018); two studies received no funding (Deibert 2016; Roth 2013); and two studies provided no disclosure of funding sources (Daly 1982; Rovera 1989).

Two included studies conducted in the USA (134 participants) evaluated amino acid solutions with and without dextrose compared to dextrose solution in the postoperative management of people following RC (Daly 1982; Hensle 1978). Daly 1982 randomised 93 participants into three arms, although only two arms are included in the analysis with 60 participants comparing amino acid solution plus dextrose to dextrose solution as the control. One study (19 participants) in the USA compared two different branched chain amino acid solutions to dextrose solution (Bonau 1984). There were three arms although only two arms were suitable to be included in this review including 10 participants (Bonau 1984). One study conducted in Italy (28 participants) investigated preoperative oral nutritional support and postoperative PN compared to a control group that only received postoperative PN (Rovera 1989). One study including 157 participants conducted in Switzerland also investigated PN and evaluated PN postoperatively compared to oral diet (Roth 2013). One study with 29 participants compared immuno-enhancing nutrition supplements and standard oral nutritional supplements given for five days before and five days after RC surgery (HamiltonReeves 2016). One study including 102 participants compared early feeding with clear liquid on day one after surgery followed by access to full oral diet on day two after surgery, in comparison to standard postoperative management (Deibert 2016). One study including 61 participants compared oral nutritional supplements administered three to four weeks preoperatively and four weeks postoperatively to oral multivitamin and mineral supplement (Ritch 2018).

\section{Excluded studies}

See Characteristics of excluded studies table.

We excluded 10 studies from the review (Brodner 2001; Daly 1987; de Vries 2012; Hensle 1985; Karl 2009; Malossini 1987; Mangano 1993; McArdle 1986; Olbert 2009; Solomon 1978). Six studies did not randomise participants, two studies did not include a nutritional 
intervention, one study had insufficient RC participants included and one study did not fully meet the inclusion criteria.

\section{Ongoing studies}

See Characteristics of ongoing studies table.

We classified three studies as ongoing studies (NCT02238886; NCT03147586; NCT03204266). One of these studies is being undertaken in the USA (NCT03204266), one in Denmark (NCT02238886), and one in Egypt (NCT03147586).

\section{Risk of bias in included studies}

The risk of bias in the included studies is summarised in Figure 1 and displayed graphically in Figure 2.

\section{Allocation}

Selection bias was assessed in the form of the risk of bias domains of random sequence generation and allocation concealment.

\section{Random sequence generation}

In relation to random sequence generation, there was a low risk of bias in three studies as randomisation was undertaken by a statistician in one study (Hamilton-Reeves 2016), by a computer in one study (Roth 2013), and described in the protocol in one study (Deibert 2016). In four studies, the risk of bias was unclear (Bonau 1984; Daly 1982; Ritch 2018; Rovera 1989). There was a high risk of selection bias in one study as primary physicians changed some group allocations so not all participants received the treatment they were assigned from the randomisation process (Hensle 1978).

\section{Allocation concealment}

In one study, there was a low risk of bias in relation to allocation concealment (Hamilton-Reeves 2016). In six studies, the information on allocation to groups was limited, so level of bias was unclear (Bonau 1984; Daly 1982; Deibert 2016; Ritch 2018; Roth 2013; Rovera 1989). In one study, the risk of bias was high as the allocation was not concealed (Hensle 1978).

\section{Blinding}

\section{Blinding of participants and personnel}

For objective outcomes (mortality), eight studies had a low risk of bias (Bonau 1984; Daly 1982; Deibert 2016; Hamilton-Reeves 2016; Hensle 1978; Ritch 2018; Roth 2013; Rovera 1989).

For subjective outcomes (complications and length of hospital stay), one study had a low risk of bias (Hamilton-Reeves 2016). The risk of bias was unclear for seven studies (Bonau 1984; Daly 1982; Deibert 2016; Hensle 1978; Ritch 2018; Roth 2013; Rovera 1989).

\section{Blinding of outcome assessment}

Outcome - complications: two studies had a low risk of bias (Hamilton-Reeves 2016; Roth 2013), and six studies had an unclear risk of bias (Bonau 1984; Daly 1982; Deibert 2016; Hensle 1978; Ritch 2018; Rovera 1989)

Outcome - length of hospital stay: eight studies had a low risk of bias (Bonau 1984; Daly 1982; Deibert 2016; Hamilton-Reeves 2016; Hensle 1978; Ritch 2018; Roth 2013; Rovera 1989).
Outcome - mortality: eight studies had a low risk of bias (Bonau 1984; Daly 1982; Deibert 2016; Hamilton-Reeves 2016; Hensle 1978; Ritch 2018; Roth 2013; Rovera 1989).

\section{Incomplete outcome data}

Outcome - complications: one study had an unclear risk of bias (Bonau 1984); seven studies had a low risk of bias (Daly 1982; Deibert 2016; Hamilton-Reeves 2016; Hensle 1978; Ritch 2018; Roth 2013; Rovera 1989).

Outcome - length of hospital stay: six studies had a low risk of bias (Daly 1982; Deibert 2016; Hamilton-Reeves 2016; Hensle 1978; Ritch 2018; Roth 2013; Rovera 1989), and two studies had an unclear risk of bias (Bonau 1984; Rovera 1989).

Outcome - mortality: eight studies had a low risk of bias (Bonau 1984; Daly 1982; Deibert 2016; Hamilton-Reeves 2016; Hensle 1978; Ritch 2018; Roth 2013; Rovera 1989).

\section{Selective reporting}

Three studies had a low risk of bias (Deibert 2016; Hamilton-Reeves 2016; Ritch 2018), and five studies had an unclear level of reporting bias where study protocols were not located although all outcomes in the methods section of the studies were reported in the results (Bonau 1984; Daly 1982; Hensle 1978; Roth 2013; Rovera 1989).

\section{Other potential sources of bias}

Eight studies were at low risk for other sources of bias Bonau 1984; Daly 1982; Deibert 2016; Hamilton-Reeves 2016; Hensle 1978; Ritch 2018; Roth 2013; Rovera 1989.

A description of the interventions are shown in Table 1 and baseline characteristics are shown in Table 2.

\section{Effects of interventions}

See: Summary of findings for the main comparison Postoperative parenteral nutrition compared to oral nutrition alone for the treatment of bladder cancer by radical cystectomy; Summary of findings 2 Immunonutrition compared to standard nutritional supplements for the treatment of bladder cancer by radical cystectomy; Summary of findings 3 Preoperative oral nutritional support compared to normal diet for the treatment of bladder cancer by radical cystectomy; Summary of findings 4 Early postoperative feeding compared to standard management for the treatment of bladder cancer by radical cystectomy; Summary of findings 5 Amino acid solution, alone or in combination with dextrose compared to dextrose solution for the treatment of bladder cancer by radical cystectomy; Summary of findings 6 Branch chain amino acids compared to dextrose for the treatment of bladder cancer by radical cystectomy; Summary of findings 7 Oral nutritional supplements compared to multivitamin and mineral supplement for treatment of bladder cancer by radical cystectomy

\section{Comparison 1: postoperative parenteral nutrition compared to oral nutrition}

We found one study, including157 participants (74 PN, 83 control) that compared postoperative PN to oral nutrition alone (Roth 2013). See Summary of findings for the main comparison. 


\section{Primary outcomes}

\section{Complications up to 90 days after surgery}

Based on one study with 157 participants, PN may have increased postoperative complications within 30 days (RR 1.40, $95 \% \mathrm{Cl} 1.07$ to 1.82; low-quality evidence; Analysis 1.1). We downgraded the quality of evidence for serious study limitations (unclear risk of selection, performance and selective reporting bias) and serious imprecision. Assuming a baseline risk of postoperative complications of 49\%, this corresponded to 198 more complications per 1000 participants (95\% Cl 35 more to 405 more).

This study was discontinued prematurely due to more complications occurring in the PN group.

\section{Length of hospital stay}

Length of hospital stay may have been similar (MD 0.5 days more, $\mathrm{Cl}$ not reported; low-quality evidence). We downgraded the quality of evidence for serious study limitations (unclear risk of selection, performance and selective reporting bias) and serious imprecision. Length of hospital stay was recorded as a mean of 16 days in the PN group and in the oral diet group was a mean of 15.5 days.

\section{Secondary outcomes}

\section{Mortality}

We were very uncertain of the effect of PN compared to oral diet on postoperative mortality rates (RR $1.12,95 \% \mathrm{Cl} 0.07$ to 17.62; very low-quality evidence; Analysis 1.2). We downgraded the quality of evidence for serious study limitations (unclear risk of selection, performance and selective reporting bias) and very serious imprecision. Assuming a baseline risk of postoperative mortality of $1 \%$, PN may have resulted in 1 more death per 1000 participants ( $95 \% \mathrm{Cl} 11$ fewer to 200 more).

\section{Comparison 2: immuno-enhancing nutrition compared to standard oral nutritional supplements}

We found one study including 29 participants that compared specialised immuno-enhancing oral supplements to standard oral nutritional supplements given three times per day for five days before and five days after RC surgery (Hamilton-Reeves 2016). See Summary of findings 2 .

\section{Primary outcomes}

\section{Complications up to 90 days after surgery}

Immuno-enhancing nutrition may improve rates of 90-day postoperative complications compared to usual diet (RR $0.31,95 \%$ $\mathrm{Cl} 0.08$ to 1.23; low-quality evidence; Analysis 2.1). We downgraded the quality of evidence for very serious imprecision. Assuming a baseline risk of postoperative complications of $46 \%$, immunoenhancing nutrition may have resulted in 322 fewer occurrences per 1000 participants ( $95 \% \mathrm{Cl} 429$ fewer to 107 more).

We also found data on 30-day complication rates, which we chose to report given that it was the most prevalently reported time-frame for the outcome of complications for other comparisons. Immunoenhancing nutrition versus usual care may have had little or no effect on rates of 30-day postoperative complications (RR 0.97, 95\% $\mathrm{Cl} 0.62$ to 1.53; low-quality evidence; Analysis 2.2). We downgraded the quality of evidence for imprecision. Assuming a baseline risk of postoperative complications of $66 \%$, immuno-enhancing nutrition would have resulted in 20 fewer occurrences per 1000 participants (95\% Cl 253 fewer to 353 more).

\section{Length of hospital stay}

Length of hospital stay may have been similar (MD 0.20 days fewer, $95 \% \mathrm{Cl} 1.69$ fewer to 2.09 more; low-quality evidence; Analysis 2.3). We downgraded the quality of evidence for very serious imprecision.

\section{Secondary outcomes}

\section{Mortality}

Immuno-enhancing nutrition compared to standard may have had little or no effect on mortality rates (RR approximately $1, \mathrm{Cl}$ not reported; low-quality evidence). There were no deaths reported in the period up to 90 days postoperatively. We downgraded the quality of evidence for assumed very serious imprecision. No absolute effect size estimates for the Cls could be generated.

\section{Comparison 3: preoperative oral nutritional support compared to normal diet}

We found one study including 28 participants that compared preoperative oral nutritional support to normal diet (Rovera 1989). Both groups also had postoperative PN. See Summary of findings 3.

\section{Primary outcomes}

\section{Complications up to 90 days after surgery}

We were very uncertain if preoperative oral supplements reduced postoperative complications (Analysis 3.1). We downgraded for serious study limitations (unclear risk of selection, performance, attrition and selective reporting bias) and very serious imprecision. Assuming a baseline risk of postoperative complications of $18 \%$, preoperative nutrition would have resulted in 21 fewer occurrences per 1000 participants ( $95 \% \mathrm{Cl} 154$ fewer to 658 more).

\section{Length of hospital stay}

The study did not report length of hospital stay.

\section{Secondary outcomes}

\section{Mortality}

We were uncertain whether preoperative oral nutrition compared to standard care had an effect on mortality rates (RR approximately $1, \mathrm{Cl}$ not reported; very low-quality evidence). We downgraded the quality of evidence for study limitations and too few events to reliably evaluate this outcome. There were no deaths reported in either group.

\section{Comparison 4: early postoperative feeding compared to standard postoperative management}

We found one study including 102 participants that compared the provision of clear fluids on the first day after surgery and access to a full diet on the second day following RC compared with standard postoperative care where oral intake was delayed until either flatus or a bowel movement had occurred (Deibert 2016). Follow-up was reported for a period of 90 days after surgery.

See Summary of findings 4. All data for this comparison were obtained from the published report, the authors provided us with the study protocol. 


\section{Primary outcomes}

\section{Complications up to 90 days after surgery}

Early postoperative feeding compared to standard care may have had little or no effect on postoperative complications (RR 1.14, $95 \% \mathrm{Cl} 0.85$ to 1.53 ; very low-quality evidence; Analysis 4.1 ). We downgraded the quality of evidence for study limitations and very serious imprecision. Assuming a baseline risk of postoperative complications of $59 \%$, early postoperative feeding would have resulted in 83 more occurrences per 1000 participants (95\% Cl 89 fewer to 316 more).

\section{Length of hospital stay}

Early postoperative feeding compared to standard care may have had little or no effect on length of hospital stay (MD 0.95 days fewer, $\mathrm{Cl}$ not reported; low-quality evidence). We downgraded the quality of evidence for study limitations and the study was underpowered to demonstrate a clinically important difference of one day in length of hospital stay.

\section{Secondary outcomes}

\section{Mortality}

Early postoperative feeding compared to standard care may have had little or no effect on postoperative mortality rates (RR 0.52, 95\% $\mathrm{Cl} 0.10$ to 2.71; low-quality evidence; Analysis 4.2). We downgraded the quality of evidence for study limitations and imprecision.
Assuming a baseline risk of postoperative mortality of 3.8\%, early feeding would have resulted in 19 fewer occurrences per 1000 participants ( $95 \% \mathrm{Cl} 35$ fewer to 72 more).

\section{Comparison 5: amino acid solution with dextrose compared to dextrose solution alone}

We found two studies including 104 participants that compared an amino acid solution alone or in combination with dextrose, to dextrose solution (Daly 1982; Hensle 1978). See Summary of findings 5 .

\section{Primary outcomes}

\section{Complications up to 90 days after surgery}

Two studies including 104 participants reported complications (Daly 1982; Hensle 1978).

We were uncertain if amino acid solution alone or in combination with dextrose solution had any effect on postoperative complications (RR $0.77,95 \% \mathrm{Cl} 0.32$ to 1.82 ; $\mathrm{I}^{2}=13 \%$; very lowquality evidence; Analysis 5.1; Figure 4). We downgraded the quality of evidence for study limitations, indirectness as the study used historical methods and imprecision. Assuming a baseline risk of postoperative complications of $20 \%$, amino acid solution alone or in combination with dextrose solution would have resulted in 46 fewer occurrences per 1000 participants $(95 \% \mathrm{Cl} 136$ fewer to 164 more).

Figure 4. Forest plot of comparison 5: amino acid and dextrose compared to dextrose, outcome: 5.1 complications.

\begin{tabular}{|c|c|c|c|c|c|c|c|c|}
\hline \multirow[b]{2}{*}{ Study or Subgroup } & \multicolumn{2}{|c|}{ Amino acid } & \multicolumn{2}{|c|}{ Dextrose } & \multirow[b]{2}{*}{ Weight } & \multirow{2}{*}{$\begin{array}{c}\text { Risk Ratio } \\
\text { M-H, Random, } 95 \% \mathrm{Cl}\end{array}$} & \multirow{2}{*}{$\begin{array}{c}\text { Risk Ratio } \\
\text { M-H, Random, } 95 \% \text { Cl } \\
\end{array}$} & Risk of Bias \\
\hline & Events & Total & Events & Total & & & & A B C D E F G \\
\hline Daly 1982 & 5 & 30 & 4 & 30 & $44.6 \%$ & $1.25[0.37,4.21]$ & & ????૯? \\
\hline Hensle 1978 & 5 & 29 & 5 & 15 & $55.4 \%$ & $0.52[0.18,1.51]$ & & $\odot \ominus ? ? \odot ? \odot$ \\
\hline Total $(95 \% \mathrm{Cl})$ & & 59 & & 45 & $100.0 \%$ & $0.77[0.32,1.82]$ & & \\
\hline Total events & 10 & & 9 & & & & & \\
\hline $\begin{array}{l}\text { Heterogeneity: Tauz } \\
\text { Test for overall effect }\end{array}$ & $\begin{array}{l}0.05 ; \mathrm{Chi}^{2} \\
\mathrm{Z}=0.60(\mathrm{P}\end{array}$ & $\begin{array}{l}P=1.15 \\
P=0.5\end{array}$ & $\begin{array}{l}\text {, df }=1(F \\
5)\end{array}$ & $=0.28$ & 3) $\left.\right|^{2}=139$ & & $\begin{array}{llll}0.01 & 0.1 & 1 & 10 \\
\text { Favours amino acid } & \text { Favours de }\end{array}$ & 100 \\
\hline
\end{tabular}

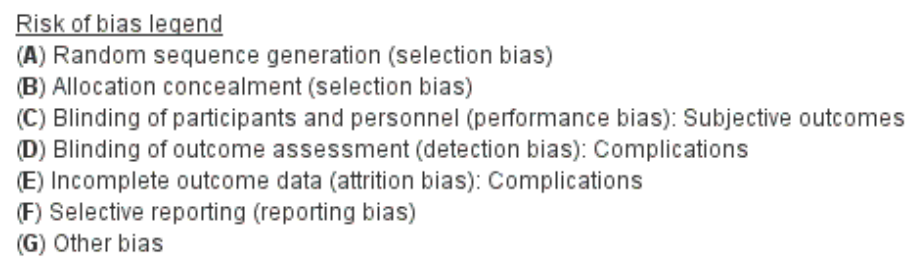

\section{Length of hospital stay}

Two studies including 104 participants measured length of hospital stay, but only one study including 44 participants had data suitable for reporting (Hensle 1978); the other study reported no difference between groups (Daly 1982).

We were uncertain if amino acid solution alone or in combination with dextrose solution had any effect on length of hospital stay (MD 0.5 days fewer; very low-quality evidence) (Hensle 1978). We downgraded the quality of evidence for study limitations, indirectness as the data used historic methods and very serious imprecision as the study was underpowered to demonstrate a clinically important difference of one day in length of hospital stay.

\section{Secondary outcomes}

\section{Mortality}

One study including 60 participants reported mortality (Daly 1982).

We were uncertain if amino acid solution alone or in combination with dextrose solution had any effect on mortality rates (RR approximately $1, \mathrm{Cl}$ not reported; very low-quality evidence). We downgraded the quality of evidence for study limitations, indirectness and there were too few events to reliably assess this outcome. 
Comparison 6: branched chain amino acid solution and dextrose compared to dextrose only

We found one study including 19 participants that compared branched chain amino acids solution and dextrose to dextrose only (Bonau 1984). See Summary of findings 6.

\section{Primary outcomes}

\section{Complications up to 90 days after surgery}

We were uncertain if branch chain amino acids solution and dextrose compared to dextrose had any effect on complication rates (RR approximately $1, \mathrm{Cl}$ not reported; very low-quality evidence). We downgraded the quality of evidence for study limitations, indirectness given that this study was conducted in the early 1980s and many important aspects of care related to patient population have changed, and for very serious imprecision. No complications reported in either group; therefore, no analysis was conducted.

\section{Length of hospital stay}

The study did not report length of hospital stay.

\section{Secondary outcomes}

\section{Mortality}

The study did not report mortality.

\section{Comparison 7: perioperative oral nutritional supplements compared to oral multivitamin and mineral supplement}

We found one study including 61 participants that compared the provision of oral nutritional supplements three to four weeks preoperatively and four weeks postoperatively to multivitamin and mineral supplement (Ritch 2018). Follow-up was reported for a period of 30 days after surgery.

See Summary of findings 7. All data for this comparison were obtained from the published report and the published protocol.

\section{Primary outcomes}

\section{Complications up to 90 days after surgery}

Perioperative oral supplements compared to an oral multivitamin and mineral supplement may have slightly decreased postoperative complications (RR $0.73,95 \% \mathrm{Cl} 0.47$ to 1.13 ; lowquality evidence; Analysis 6.1). We downgraded the quality of evidence for study limitations and imprecision. Assuming a baseline risk of postoperative complications of $66 \%$, perioperative oral supplement would have resulted in 135 fewer occurrences per 1000 participants ( $95 \% \mathrm{Cl} 256$ fewer to 65 more).

\section{Length of hospital stay}

Perioperative oral supplements compared to an oral multivitamin and mineral supplement may have had little or no effect on length of hospital stay (MD 0.30 days lower, $95 \% \mathrm{Cl} 3.64$ lower to 3.04 more; low-quality evidence; Analysis 6.2). We downgraded quality of evidence for study limitations and the study was underpowered to demonstrate a clinically important difference of one day in length of hospital stay.

\section{Secondary outcomes}

\section{Mortality}

Perioperative oral supplements compared to an oral multivitamin and mineral supplement may have had little or no effect on postoperative mortality rates (RR $0.97,95 \% \mathrm{Cl} 0.06$ to 14.78 ; low-quality evidence; Analysis 6.3). We downgraded the quality of evidence for study limitations and imprecision. Assuming a baseline risk of postoperative mortality of 0.03 , early feeding would have resulted in 1 fewer occurrences per 1000 participants $(95 \% \mathrm{Cl}$ 31 fewer to 459 more).

\section{Subgroup analysis}

Subgroup analyses were not possible due to insufficient data.

\section{Sensitivity analysis}

Sensitivity analyses were not possible due to insufficient data.

\section{DISCUSSION}

\section{Summary of main results}

We identified eight RCTs which informed seven separate comparisons including 500 participants with bladder cancer undergoing an RC (Bonau 1984; Daly 1982; Deibert 2016; HamiltonReeves 2016; Hensle 1978; Ritch 2018; Roth 2013; Rovera 1989). The mean or median age of included participants was 61.5 to 69 (range 30 to 84 ) years. The majority of studies reported outcomes at 30 days (Hamilton-Reeves 2016; Ritch 2018; Roth 2013; Rovera 1989). One study reported outcomes up to 8 days postoperatively (Bonau 1984), one up to 60 days (Hensle 1978) and one to 90 days (Deibert 2016). In one study the follow up time was unclear (Daly 1982).

We found limited evidence that perioperative nutrition improved patient-important outcomes. Specifically, immuno-enhancing nutrition may have reduced 90-day complication rates (low-quality evidence). Preoperative oral nutrition support and amino acids with dextrose compared to dextrose alone may have reduced 30-day complication rates but we were uncertain of both these findings. PN when compared to oral nutrition may have increased complications (low-quality evidence) and so might postoperative feeding (very low-quality evidence), although we were very uncertain of the latter finding. Oral supplements given in the perioperative period may have slightly decreased postoperative complications (low-quality evidence); length of hospital stay may have been similar (low-quality evidence).

\section{Overall completeness and applicability of evidence}

This review excluded cohort studies and, therefore, the results do not reflect all the research in this area. There have been morerecent studies that have been single cohort reviews. We excluded studies that evaluated ERAS since the results of nutritional interventions could not be separated from the results of a multimodal approach to perioperative management.

The objective of this review was to assess the literature on the effects of perioperative nutrition in people undergoing RC for the treatment of bladder cancer on complications, length of hospital stay and mortality. Due to the lack of studies identified, this objective has only been partially met by the review. The included studies cover a period of almost 30 years during which time multiple changes have occurred in surgical technique and the 
provision of artificial nutritional support. The included studies reflected the variety of approaches that have been devised to enhance the nutritional needs of people undergoing surgery.

One early study with a small sample size examined preoperative oral supplements but participants also had postoperative feeding with PN thus limiting the ability to assess the effect of the preoperative supplementation (Rovera 1989). There was no RCT evidence on enteral (nasogastric) feeding. One study examined $\mathrm{PN}$ and reported complications as an outcome in all participants postoperatively but showed this had an adverse effect on outcome measures (Roth 2013). We found no studies that evaluated PN in people with a non-functioning gut with or without malnutrition where PN would be potentially recommended in current clinical practice.

A more recent development in nutrition support is the use of specialised immuno-enhancing nutrition supplements and one study evaluated these supplements and found a reduction in complication and infection rates 90 days postsurgery but not at 30 days postsurgery; the study was a pilot study so had limited applicability without further replication (Hamilton-Reeves 2016). Although one study which evaluated early oral feeding in this group was unable to recruit the planned participants, it examined one of the nutrition elements of ERAS or 'fast track' protocols and showed that there was not an increase in complications after RC if early access to oral feeding was administered (Deibert 2016).

In summary, applicability of this review was severely limited by the paucity of studies, some of which were very old and therefore not directly applicable to today's patient population, RC practice and the type of nutritional interventions available. Interestingly, none of the studies looked at nutritional status as an inclusion criteria. Where nutritional interventions have been reported successful in other cancer settings (Burden 2017), participants had lost weight or were at particular risk or malnourished preoperatively.

\section{Quality of the evidence}

We consistently downgraded the quality of evidence for all six comparisons. The quality of evidence was rated as low to very low. Issues that lowered our confidence in the estimates of effect were study limitations, specifically unclear allocation concealment (selection bias) and the lack of blinding (performance and detection bias). We also frequently downgraded for imprecision due to small sample sizes and wide Cls. Some of the older studies made use of products which would no longer be used for nutrition support and we downgraded for indirectness. Due to the paucity of studies, we were unable to formally assess the possibility of publication bias.

\section{Potential biases in the review process}

Although we conducted this systematic review with a comprehensive search strategy identical with current standards of Cochrane, we found only eight RCTs. There is a possibility that despite our best efforts, we may have missed additional studies. This may be because they were published in languages other than English (although we applied no language restrictions), were published in non-indexed journals or were unpublished.

We contacted the study authors on several occasions and one provided feedback to our queries. However, we did not obtain data on standard deviations or standard errors that would have allowed us to undertake more comprehensive analyses. This may represent a source of bias with potential under-reporting of the true effects of the interventions.

Three studies were listed as ongoing (see Characteristics of ongoing studies table); however, one was reported as having been completed (personal correspondence) and the other was due to have been completed. The reporting of results from these trials would have added to the information from this review.

\section{Agreements and disagreements with other studies or reviews}

We identified no systematic reviews specifically examining standard nutritional interventions in the perioperative treatment of people with bladder cancer undergoing an RC other than reviews of studies reporting nutritional intervention as part of ERAS protocols (Cerantola 2013; Maffezzini 2008; Melnyk 2011). We excluded studies reporting ERAS protocols from this review. Outcomes need to include both clinical outcomes and patient-reported outcomes with economic evaluations. We identified one review on immunoenhancing nutrition, which concurred that there is a paucity in the literature regarding perioperative feeding in RC (Munbauhal 2014). This topic will have been partially answered by the reported small study on perioperative, preoperative and postoperative oral supplements (Hamilton-Reeves 2016). One review of people undergoing RC published since the initiation of this Cochrane Review identified preoperative nutrition optimisation and early postoperative feeding as important components that urologists should incorporate in a package of care for people undergoing this surgery (Matulewicz 2015)

\section{AUTHORS' CONCLUSIONS}

\section{Implications for practice}

Immuno-enhancing nutrition may reduce complication rates as may preoperative oral nutrition support and amino acids with dextrose (compared to dextrose alone) but we are uncertain of the latter two findings. Parenteral nutrition when compared to oral nutrition may increase complications (low-quality evidence) and so may postoperative feeding, although we are very uncertain of the latter finding. Length of hospital stay may not be impacted by any of the nutritional interventions for which we found randomised controlled trial (RCT) evidence.

\section{Implications for research}

This review highlights the need for better-quality research on the perioperative nutritional management of bladder cancer. Further research, particularly RCTs are required to evaluate nutritional interventions pre- and postoperatively in the surgical treatment of people diagnosed with muscle-invasive bladder cancer requiring radical cystectomy. There is a paucity of research evaluating oral and enteral nutritional support in this group using robust research methods. Parenteral nutrition needs to be evaluated further in people who are malnourished following surgery where the feeding regimens are calculated to meet individual requirements. It is also important to consider the risks of refeeding syndrome (a metabolic response to overfeeding after a period of nutritional deprivation).

Specific comparisons which require further research include: 
- preoperative nutritional support using oral supplements compared to standard diet;

- postoperative oral nutritional support compared to standard diet;

- immuno-enhancing nutrition supplements compared to standard nutrition supplements;

- parenteral nutrition requires further evaluation in the postoperative period where participants have a non-functioning gastrointestinal tract in early compared to late provision of feeding;

- patient-reported outcomes and quality of life measures need to be incorporated into future research as outcome measures;

- body composition measurements along with measures of nutritional status need to be included in trials to determine if the interventions are altering nutritional status and body composition.

\section{ACKNOWLEDGEMENTS}

We would like to thank Richard Silvioli and Antje Teubner for assistance in translation of papers from Italian and German into English. We would like to thank our dietetic colleague Christel Lyell for assisting with the task of examining titles and abstracts. We would also like to thank library staff at Central Manchester Foundation Trust for assistance with acquiring reports of studies. Asif Muneer acknowledges support from the NIHR BRC University College London Hospitals.

We acknowledge the work of Molly $M$ Neuberger as former Managing Editor of Cochrane Urology in the preparation of the protocol. We are very grateful to Ted Skorarus, Heidi Silver, Yair Lotan and Jeffrey Holzbeierlein for their critical appraisal of this review as part of the peer review process. We would like to thank Cochrane Urology Managing Editors Alea Miller and Robert Lane as well as Contact Editor Michael Risk for all their help and assistance with this review. 
R E F E R E N C E S

\section{References to studies included in this review}

Bonau 1984 \{published data only\}

Bonau RA, Ang SD, Jeevanandam M, Daly JM. High-branched chain amino acid solutions: relationship of composition to efficacy. Journal of Parenteral and Enteral Nutrition 1984;8(6):622-7.

\section{Daly 1982 \{published data only\}}

Daly J, Copeland E, Johnson D, Massar E, Dudrick S. Effects of perioperative infusion of dextrose and amino acid solutions in bladder cancer patients. Clinical Nutrition 1982;1:98.

\section{Deibert 2016 \{published data only\}}

Deibert CM, Silva MV, RoyChowdry A, McKiernan J, Scherr DS, Seres $D$, et al. A prospective randomized trial of the effects of early enteral feeding after radical cystectomy. Urology 2016;96:69-73.

\section{Hamilton-Reeves 2016 \{published data only\}}

Hamilton-Reeves JM, Bechtel MD, Hand LK, Schleper A, Yankee TM, Eugene PC, et al. Effects of immunonutrition for cystectomy on immune response and infection rates: a pilot randomized controlled clinical trial. European Urology 2016;69:389-92.

\section{Hensle 1978 \{published data only\}}

Hensle TW. Protein-sparing in cystectomy patients. Journal of Parenteral and Enteral Nutrition 1978;2(4):519-23.

\section{Ritch 2018 \{published data only\}}

Ritch CR, Cookson MS, Clark PE, Chang SS, Fakhoury K, Ralls V, et al. Perioperative oral nutrition supplementation reduces prevalence of sarcopenia following radical cystectomy: results of a prospective randomized controlled trial. Journal of Urology 2019;201(3):470-7.

\section{Roth 2013 \{published data only\}}

Faune AV, Kiss B, Burkhard FC, Studer LE, Thalmann GN, Roth B. Administration of postoperative parenteral nutrition does not affect oncological outcomes after radical cystectomy (RC) in bladder cancer patients. Journal of Urology 2015;193((4 Suppl 1)):e813.

* Roth B, Birkhauser FD, Zehnder P, Thalmann GN, Huwyler M, Burkhard FC, et al. Parenteral nutrition does not improve postoperative recovery from radical cystectomy: results of a prospective randomised trial. European Urology 2013;63(3):475-82.

Vidal Faune A, Arnold N, Vartolomei M, Kiss B, Burkhard FC, Thalmann GN, et al. Does postoperative parenteral nutrition after radical cystectomy impact oncological and functional outcomes in bladder cancer patients?. European Urology 2016;15(3):e515.

\section{Rovera 1989 \{published data only\}}

Rovera L, Rolle G, Alliaudi C, Aloi MR, Buffa G, Cocimano V, et al. Usefulness of preoperative nutritional support in patients with bladder carcinoma [Utilità di un supporto nutrizionale preoperatorio in pazienti affetti da carcinoa vescicale]. Rivista Italiana di Nutrizione ed Enterale 1989;7(2):79-85.

\section{References to studies excluded from this review}

Brodner 2001 \{published data only\}

Brodner G, Van Aken H, Hertle L, Fobker M, Von Eckardstein A, Goeters C, et al. Multimodal perioperative management combining thoracic epidural analgesia, forced mobilization, and oral nutrition-reduces hormonal and metabolic stress and improves convalescence after major urologic surgery. Anesthesia and Analgesia 2001;92(6):1594-600. [PUBMED: 11375853]

Daly 1987 \{published data only\}

Daly JM, Bonau R, Stofberg P, Bloch A, Jeevanandam M, Morse M. Immediate postoperative jejunostomy feeding clinical and metabolic results in a prospective trial. American Journal of Surgery 1987;153(2):198-206. [PUBMED: 3101530]

de Vries 2012 \{published data only\}

de Vries RR, Kauer P, van Tinteren $\mathrm{H}$, van der Poel HG, Bex A, Meinhardt W, et al. Short-term outcome after cystectomy: comparison of two different perioperative protocols. Urologia Internationalis 2012;88(4):383-9. [PUBMED: 22433508]

Hensle 1985 \{published data only\}

Hensle TW, Askanazi J, Rosenbaum LH, Bernstein G, Kinney JM. Metabolic changes associated with radical cystectomy. Journal of Urology 1985;134(5):1032-6.

\section{Karl 2014 \{published data only\}}

Karl A, Buchner A, Becker A, Staehler M, Seitz M, Khoder W, et al. A new concept for early recovery after surgery for patients undergoing radical cystectomy for bladder cancer: results of a prospective randomized study. Journal of Urology 2014; 191:335-40.

\section{Malossini 1987 \{published data only\}}

Malossini G, Cavalleri S, Bianchi G, Carpi I, Lamberti L, Scroccaro G. Protein-sparing peripheral parenteral nutrition in urologic surgery [Nutrizione parenterale periferica "protein sparing" nella chirurgia urologica.]. Chirurgia Italiana 1987;39(5):489-95. [PUBMED: 3121199]

Mangano 1993 \{published data only\}

Mangano A, Panza N, Paganini N, Croce G, Cassone E, Trevisan M, et al. Effects of parenteral glutamine supplementation on the nutritional status of patients with radical cystectomy in neoplasia [Effetti della supplementazione parenterale di glutammina sullo stato nutrizionale di pazient sottoposti a cistectomia radicale per neoplasia]. Acta Urologica Italica 1993;7 (Suppl 2):119-20.

\section{McArdle 1986 \{published data only\}}

McArdle AH, Reid EC, Laplante MP, Freeman CR. Prophylaxis against radiation injury. The use of elemental diet prior to and during radiotherapy for invasive bladder cancer and in early 
postoperative feeding following radical cystectomy and ileal conduit. Archives of Surgery 1986;121(8):879-85. [PUBMED: 3089195]

\section{Olbert 2009 \{published data only\}}

Olbert PJ, Baumann L, Hegele A, Schrader AJ, Hofmann R. Fast-track concepts in the perioperative management of patients undergoing radical cystectomy and urinary diversion: review of the literature and research results [Fast-trackKonzepte im perioperativen Management bei Zystektomie und Harnableitung: Literaturubersicht und eigene Ergebnisse]. Der Urologe. Ausg. A 2009;48(2):137-42. [PUBMED: 19142627]

\section{Solomon 1978 \{published data only\}}

Solomon MJ, Smith MF, Dowd JB, Bistrian BR, Blackburn GL. Optimal nutritional support in surgery for bladder cancer: preservation of visceral protein by amino acid infusions. Journal of Urology 1978;119(3):350-4. [PUBMED: 565418]

\section{References to ongoing studies}

NCT02238886 \{published data only\}

NCT02238886. Radical cystectomy, nutrition and convalescence: can goal-directed postoperative nutritional therapy reduce the convalescence period for patients undergoing radical cystectomy (RC)?. clinicaltrials.gov/ct2/show/NCT02238886 (first received 12 September 2014).

\section{NCT03147586 \{published data only\}}

NCT03147586. Influence of immune nutrition diet on 90day outcomes in patients undergoing radical cystectomy. clinicaltrials.gov/ct2/show/NCT03147586 (first received 10 May 2017).

\section{NCT03204266 \{published data only\}}

NCT03204266. Oral supplementation to enhance recovery pilot study. clinicaltrials.gov/ct2/show/NCT03204266 (first received 29 June 2017).

\section{Additional references}

\section{Arumainayagam 2008}

Arumainayagam N, McGrath J, Jefferson KP, Gillatt DA. Introduction of an enhanced recovery protocol for radical cystectomy. BJU International 2008;101(6):698-701. [PUBMED: 18190646]

\section{Askanazi 1986}

Askanazi J, Hensle TW, Starker PM, Lockhart SH, LaSala PA, Olsson C, et al. Effect of immediate postoperative nutritional support on length of hospitalization. Annals of Surgery 1986;203(3):236-9. [PUBMED: 3082301]

\section{Azhar 2016}

Azhar RA, Bochner B, Catto J, Goh AC, Kelly J, Patel HD, et al. Enhanced recovery after urological surgery: a contemporary systematic review of outcomes, key elements, and research needs. European Urology 2016; Vol. 70, issue 1:176-87. [DOI: 10.1016/j.eururo.2016.02.051]

\section{Barrass 2006}

Barrass BJ, Thurairaja R, Collins JW, Gillatt D, Persad RA. Optimal nutrition should improve the outcome and costs of radical cystectomy. Urologia Internationalis 2006;77:139-42.

\section{Billson 2013}

Billson HA, Holland C, Curwell J, Davey VL, Kinsey L, Lawton LJ, et al. Perioperative nutrition interventions for women with ovarian cancer. Cochrane Database of Systematic Reviews 2013 , Issue 9. [DOI: 10.1002/14651858.CD009884]

\section{Burden 2012a}

Burden S, Todd C, Hill J, Lal S. Pre-operative nutrition support in patients undergoing gastrointestinal surgery. Cochrane Database of Systematic Reviews 2012, Issue 11. [DOI: 10.1002/14651858.CD008879.pub2]

\section{Burden 2017}

Burden ST, Gibson D, Lal S, Hill J, Pilling M, Soop M, et al. Preoperative oral nutritional supplementation with dietary advice versus dietary advice alone in weight-losing patients with colorectal cancer: single-blind randomized controlled trial. Journal of Cachexia, Sarcopenia and Muscle 2017; Vol. 8, issue 3:437-46. [DOI: 10.1002/jcsm.12170]

\section{Cerantola 2013}

Cerantola Y, Valerio M, Persson B, Jichlinski P, Ljungqvist O, Hubner M, et al. Guidelines for perioperative care after radical cystectomy for bladder cancer: Enhanced Recovery After Surgery $\left(\right.$ ERAS $\left.^{\circledR}\right)$ Society recommendations. Clinical Nutrition 2013;32:879-87.

\section{Chin 1983}

Chin JL, Wyatt JK. Effects of total parenteral nutrition on patients with bladder cancer who undergo cystectomy. Canadian Journal of Surgery 1983;26(6):495-8.

\section{de Braud 2002}

de Braud F, Maffezzini M, Vitale V, Bruzzi P, Gatta G, Hendry WF, et al. Bladder cancer. Critical Reviews in Oncology/hematology 2002;41:89-106.

\section{Deeks 2001}

Deeks JJ, Altman DG, Bradburn MJ. Statistical methods for examining heterogeneity and combining results from several studies in meta-analysis. In: Egger M, Davey Smith G, Altman DG editor(s). Systematic Reviews in Health Care: Meta-Analysis in Context. 2nd Edition. London: BMJ Publication Group, 2001.

\section{Dindo 2004}

Dindo D, Demartines N, Clavien PA. Classification of surgical complications a new proposal with evaluation in a cohort of 6336 patients and results of a survey. Annals of Surgery 2004;2:205-13.

\section{GLOBOCAN 2012}

Ferlay J, Soerjomataram I, Ervik M, Dikshit R, Eser S, Mathers C, et al. GLOBOCAN 2012 v.1.0, Cancer Incidence and Mortality Worldwide: IARC Cancer Base No. 11. Lyon, France: International Agency for Research on Cancer; 2013. Available from globocan.iarc.fr (accessed 3 September 2014). 


\section{GRADEpro GDT [Computer program]}

McMaster University (developed by Evidence Prime). GRADEpro GDT. Version accessed 2 June 2017. Hamilton (ON): McMaster University (developed by Evidence Prime), 2015.

\section{Gregg 2011}

Gregg JR, Cookson MS, Phillips S, Salem S, Chang SS, Clark PE, et al. Effect of preoperative nutritional deficiency on mortality after radical cystectomy for bladder cancer. Journal of Urology 2011;185(1):90-6. [PUBMED: 21074802]

\section{Guyatt 2008}

Guyatt GH, Oxman AD, Vist GE, Kunz R, Falck-Ytter Y, Schünemann HJ, et al. GRADE: what is "quality of evidence" and why is it important to clinicians?. BMJ (Clinical Research Ed.) 2008;336(7651):995-8. [DOI: 10.1136/bmj.39490.551019.BE]

\section{Henry 2011}

Henry C. Chapter 4, Effect of malnutrition on cancer patients In: Shaw C editor(s). Nutrition and Cancer. Hoboken (NJ): WileyBlackwell, 2011:46.

\section{Heyland 2001}

Heyland DK, Montalvo M, MacDonald S, Keefe L, Su XY, Drover JW. Total parenteral nutrition in the surgical patient: a meta-analysis. Canadian Journal of Surgery 2001;44(2):102-11. [PUBMED: 11308231]

\section{Higgins 2003}

Higgins JP, Thompson SG, Deeks JJ, Altman DG. Measuring inconsistency in meta-analyses. BMJ 2003;327:557-60.

\section{Higgins 2011}

Higgins JP, Green S, editor(s). Cochrane Handbook for Systematic Reviews of Interventions Version 5.1.0 (updated March 2011). The Cochrane Collaboration, 2011. Available from handbook.cochrane.org.

\section{Hollenbeck 2006}

Hollenbeck BK, Miller DC, Taub DA, Dunn RL, Khuri SF, Henderson WG, et al. The effects of adjusting for case mix on mortality and length of stay following radical cystectomy. Journal of Urology 2006;176(4 Pt 1):1363-8. [PUBMED: 16952633]

\section{Jensen 2018}

Jensen BT, Lauridsen SV, Jensen JB. Prehabilitation for major abdominal urologic oncology surgery. Current Opinion in Urology 2018;28(3):243-50.

\section{Karl 2009}

Karl A, Rittler P, Buchner A, Fradet V, Speer R, Walther S, et al. Prospective assessment of malnutrition in urologic patients. Urology 2009;73(5):1072-6.

\section{Kondrup 2003}

Kondrup J, Allison SP, Elia M, Vellas B, Plauth M. ESPEN guidelines for nutrition screening 2002. Clinical Nutrition 2003;22(4):415-21. [PUBMED: 12880610]

\section{Lawrie 2018}

Lawrie TA, Green JT, Beresford M, Wedlake L, Burden S, Davidson SE, et al. Interventions to reduce acute and late adverse gastrointestinal effects of pelvic radiotherapy for primary pelvic cancers. Cochrane Database of Systematic Reviews 2018, Issue 1. [DOI: 10.1002/14651858.CD012529.pub2]

\section{Maffezzini 2006}

Maffezzini M, Gerbi G, Campodonico F, Parodi D. A multimodal perioperative plan for radical cystectomy and urinary intestinal diversion: effects, limits and complications of early artificial nutrition. Journal of Urology 2006;176(3):945-8; discussion 948-9. [PUBMED: 16890663]

\section{Maffezzini 2008}

Maffezzini M, Campodonico F, Canepa G, Gerbi G, Parodi D. Current perioperative management of radical cystectomy with intestinal urinary reconstruction for muscle-invasive bladder cancer and reduction of the incidence of postoperative ileus. Surgical Oncology 2008;17(1):41-8.

\section{Mathur 2007}

Mathur S, Plank LD, Hill AG, Rice MA, Hill GL. Changes in body composition, muscle function and energy expenditure after radical cystectomy. BJU International 2007;101:973-7.

\section{Matulewicz 2015}

Matulewicz RS, Brennan J, Pruthi RS, Kundu SD, Gonzalez CM, Meeks JJ. Radical cystectomy perioperative care redesign. Urology 2015;86(6):1076-86.

\section{Melnyk 2011}

Melnyk M, Casey RG, Black P, Koupparis AJ. Enhanced Recovery After Surgery (ERAS) protocols: time to change practice?. Canadian Urological Association Journal 2011;5(5):342-8.

\section{Mohler 1987}

Mohler JL, Flanigan RC. The effect of nutritional status and support on morbidity and mortality of bladder cancer patients treated by radical cystectomy. Journal of Urology 1987;137:404-8.

\section{Mueller 2011}

Mueller C, Compher C, Ellen DM, American Society for Parenteral and Enteral Nutrition (A.S.P.E.N.) Board of Directors. A.S.P.E.N. clinical guidelines: nutrition screening, assessment, and intervention in adults. Journal of Parenteral and Enteral Nutrition 2011;35(1):16-24. [PUBMED: 21224430]

\section{Munbauhal 2014}

Munbauhal G, Drouin SJ, Mozer P, Colin P, Phé V, Cussenot O, et al. Malnourishment in bladder cancer and the role of immunonutrition at the time of cystectomy: an overview for urologists. BJU International 2014;114(2):177-84

\section{NICE 2006}

National Institute for Health and Care Excellence. Nutrition support in adults: oral nutrition support, enteral tube feeding and parenteral nutrition, 2006. Available from guidance.nice.org.uk/cg32. 


\section{NICE 2015}

National Institute for Health and Care Excellence. Bladder cancer: diagnosis and management, 2015. Available from nice.org.uk/guidance/ng2. NICE.

\section{Pruthi 2003}

Pruthi RS, Chun J, Richman M. Reducing time to oral diet and hospital discharge in patients undergoing radical cystectomy using a perioperative care plan. Urology 2003;62(4):661-5; discussion 665-6. [PUBMED: 14550438]

\section{Rattray 2018}

Rattray M, Roberts S, Marshall A, Desbrow B. A systematic review of feeding practices among postoperative patients: is practice in-line with evidenced-based guidelines?. Journal of Human Nutrition and Dietetics 2018;31(2):151-67. [DOI: 10.1111/ jhn.12486]

\section{Review Manager 2014 [Computer program]}

The Nordic Cochrane Centre, The Cochrane Collaboration. Review Manager 5 (RevMan 5). Version 5.3. Copenhagen: The Nordic Cochrane Centre, The Cochrane Collaboration, 2014.

\section{Schünemann 2011}

Schünemann HJ, Oxman AD, Higgins JP, Vist GE, Glasziou P, Guyatt GH. Chapter 11: Presenting results and 'Summary of findings' tables. In: Higgins JP, Green S, editor(s), Cochrane Handbook for Systematic Reviews of Interventions. Version 5.1.0 (updated March 2011). The Cochrane Collaboration, 2011. Available from handbook.cochrane.org.

\section{Shabsigh 2009}

Shabsigh A, Korets R, Vora KC, Brooks CM, Cronin AM, Savage C, et al. Defining early morbidity of radical cystectomy for patients with bladder cancer using a standardized reporting methodology. European Urology 2009;55:164-76.

\section{Smith 2014}

Smith AB, Deal AM, Yu H, Boyd B, Matthews J, Wallen EM, et al. Sarcopenia as a predictor of complications and survival following radical cystectomy. Journal of Urology 2014;191(6):1714-20.

\section{CHARACTERISTICS OF STUDIES}

Characteristics of included studies [ordered by study ID]

\section{Stein 2003}

Stein JP, Skinner DG. Results with radical cystectomy for treating bladder cancer: a 'reference standard' for high-grade, invasive bladder cancer. BJU International 2003;92:12-7.

\section{Sterne 2011}

Sterne JA, Egger M, Moher D. Chapter 10: Addressing reporting biases. In: Higgins JP, Green S, editor(s). Cochrane Handbook for Systematic Reviews of Interventions. Version 5.1.0 (updated March 2011). The Cochrane Collaboration, 2011. Available from handbook.cochrane.org.

\section{SWPHO 2011}

South West Public Health Observatory (SWPHO), UK. Survival in patients treated by cystectomy for bladder cancer, Urological Cancers SSCRG. National Cancer Intelligence Network 2011.

\section{Thurairaja 2005}

Thurairaja R, Whittleston T, McFarlane J, Persad R. Is nutritional support beneficial to patients after cystectomy?. BJU International 2005;95(9):1168-70. [PUBMED: 15892795]

\section{Tobias 2010}

Tobias J, Hochhauser D. Cancer and its Management. 6th Edition. Hoboken (NJ): Wiley-Blackwell, 2010.

\section{Villa 2017}

Villa G, Bresciani M, Boarin M, Duilio FM. The impact of oral nutrition in patients after radical cystectomy: an overview. International Journal of Urological Nursing 2017;11(3):136-43.

\section{Weimann 2017}

Weimann A, Braga M, Carli F, Higashiguchi T, Hübner M, Klek S, et al. ESPEN guideline: clinical nutrition in surgery. Clinical Nutrition 2017; Vol. 36, issue 3:623-50.

\section{References to other published versions of this review Burden 2012b}

Burden S, Billson HA, Lal S, Sharma A, Lyell C, Owen KA, et al. Perioperative nutrition for the treatment of bladder cancer by radical cystectomy. Cochrane Database of Systematic Reviews 2012, Issue 11. [DOI: 10.1002/14651858.CD010127]

* Indicates the major publication for the study

Bonau 1984

\begin{tabular}{ll} 
Methods & Study design: parallel-group randomised controlled trial \\
& Study dates: not reported \\
& Setting: Memorial Sloan-Kettering Centre, New York, NY, USA \\
\hline Participants & Inclusion criteria: men with stage I bladder cancer who underwent a radical cystectomy and an ileal \\
conduit diversion.
\end{tabular}


Total number of participants randomly assigned: 19

Age: range $46-76$ years

Sex: men

Nutrition status: participants were judged to be of normal nutrition status with no prior weight loss (no further details reported)

\section{Group 1: intravenous dextrose}

Number of all participants randomly assigned: 4

Age: not reported

Sex: men

Tumour stage/grade: not reported

Comorbidities: not reported

Group 2: intravenous dextrose and a commercially available amino acid solution containing $25 \%$ branched chain amino acids

Number of all participants randomly assigned: 9

Age: not reported

Sex: men

Tumour stage/grade: not reported

Comorbidities: not reported

Group 3: intravenous dextrose and a commercially available amino acid solution enriched with $45 \%$ branched chain amino acids

Number of all participants randomly assigned: 6

Age: not reported

Sex: men

Tumour stage/grade: not reported

Comorbidities: not reported

Group 4: see 'Notes' below

All groups: intravenous solutions as detailed below, but containing similar amounts of electrolytes, trace minerals and vitamins. Infusions began at 8 a.m. postoperative day 1 and infusions were stopped at postoperative day 8 . During the 7-day postoperative study period, none of the participants had any oral intake

Group $1(n=4): 150$ g dextrose in $3 \mathrm{~L}$ of water administered intravenously over 24 hours.

Group 2 ( $n=9$ ): intravenous dextrose solution and a commercially available amino acid solution containing 25\% branched chain amino acids (Aminosyn 7\%; Abbott Laboratories). Administration rates were designed to deliver $30 \mathrm{kcal} / \mathrm{kg} /$ day and $1.5 \mathrm{~g}$ protein $/ \mathrm{kg} /$ day.

Group $3(n=6)$ : intravenous dextrose solution and an amino acid solution enhanced with $45 \%$ branched chain amino acids. Administration rates were designed to deliver $30 \mathrm{kcal} / \mathrm{kg} / \mathrm{day}$ and $1.5 \mathrm{~g}$ protein $/ \mathrm{kg} /$ day. 
Bonau 1984 (Continued)

Outcomes

Complications: no participants had sepsis or wound infection during the postoperative study period. Postoperative ileus is reported to have occurred but there is no reporting on the number of participants affected.

How measured: not reported

Time point measured: not reported

Time point reported: at the end of the postoperative study period (day 8)

Length of hospital stay: not reported

Mortality: not reported

\begin{tabular}{ll}
\hline Funding sources & Supported in part by a National Institute Health grant and by a grant from Abbott Laboratories \\
\hline Declarations of interest & No declarations of interest reported \\
\hline Notes & $\begin{array}{l}\text { Language of publication: English } \\
\text { A 4th group comprising of } 6 \text { participants was studied but not included above as this group consisted of } \\
\text { consecutive referrals and not randomly assigned participants. }\end{array}$ \\
\hline
\end{tabular}

\section{Risk of bias}

\section{Bias}

Authors' judgement Support for judgement

Random sequence genera- Unclear risk Randomisation reported to have occurred but not fully described.
tion (selection bias)

\begin{tabular}{|c|c|c|}
\hline $\begin{array}{l}\text { Allocation concealment } \\
\text { (selection bias) }\end{array}$ & Unclear risk & Allocation concealment not described. \\
\hline $\begin{array}{l}\text { Blinding of participants } \\
\text { and personnel (perfor- } \\
\text { mance bias) } \\
\text { Subjective outcomes }\end{array}$ & Unclear risk & No blinding reported. \\
\hline
\end{tabular}

Blinding of outcome as- Unclear risk No blinding described.

sessment (detection bias)

Complications

Blinding of outcome as- Unclear risk Length of hospital stay not reported.
sessment (detection bias)
Length of hospital stay

\begin{tabular}{lll}
\hline $\begin{array}{l}\text { Blinding of outcome as- } \\
\text { sessment (detection bias) }\end{array}$ & Low risk & Mortality not reported. \\
Mortality & \\
\hline $\begin{array}{l}\text { Incomplete outcome data } \\
\text { (attrition bias) }\end{array}$ & Unclear risk & Reporting unclear and data not available by group. \\
Complications & \\
\hline
\end{tabular}


Bonau 1984 (Continued)

Incomplete outcome data Unclear risk Length of hospital stay not reported.

(attrition bias)

Length of hospital stay

Incomplete outcome data Low risk Mortality not reported.

(attrition bias)

Mortality

Selective reporting (re- $\quad$ Unclear risk $\quad$ No protocol available.
porting bias)

Other bias Low risk No other bias detected.

Daly 1982

Methods Study design: parallel-group randomised controlled trial

Study dates: not reported

Setting: Memorial Sloan-Kettering Centre, New York, NY, USA

Participants Inclusion criteria: undergoing a radical cystectomy and ileal loop diversion following preoperative radiotherapy for bladder cancer

Exclusion criteria: not reported

Total number of participants randomly assigned: 93

Age: mean age across groups 61-63 years

Sex: not reported, but described as similar in each group

Nutrition status: mean \% ideal bodyweight was 107-108 although it was unclear if this was at baseline.

\section{Group 1: intravenous dextrose}

Number of all participants randomly assigned: 30

Age: not reported

Sex: not reported

Tumour stage/grade: not reported

Comorbidities: not reported

Group 2: intravenous fluids containing amino acids

Number of all participants randomly assigned: 30

Age: not reported

Sex: not reported

Tumour stage/grade: not reported

Comorbidities: not reported

\section{Group 3: intravenous dextrose and amino acids solution}

Number of all participants randomly assigned: 30 
Daly 1982 (Continued)
Age: not reported
Sex: not reported
Tumour stage/grade: not reported
Comorbidities: not reported

\begin{tabular}{|c|c|}
\hline \multirow[t]{4}{*}{ Interventions } & $\begin{array}{l}\text { All groups: interventions were given from } 3 \text { days preope } \\
\text { tively }\end{array}$ \\
\hline & Group $1(n=30)$ : intravenous dextrose solution \\
\hline & Group $2(n=30)$ : intravenous fluids containing $1.3-1.5 \mathrm{~g}$ \\
\hline & Group $3(n=30)$ : intravenous dextrose plus $1.3-1.5 \mathrm{~g} / \mathrm{k}$ \\
\hline \multirow[t]{12}{*}{ Outcomes } & $\begin{array}{l}\text { Complications: unspecified complications were reporte } \\
\text { (group 3) }\end{array}$ \\
\hline & How measured: not reported \\
\hline & Time point measured: not reported \\
\hline & Time point reported: at the end of the study period \\
\hline & Length of hospital stay: reported as similar in all groups \\
\hline & How measured: not reported \\
\hline & Time point measured: not reported \\
\hline & Time point reported: not reported \\
\hline & Mortality: no deaths during the study period \\
\hline & How measured: number of deaths \\
\hline & Time point measured: not reported \\
\hline & Time point reported: at end of the study period \\
\hline
\end{tabular}

\begin{tabular}{ll}
\hline Funding sources & Not reported \\
\hline Declarations of interest & No declarations of interest reported \\
\hline Notes & Language of publication: English \\
& $\begin{array}{l}93 \text { participants cited as the total number randomised to } 3 \text { groups with } 30 \text { in each group. There were } 3 \\
\text { participants unaccounted for in the report. The study was briefly described as the report was a short } \\
\text { abstract. }\end{array}$
\end{tabular}

\section{Risk of bias}

\begin{tabular}{lll}
\hline Bias & Authors' judgement & Support for judgement \\
\hline $\begin{array}{l}\text { Random sequence genera- } \\
\text { tion (selection bias) }\end{array}$ & Unclear risk & Random sequence generation not described. \\
\hline $\begin{array}{l}\text { Allocation concealment } \\
\text { (selection bias) }\end{array}$ & Unclear risk & Process of allocation not described. \\
\hline
\end{tabular}


Daly 1982 (Continued)

Blinding of participants Low risk Mortality not likely to be affected by blinding. and personnel (perfor-

mance bias)

Objective outcomes

Blinding of participants Unclear risk No blinding described.

and personnel (perfor-

mance bias)

Subjective outcomes

\begin{tabular}{|c|c|c|}
\hline $\begin{array}{l}\text { Blinding of outcome as- } \\
\text { sessment (detection bias) } \\
\text { Complications }\end{array}$ & Unclear risk & No blinding described. \\
\hline
\end{tabular}

Blinding of outcome as-
sessment (detection bias) $\quad$ Low risk $\quad$ No blinding described.

sessment (detection bias)

Length of hospital stay

\begin{tabular}{|c|c|c|}
\hline $\begin{array}{l}\text { Blinding of outcome as- } \\
\text { sessment (detection bias) } \\
\text { Mortality }\end{array}$ & Low risk & Assessment of mortality unlikely to be affected by blinding. \\
\hline $\begin{array}{l}\text { Incomplete outcome data } \\
\text { (attrition bias) } \\
\text { Complications }\end{array}$ & Low risk & 93 participants randomised and 90 participants reported in analysis. \\
\hline $\begin{array}{l}\text { Incomplete outcome data } \\
\text { (attrition bias) } \\
\text { Length of hospital stay }\end{array}$ & Low risk & 93 participants randomised and 90 participants reported in analysis. \\
\hline $\begin{array}{l}\text { Incomplete outcome data } \\
\text { (attrition bias) } \\
\text { Mortality }\end{array}$ & Low risk & 93 participants randomised and 90 participants reported in analysis. \\
\hline $\begin{array}{l}\text { Selective reporting (re- } \\
\text { porting bias) }\end{array}$ & Unclear risk & No protocol seen. \\
\hline Other bias & Low risk & No other bias detected. \\
\hline
\end{tabular}

Deibert 2016

Methods Study design: randomised controlled trial

Study dates: 2011-2014

Setting: 2 large hospitals in USA

\begin{tabular}{ll}
\hline Participants & Inclusion criteria: adults undergoing radical cystectomy and urinary diversion for bladder cancer \\
& Exclusion criteria: not reported \\
& Total number of participants randomly assigned: 102 \\
& Age: not reported \\
Sex: 84 men, 18 women & Nutrition status: not reported \\
\hline
\end{tabular}




\section{Group 1: early feeding group}

Number of participants randomly assigned: 50

Age: not reported

Sex: 37 men, 13 women

Tumour stage/grade:

T0: $\mathrm{n}=0$; Ta: $\mathrm{n}=3 ; \mathrm{T1}: \mathrm{n}=15 ; \mathrm{T2}: \mathrm{n}=22 ; \mathrm{T3}: \mathrm{n}=1 ; \mathrm{T} 4: \mathrm{n}=1$

Node positive: $\mathrm{n}=3$

Comorbidities: diabetes: $\mathrm{n}=6$

\section{Group 2: standard postoperative care}

Number of participants randomly assigned: 52

Age: not reported

Sex: 47 men, 5 women

Tumour stage/grade:

T0: $\mathrm{n}=1 ;$ Ta: $\mathrm{n}=0 ; \mathrm{T} 1: \mathrm{n}=12 ; \mathrm{T2}: \mathrm{n}=23 ;$ T3: $\mathrm{n}=6 ; \mathrm{T} 4: \mathrm{n}=0$

Node positive: $\mathrm{n}=1$

Comorbidities: diabetes: $\mathrm{n}=12$

Interventions

All groups: both groups had prokinetic medications, early ambulation and no nasogastric tube. Participants with nausea were advised to decrease their intake of the allocated diet. Where vomiting occurred on oral intake, oral intake was withheld for 8 hours and then clear liquid diet was resumed. Where nasogastric tube decompression was needed for persistent vomiting, standard diet was instigated after tube removal.

Group 1 ( $n=50)$ : early feeding group given clear liquid diet on postoperative day 1 and access to full normal diet on postoperative day 2

Duration: from postoperative day 1 onwards

Group 2 ( $n=52$ ): standard postoperative care not part of a specific fast track pathway including nil by mouth status until either flatus or bowel sounds

Duration: postoperatively onwards

Outcomes

Postoperative complications

How measured: using Clavien system

Time point measured: not reported

Time point reported: not reported

Rates of ileus: how many participants had ileus

How measured: defined as $\geq 3$ days from the induction of food until tolerance or if nasogastric tube insertion was required due to persistent vomiting prior to or after any introduction of food.

Time point measured: up to 90 days postoperatively

Time point reported: up to 90 days postoperatively

Length of hospital stay: reported as not significantly different between groups 
Deibert 2016 (Continued)

How measured: number of days

Time point measured: number of days in hospital

Time point reported: not reported

Mortality: 2 deaths in group 1 and 4 deaths in group 2

How measured: number of deaths

Time point measured: up to 90 days postoperatively

Time point reported: up to 90 days postoperatively

\begin{tabular}{ll}
\hline Funding sources & Not described \\
\hline Declarations of interest & No declarations of interest reported. \\
\hline Notes & $\begin{array}{l}\text { Language of publication: English } \\
\text { This study was terminated before reaching the planned recruitment numbers due to slow accrual of } \\
\text { participants. }\end{array}$
\end{tabular}

\section{Risk of bias}

\begin{tabular}{lll}
\hline Bias & Authors' judgement & Support for judgement \\
\hline $\begin{array}{l}\text { Random sequence genera- } \\
\text { tion (selection bias) }\end{array}$ & Low risk & $\begin{array}{l}\text { The process of random sequence generation was not described in the pub- } \\
\text { lished study but a process of random sequence generation was described in } \\
\text { the protocol. }\end{array}$ \\
\hline $\begin{array}{l}\text { Allocation concealment } \\
\text { (selection bias) }\end{array}$ & Unclear risk & Method of allocation not described. \\
\hline $\begin{array}{l}\text { Blinding of participants } \\
\begin{array}{l}\text { and personnel (perfor- } \\
\text { mance bias) } \\
\text { Objective outcomes }\end{array}\end{array}$ & Low risk & Mortality unlikely to be affected by blinding. \\
\hline
\end{tabular}

Blinding of participants Unclear risk No blinding described.

and personnel (perfor-

mance bias)

Subjective outcomes

Blinding of outcome as-
sessment (detection bias) $\quad$ Unclear risk $\quad$ No blinding described.

Complications

\begin{tabular}{lll}
\hline $\begin{array}{l}\text { Blinding of outcome as- } \\
\text { sessment (detection bias) } \\
\text { Length of hospital stay }\end{array}$ & Low risk & No blinding described. \\
\hline $\begin{array}{l}\text { Blinding of outcome as- } \\
\text { sessment (detection bias) } \\
\text { Mortality }\end{array}$ & Low risk & Mortality unlikely to be affected by lack of blinding. \\
\hline $\begin{array}{l}\text { Incomplete outcome data } \\
\text { (attrition bias) }\end{array}$ & Low risk & All randomised participants were included in the analysis of complications. \\
\hline \begin{tabular}{l} 
Complications \\
\hline
\end{tabular}
\end{tabular}


Deibert 2016 (Continued)

Incomplete outcome data Low risk All randomised participants were included in the analysis of length of hospital (attrition bias) stay.

Length of hospital stay

Incomplete outcome data Low risk All randomised participants were included in the analysis of mortality.
(attrition bias)

Mortality

Selective reporting (re- Low risk
porting bias)

The outcomes planned in the protocol were reported although fewer statistical tests than planned in the protocol could be done due to the trial being terminated prior to recruitment of planned numbers of participants.

Other bias Low risk No other bias detected.

Hamilton-Reeves 2016

\begin{tabular}{ll}
\hline Methods & Study design: randomised controlled trial \\
& Study dates: September 2013 to April 2015 \\
& Setting: hospital, Kansas City, MO, USA \\
\hline
\end{tabular}

Participants

Inclusion criteria: people undergoing radical cystectomy for primary bladder cancer

Exclusion criteria: swallowing difficulties, metastasis, $\geq 10 \%$ weight loss in previous 6 months, BMI < 18.5 , viral infection, immune deficiency, gout or relevant food allergies

Total number of participants randomly assigned: 29

Age: not reported

Sex: men

Comorbidities: assessed using the Charlson Comorbidity Index

Nutrition status: assessed using the PG-SGA validated tool and BMI calculated.

\section{Group 1: immunonutrition}

Number of participants randomly assigned: 14

Age: mean age 69.6 (SD 7.1) years

Sex: men

Tumour stage/grade: Ta: $\mathrm{n}=1 ;$ Tis: $\mathrm{n}=0 ; \mathrm{T1}: \mathrm{n}=2 ; \mathrm{T2}: \mathrm{n}=11$

Comorbidities: mean index result 4.9

Nutrition status: mean BMI 26, mean PG-SGA score 6.7

\section{Group 2: oral nutritional supplements}

Number of participants randomly assigned: 15

Age: mean age (SD) $68.1(8.0)$ years

Sex: men

Tumour stage/grade: Ta: $n=2 ;$ Tis: $n=2 ; T 1: n=2 ; T 2: n=7$

Comorbidities: mean index result was 5.1 
Hamilton-Reeves 2016 (Continued)

Nutrition status: mean BMI 29, mean PG-SGA score 5.5

All groups: nutrition supplements given for 5 days preoperatively an
cartons per day
Group 1: immunonutrition supplement drinks
Group 2: oral nutrition supplement drinks
Postoperative complications
Measured: graded according to Clavien-Dindo scheme (Dindo 2004)
Time point measured: $\leq 30$ days and 31-90 days after surgery
Time point reported: 30 and 90 days after surgery
Infection rates
Measured: defined by the need for intervention or prescription
Time point measured: $\geq 30$ and $31-90$ days after surgery
Time point reported: 30 and 90 days after surgery
Length of hospital stay
Measured: number of days
Time point measured: up to discharge
Time point reported: up to discharge
Mortality:
Measured: number of deaths
Time point: measured up to 90 days postoperatively
Time point reported: up to 90 days postoperatively
Times

\begin{tabular}{ll}
\hline Funding sources & American Cancer Society \\
& Nestle Healthcare Research grant \\
KL2 Scholars Award \\
Nestle HealthCare Nutrition provided the supplement drinks
\end{tabular}

Declarations of interest Research funding from Nestle Healthcare and travel support received by Hamilton-Reeves.

\begin{tabular}{|c|c|c|}
\hline \multirow[t]{2}{*}{ Notes } & \multicolumn{2}{|c|}{ Language of publication: English } \\
\hline & \multicolumn{2}{|c|}{ Some data for this study were published in supplementary tables to the published paper. } \\
\hline Risk of bias & & \\
\hline Bias & Authors' judgement & Support for judgement \\
\hline $\begin{array}{l}\text { Random sequence genera- } \\
\text { tion (selection bias) }\end{array}$ & Low risk & $\begin{array}{l}\text { Random allocation was done "using a computer generated randomisation list } \\
\text { administered by a statistician who was not involved in the implementation of } \\
\text { the study." Adequate sequence generation. }\end{array}$ \\
\hline
\end{tabular}


Hamilton-Reeves 2016 (Continued)

\begin{tabular}{|c|c|c|}
\hline $\begin{array}{l}\text { Allocation concealment } \\
\text { (selection bias) }\end{array}$ & Low risk & $\begin{array}{l}\text { Allocation list was "only accessible to study coordinator via password-protect- } \\
\text { ed computer database." }\end{array}$ \\
\hline
\end{tabular}

Blinding of participants Low risk Mortality rates unlikely to be affected by blinding.

and personnel (perfor-

Mortality rates unlikely to be affected by blinding.

mance bias)

Objective outcomes

\begin{tabular}{lll}
$\begin{array}{l}\text { Blinding of participants } \\
\text { and personnel (perfor- } \\
\text { mance bias) } \\
\text { Subjective outcomes }\end{array}$ & Low risk & $\begin{array}{l}\text { Supplement cartons were wrapped with opaque tape and numbered by staff } \\
\text { not involved in patient care or data collection so the intervention was masked. }\end{array}$ \\
\hline $\begin{array}{l}\text { Blinding of outcome as- } \\
\text { sessment (detection bias) } \\
\text { Complications }\end{array}$ & Low risk & $\begin{array}{l}\text { Supplement cartons were wrapped with opaque tape and numbered by staff } \\
\text { not involved in patient care or data collection so the intervention was masked. }\end{array}$
\end{tabular}

Blinding of outcome as-
sessment (detection bias) $\quad$ Low risk $\quad$ Assessment of length of hospital stay unlikely to be affected by blinding.

Length of hospital stay

\begin{tabular}{|c|c|c|}
\hline $\begin{array}{l}\text { Blinding of outcome as- } \\
\text { sessment (detection bias) } \\
\text { Mortality }\end{array}$ & Low risk & Assessment of mortality rates unlikely to be affected by blinding. \\
\hline $\begin{array}{l}\text { Incomplete outcome data } \\
\text { (attrition bias) } \\
\text { Complications }\end{array}$ & Low risk & All randomised participants included in analysis of complications. \\
\hline $\begin{array}{l}\text { Incomplete outcome data } \\
\text { (attrition bias) } \\
\text { Length of hospital stay }\end{array}$ & Low risk & All randomised participants included in analysis of length of hospital stay. \\
\hline $\begin{array}{l}\text { Incomplete outcome data } \\
\text { (attrition bias) } \\
\text { Mortality }\end{array}$ & Low risk & All randomised participants included in analysis of mortality. \\
\hline $\begin{array}{l}\text { Selective reporting (re- } \\
\text { porting bias) }\end{array}$ & Low risk & $\begin{array}{l}\text { In the protocol recorded on www.clinicaltrials.gov, all planned outcomes were } \\
\text { reported. }\end{array}$ \\
\hline Other bias & Low risk & No other bias detected. \\
\hline
\end{tabular}

Hensle 1978

Methods Study design: parallel-group randomised controlled trial

Study dates: not reported

Setting: Columbia-Presbyterian Medical Centre, New York, NY, USA

Participants Inclusion criteria: people undergoing radical cystectomy and urinary diversion for invasive bladder cancer

Exclusion criteria: people with renal failure or insulin-dependent diabetes, or both

Total number of participants randomly assigned: 44 
Hensle 1978 (Continued)

Age: not reported

Sex: not reported

Nutrition status: 17 participants were defined by the study authors as having 'nutritional depletion' prior to operation.

\section{Group 1: fluid management with $5 \%$ dextrose solution}

Number of all participants randomly assigned: 15

Age: not reported

Sex: not reported

Tumour stage/grade: not reported

Comorbidities: not reported

Nutrition status: 6 participants were nutritionally depleted preoperatively.

\section{Group 2: crystalline amino acid solution}

Number of all participants randomly assigned: 29

Age: not reported

Sex: not reported

Tumour stage/grade: not reported

Comorbidities: not reported

Nutrition status: 11 participants were nutritionally depleted.

Duration of intervention not described

Group 1 ( $n=15)$ : postoperative fluid management of $5 \%$ dextrose solution along with balanced electrolytes and whole blood and blood byproducts as necessary. Participants began oral intake as clinical status indicated.

Group 2 ( $n=29)$ : crystalline amino acid solution containing a 3\% mixture of essential and non-essential amino acids with appropriate micronutrient and cofactors designed to deliver $0.7-1.0 \mathrm{~g} / \mathrm{kg} / 24$ hours of amino acid with a calorie value of approximately $240 \mathrm{kcal} /$ day; also electrolytes and whole blood and blood byproducts as necessary. This supplementation continued until the participants were able to meet their energy needs orally.

Postoperative complications: occurred in 33\% of participants in group 1 and in $17 \%$ of participants in group 2

How measured: not reported but included sepsis, wound dehiscence and renal failure

Time point measured: not reported

Time point reported: not reported

Length of hospital stay: group 1: mean 32 days, range 17-66 days; group 2: mean 27 days, range 16-44 days

How measured: number of days in hospital

Time point measured: not reported

Time point reported: not reported 
Hensle 1978 (Continued)

Mortality: no deaths in either group.

How measured: number of deaths

Time point measured: up to 60 days after surgery

Time point reported: not reported

\begin{tabular}{ll}
\hline Funding sources & Supported by a grant from the Medical Department, McGaw Laboratories. \\
\hline Declarations of interest & No declarations of interest reported \\
\hline Notes & Language of publication: English \\
& $\begin{array}{l}30 \text { participants received preoperative radiotherapy. } 4 \text { participants in Group } 1 \text { had to be switched to to- } \\
\text { tal PN. }\end{array}$ \\
\hline
\end{tabular}

\section{Risk of bias}

\begin{tabular}{|c|c|c|}
\hline Bias & Authors' judgement & Support for judgement \\
\hline $\begin{array}{l}\text { Random sequence genera- } \\
\text { tion (selection bias) }\end{array}$ & High risk & Primary physicians changed some group allocations. \\
\hline $\begin{array}{l}\text { Allocation concealment } \\
\text { (selection bias) }\end{array}$ & High risk & Primary physicians changed some group allocations. \\
\hline $\begin{array}{l}\text { Blinding of participants } \\
\text { and personnel (perfor- } \\
\text { mance bias) } \\
\text { Objective outcomes }\end{array}$ & Low risk & Blinding unlikely to affect outcome. \\
\hline $\begin{array}{l}\text { Blinding of participants } \\
\text { and personnel (perfor- } \\
\text { mance bias) } \\
\text { Subjective outcomes }\end{array}$ & Unclear risk & No blinding described. \\
\hline
\end{tabular}

Blinding of outcome as-
sessment (detection bias) $\quad$ Unclear risk $\quad$ No blinding described.

sessment (detection bias)

Complications

Blinding of outcome as- $\quad$ Low risk $\quad$ No blinding described.
sessment (detection bias)

Length of hospital stay

\begin{tabular}{ll}
\hline Blinding of outcome as- \\
sessment (detection bias)
\end{tabular}$\quad$ Low risk $\quad$ Assessment of mortality unlikely to be affected by blinding.

Mortality

Incomplete outcome data Low risk $\quad$ All participants randomised were reported in the analysis.
(attrition bias)

(attrition bias)

Complications

Incomplete outcome data Low risk All participants randomised were reported in the analysis
(attrition bias)
Length of hospital stay

Length of hospital stay

Incomplete outcome data Low risk $\quad$ All participants randomised were included in the analysis.
(attrition bias)


Hensle 1978 (Continued)

Mortality

Selective reporting (re- Unclear risk $\quad$ No protocol available.
porting bias)

Other bias Low risk No further bias detected.

Ritch 2018

Methods

Study design: parallel-group randomised controlled trial

Study dates: April 2014 to December 2016

Setting: Vanderbilt University Medical Center, Nashville, TN, USA

Participants Inclusion criteria: people with urothelial carcinoma of the bladder

Exclusion criteria: people who were not surgical candidates

Total number of participants randomly assigned: 61

Age: $\geq 18$ years

Sex: 54 men, 7 women

Performance status: Eastern Cooperative Oncology Group performance status $\leq 3$

Group 1: oral nutritional supplements

Number of all participants randomly assigned: 31

Age: mean 69 (SD 14.1) years

Sex: 26 men, 5 women

Tumour stage: $\leq \mathrm{T} 1: \mathrm{n}=14 ; \mathrm{T} 2: \mathrm{n}=11 ; \mathrm{T} 3-\mathrm{T} 4: \mathrm{n}=6$

Comorbidities:

Charlson Comorbidity Index: $0: n=13 ; 1: n=7 ; 2: n=8 ; \geq 3: n=3$

Nutrition status: mean BMI 27.8 (SD 17.9)

Group 2: multivitamin and minerals

Number of all participants randomly assigned: 30

Age: mean 66.7 (SD 9.6) years

Sex: 28 men, 2 women

Tumour stage/grade: $\leq \mathrm{T} 1: \mathrm{n}=17 ; \mathrm{T} 2: \mathrm{n}=9 ; \mathrm{T} 3-\mathrm{T} 4: \mathrm{n}=4$

Comorbidities: Charlson Comorbidity Index: $0: n=14 ; 1: n=8 ; 2: n=4, \geq n:=4$

Nutrition status: mean BMI 29.3 (SD 5.5)

Interventions

Both groups: intervention was given for 3-4 weeks preoperatively and 4 weeks postoperatively

Group 1 ( $n=31$ ): oral nutritional supplement group received Ensure Clinical Strength, Abbort Nutrition 1 serving twice daily 
Ritch 2018 (Continued)

Group $2(n=30)$ : multivitamin and mineral group received 1 serving twice daily

\begin{tabular}{ll}
\hline Outcomes & Complications \\
& How measured: Clavien-Dindo classification system (Dindo 2004) \\
& Time point measured: up to 30 days \\
& Time point reported: up to 30 days \\
& Length of hospital stay: reported in days \\
& Mortality: \\
& How measured: confirmation of obituary statement \\
& Time point measured: 30 days \\
& Time point reported: 30 days \\
\hline Funding sources & Supported by Vanderbilt CTSA, NIH National Centre and Abbort Nutrition Award \\
\hline Declarations of interest & None reported \\
\hline Notes & \\
\hline
\end{tabular}

\section{Risk of bias}

\begin{tabular}{lll}
\hline Bias & Authors' judgement & Support for judgement \\
\hline $\begin{array}{l}\text { Random sequence genera- } \\
\text { tion (selection bias) }\end{array}$ & Unclear risk & Random sequence generation not described. \\
\hline $\begin{array}{l}\text { Allocation concealment } \\
\text { (selection bias) }\end{array}$ & Unclear risk & Allocation concealment not described. \\
\hline $\begin{array}{l}\text { Blinding of participants } \\
\text { and personnel (perfor- } \\
\text { mance bias) } \\
\text { Objective outcomes }\end{array}$ & Low risk & Blinding unlikely to affect outcome. \\
\hline
\end{tabular}

Blinding of participants Unclear risk No blinding reported.

and personnel (perfor-

mance bias)

Subjective outcomes

\begin{tabular}{lll}
\hline $\begin{array}{l}\text { Blinding of outcome as- } \\
\text { sessment (detection bias) } \\
\text { Complications }\end{array}$ & Unclear risk & No blinding reported. \\
\hline $\begin{array}{l}\text { Blinding of outcome as- } \\
\text { sessment (detection bias) } \\
\text { Length of hospital stay }\end{array}$ & Low risk & Assessment of length of hospital stay unlikely to be influenced by blinding. \\
\hline $\begin{array}{l}\text { Blinding of outcome as- } \\
\text { sessment (detection bias) } \\
\text { Mortality }\end{array}$ & Low risk & Assessment of mortality unlikely to be influenced by blinding. \\
\hline $\begin{array}{l}\text { Incomplete outcome data } \\
\text { (attrition bias) }\end{array}$ & Low risk & $\begin{array}{l}\text { 8 participants were not included in reporting complications; } 1 \text { participant died } \\
\text { and surgery was aborted, and 7 participants withdrew }\end{array}$
\end{tabular}


Ritch 2018 (Continued)

Complications

\begin{tabular}{|c|c|c|}
\hline $\begin{array}{l}\text { Incomplete outcome data } \\
\text { (attrition bias) } \\
\text { Length of hospital stay }\end{array}$ & Low risk & $\begin{array}{l}8 \text { participants were not included in reporting length of hospital stay; } 1 \text { partici- } \\
\text { pant died and surgery was aborted, and } 7 \text { participants withdrew }\end{array}$ \\
\hline $\begin{array}{l}\text { Incomplete outcome data } \\
\text { (attrition bias) } \\
\text { Mortality }\end{array}$ & Low risk & $\begin{array}{l}8 \text { participants were not included in reporting mortality; } 1 \text { participant died and } \\
\text { surgery was aborted, and } 7 \text { participants withdrew }\end{array}$ \\
\hline $\begin{array}{l}\text { Selective reporting (re- } \\
\text { porting bias) }\end{array}$ & Low risk & $\begin{array}{l}\text { In the protocol recorded on www.clinicaltrials.gov, all planned outcomes were } \\
\text { reported. }\end{array}$ \\
\hline Other bias & Low risk & \\
\hline
\end{tabular}

Roth 2013

$\begin{array}{ll}\text { Methods } & \text { Study design: parallel-group randomised controlled trial } \\ & \text { Study dates: September } 2008 \text { to March } 2011 \\ & \text { Setting: University Hospital Bern, Bern, Switzerland }\end{array}$

Exclusion criteria: previous lymph node dissection, chronic inflammatory bowel disease, radiotherapy, prior bowel surgery, severe hepatic or cardiac dysfunction, inability to consent

Total number of participants randomly assigned: 157

Sex: 106 men, 51 women

Age: group 1: median 67 (range 34-80) years; group 2: median 66 (range 30-86) years

Tumour stage/grade: not reported

Comorbidities: 14 participants had diabetes, 51 participants had an ASA score III/IV

Nutrition status: 34 participants were defined as malnourished based on defined criteria.

\section{Group 1: PN}

Number of all participants randomly assigned: 74

Age: median 67 (range 34-80) years

Sex: 53 men, 21 women

Tumour stage/grade: not reported

Comorbidities: diabetes $8 \%$, ASA score III/IV 31\%

Nutrition status: malnourished 15\%

\section{Group 2: oral nutrition alone}

Number of all participants randomly assigned: 83

Age: median 66 (range 30-86) years

Sex: 53 men, 30 women 
Roth 2013 (Continued)

Tumour stage/grade: not reported

Comorbidities: diabetes 10\%, ASA score III/IV 34\%

Nutrition status: malnourished 28\%

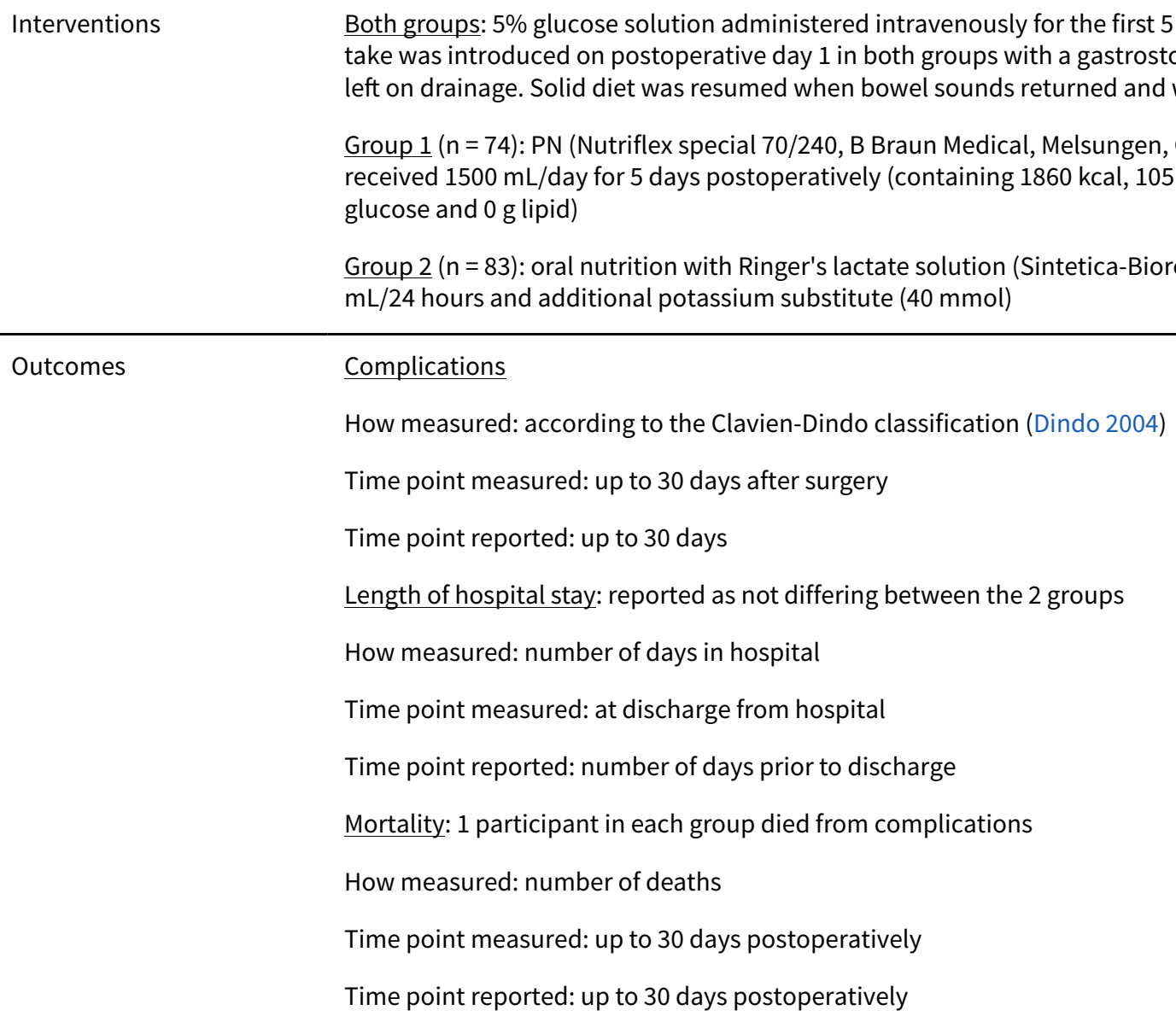

Funding sources None

\begin{tabular}{ll}
\hline Declarations of interest & None declared \\
\hline Notes & Language of publication: English \\
& Study was terminated early before enrolment targets were met following an interim statistical analysis.
\end{tabular}

\section{Risk of bias}

\begin{tabular}{lll}
\hline Bias & Authors' judgement & Support for judgement \\
\hline $\begin{array}{l}\text { Random sequence genera- } \\
\text { tion (selection bias) }\end{array}$ & Low risk & $\begin{array}{l}\text { Quote: "Randomly allocated by a computer-based program." } \\
\text { Comment: adequate sequence generation. }\end{array}$ \\
\hline $\begin{array}{l}\text { Allocation concealment } \\
\text { (selection bias) }\end{array}$ & Unclear risk & Not described. \\
\hline $\begin{array}{l}\text { Blinding of participants } \\
\begin{array}{l}\text { and personnel (perfor- } \\
\text { mance bias) }\end{array}\end{array}$ & Low risk & Mortality rates unaffected by blinding. \\
\hline
\end{tabular}


Roth 2013 (Continued)

Objective outcomes

Blinding of participants $\quad$ Unclear risk blinding reported.
and personnel (perfor-
mance bias)
Subjective outcomes

\begin{tabular}{|c|c|c|}
\hline $\begin{array}{l}\text { Blinding of outcome as- } \\
\text { sessment (detection bias) } \\
\text { Complications }\end{array}$ & Low risk & Assessed by a blinded study nurse. \\
\hline
\end{tabular}

Blinding of outcome as-
sessment (detection bias)
Length of hospital stay

\begin{tabular}{|c|c|c|}
\hline $\begin{array}{l}\text { Blinding of outcome as- } \\
\text { sessment (detection bias) } \\
\text { Mortality }\end{array}$ & Low risk & Assessment of mortality unlikely to be influenced by blinding. \\
\hline $\begin{array}{l}\text { Incomplete outcome data } \\
\text { (attrition bias) } \\
\text { Complications }\end{array}$ & Low risk & All randomised participants were included in the assessment of complications. \\
\hline $\begin{array}{l}\text { Incomplete outcome data } \\
\text { (attrition bias) } \\
\text { Length of hospital stay }\end{array}$ & Low risk & $\begin{array}{l}\text { All randomised participants were included in the assessment of length of hos- } \\
\text { pital stay. }\end{array}$ \\
\hline $\begin{array}{l}\text { Incomplete outcome data } \\
\text { (attrition bias) } \\
\text { Mortality }\end{array}$ & Low risk & All randomised participants were included in the assessment of mortality. \\
\hline $\begin{array}{l}\text { Selective reporting (re- } \\
\text { porting bias) }\end{array}$ & Unclear risk & $\begin{array}{l}\text { No protocol seen, outcomes described in the methods section of the publica- } \\
\text { tion were reported. }\end{array}$ \\
\hline Other bias & Low risk & No other bias detected. \\
\hline
\end{tabular}

Rovera 1989

\begin{tabular}{ll}
\hline Methods & Study design: parallel-group randomised controlled trial \\
& Study dates: not reported \\
& Setting: Turin, Italy \\
\hline Inclusion criteria: people undergoing radical cystectomy for bladder cancer \\
Exclusion criteria: not reported \\
Number of all participants randomly assigned: 28 \\
Age: not reported \\
Sex: 22 men, 6 women \\
Tumour stage/grade: not reported \\
Comorbidities: not reported \\
Nutrition status: not reported \\
\hline
\end{tabular}




\section{Group 1: preoperative nutrition supplementation}

Number of all participants randomly assigned: 12

Age: median 66.1 (range 45-78) years

Sex: 9 men, 3 women

Tumour stage/grade: not reported

Comorbidities: not reported

\section{Group 2: normal hospital diet preoperatively}

Number of all participants randomly assigned: 16

Age: median 65.1 (range 47-80) years

Sex: 13 men, 3 women

Tumour stage/grade: not reported

Comorbidities: not reported

Nutrition status: not reported

Interventions

Both groups: postoperative PN commenced 1 day after surgery and continued for 14 days administered via a central line. PN calculated to provide $49 \mathrm{kcal} / \mathrm{kg} /$ day and $1.7 \mathrm{~g}$ protein $/ \mathrm{kg} /$ day with a nitrogen:total calorie ratio $1: 170$ and with energy provided as $80 \%$ glucose and $20 \%$ fat plus vitamins, minerals and trace elements.

Group 1 ( $n=12)$ : preoperative oral nutritional support for 10 days prior to surgery comprised of an interview with a dietitian about usual diet and the provision of a personalised diet based on normal food combined with a supplement including a multivitamin and mineral preparation (Precision $\mathrm{N}$ ). The supplement provided $30 \mathrm{kcal} / \mathrm{kg} / \mathrm{day}$ and $1.5 \mathrm{~g}$ protein $/ \mathrm{kg} / \mathrm{day}$.

Group 2 ( $n=16)$ : normal hospital diet up to day of operation.

\begin{tabular}{ll}
\hline Outcomes & Complications \\
How measured: not reported & Time point measured: up to 30 days postsurgery \\
& Time point reported: up to 30 days postsurgery \\
& Length of hospital stay: not reported \\
& Mortality: no deaths reported \\
& How measured: number of deaths \\
& Time point measured: up to 30 days postsurgery \\
& Time point reported: up to 30 days postsurgery \\
\hline Funding sources & Not reported \\
\hline Declarations of interest & Not reported \\
\hline Notes & Language of publication: Italian \\
No information on dietary intake in the report. Some parts of the report were not translated in suffi- \\
cient detail to extract all the details.
\end{tabular}


Rovera 1989 (Continued)

Risk of bias

\begin{tabular}{|c|c|c|}
\hline Bias & Authors' judgement & Support for judgement \\
\hline $\begin{array}{l}\text { Random sequence genera- } \\
\text { tion (selection bias) }\end{array}$ & Unclear risk & Random sequence generation not described. \\
\hline $\begin{array}{l}\text { Allocation concealment } \\
\text { (selection bias) }\end{array}$ & Unclear risk & Allocation concealment not described. \\
\hline $\begin{array}{l}\text { Blinding of participants } \\
\text { and personnel (perfor- } \\
\text { mance bias) } \\
\text { Objective outcomes }\end{array}$ & Low risk & Blinding unlikely to affect outcome. \\
\hline $\begin{array}{l}\text { Blinding of participants } \\
\text { and personnel (perfor- } \\
\text { mance bias) } \\
\text { Subjective outcomes }\end{array}$ & Unclear risk & $\begin{array}{l}\text { No blinding described and these outcomes could have been influenced as re- } \\
\text { porting involves judgement. }\end{array}$ \\
\hline $\begin{array}{l}\text { Blinding of outcome as- } \\
\text { sessment (detection bias) } \\
\text { Complications }\end{array}$ & Unclear risk & No blinding described. \\
\hline $\begin{array}{l}\text { Blinding of outcome as- } \\
\text { sessment (detection bias) } \\
\text { Length of hospital stay }\end{array}$ & Low risk & Length of hospital stay not reported. \\
\hline $\begin{array}{l}\text { Blinding of outcome as- } \\
\text { sessment (detection bias) } \\
\text { Mortality }\end{array}$ & Low risk & Assessment of mortality unlikely to be influenced by blinding. \\
\hline $\begin{array}{l}\text { Incomplete outcome data } \\
\text { (attrition bias) } \\
\text { Complications }\end{array}$ & Low risk & All randomised participants were included in the assessment of complications. \\
\hline $\begin{array}{l}\text { Incomplete outcome data } \\
\text { (attrition bias) } \\
\text { Length of hospital stay }\end{array}$ & Unclear risk & Length of hospital stay not reported. \\
\hline $\begin{array}{l}\text { Incomplete outcome data } \\
\text { (attrition bias) } \\
\text { Mortality }\end{array}$ & Low risk & All randomised participants were included in the assessment of mortality. \\
\hline $\begin{array}{l}\text { Selective reporting (re- } \\
\text { porting bias) }\end{array}$ & Unclear risk & No protocol seen. Outcomes described in the methods were reported. \\
\hline Other bias & Low risk & No other bias detected. \\
\hline
\end{tabular}

ASA: American Society of Anesthesiologists; BMI: body mass index; n: number of participants; PG-SGA: Patient-Generated Subjective Global Assessment; PN: parenteral nutrition; SD: standard deviation.

Characteristics of excluded studies [ordered by study ID] 


\begin{tabular}{ll}
\hline Study & Reason for exclusion \\
\hline Brodner 2001 & $\begin{array}{l}\text { No comparison of a nutritional intervention during the randomised phase of this trial, which inves- } \\
\text { tigated the perioperative management of people undergoing radical cystectomy. Therefore, this } \\
\text { study did not meet the inclusion criteria. }\end{array}$
\end{tabular}

Daly $1987 \begin{aligned} & \text { Partially randomised trial examining postoperative jejunostomy feeding. The measured outcomes } \\ & \text { compared groups where randomisation did not occur. Therefore, this trial did not meet the inclu- } \\ & \text { sion criteria. }\end{aligned}$

de Vries $2012 \quad$ Not an RCT therefore excluded.

$\begin{array}{ll}\text { Hensle } 1985 & \text { RCT reporting only biochemical outcomes. Therefore did not report the outcomes specified for this } \\ \text { review. }\end{array}$

Karl $2014 \begin{aligned} & \text { In this RCT nutrition supplements and the early introduction of foods postoperatively were used as } \\ & \text { part of an ERAS Intervention. The study was excluded as it would not have been possible to sepa- } \\ & \text { rate out the effects of the nutrition intervention from the other interventions. }\end{aligned}$

\begin{tabular}{ll}
\hline Malossini 1987 & Not an RCT, therefore did not meet our inclusion criteria. It was a comparison of differing types of \\
parenteral nutrition given to 2 non-randomised groups of participants postcystectomy
\end{tabular}

$\begin{array}{ll}\text { Mangano } 1993 & \text { Not an RCT, therefore did not meet our inclusion criteria. } 2 \text { groups of participants who had under- } \\ \text { gone radical cystectomy were given total parenteral nutrition with or without glutamine supple- } \\ \text { mentation. }\end{array}$

McArdle $1986 \quad$ Not an RCT, therefore did not meet our inclusion criteria. Although this study was commenced as an RCT, after enrolment of the fourth participant, the protocol was modified to result in a cohort study with retrospective controls. The study investigated the use of elemental diet in people undergoing radiotherapy and associated radical cystectomy.

Olbert 2009

Did not meet our inclusion criteria as there was no comparison of a nutritional intervention in this $\mathrm{RCT}$, which compared alternate modes of perioperative management of people undergoing radical cystectomy.

Solomon 1978

Did not meet our inclusion criteria. In this RCT examining 3 hypocaloric regimens in people undergoing urological surgery, $47 \%$ had radical cystectomy for bladder cancer.

ERAS: Enhanced Recovery After Surgery; RCT: randomised controlled trial.

Characteristics of ongoing studies [ordered by study ID]

\section{NCT02238886}

\begin{tabular}{ll}
\hline Trial name or title & $\begin{array}{l}\text { Radical cystectomy, nutrition and convalescence: can goal-directed postoperative nutritional ther- } \\
\text { apy reduce the convalescence period for patients undergoing radical cystectomy (RC)? }\end{array}$ \\
\hline Methods & Randomised controlled trial with parallel assignment \\
\hline Participants & $\begin{array}{l}\text { Adults aged > } 18 \text { years undergoing radical cystectomy who are able to give informed consent (ex- } \\
\text { cluded if previous radiotherapy at the pelvic area, ureterocutaneostomy or robot-assisted surgery. }\end{array}$ \\
\hline Interventions & $\begin{array}{l}\text { Group 1: goal-directed nutritional intervention combining oral intake and parenteral nutrition us- } \\
\text { ing a parenteral nutritional intervention: dietary supplement is parenteral nutrition in central vein } \\
\text { (SMOFKABIVEN; Fresenius Kabi) } \\
\text { Group 2: standard nutritional treatment of resting the bowel until there are signs of bowel recovery } \\
\text { and then feeding orally }\end{array}$
\end{tabular}


NCT02238886 (Continued)

Outcomes
Primary outcome: quality of life using validated questionnaires.

Secondary outcomes: bodyweight, hand grip strength, biochemical measures, length of hospital stay and time to bowel recovery.

Follow-up: 12 weeks

\begin{tabular}{ll}
\hline Starting date & May 2012 \\
\hline Contact information & Line Noes Lydom, Rigshospitalet, Denmark \\
\hline Notes & Above details extracted from www.clinicaltrials.gov. Data collection completed in December 2013, \\
& $\begin{array}{l}\text { 36 participants have been recruited. Data awaiting preparation for publication (email from contact } \\
\text { author July 2017, no further updates received July 2018). }\end{array}$ \\
\hline
\end{tabular}

\section{NCT03147586}

\begin{tabular}{ll}
\hline Trial name or title & Influence of immune nutrition diet on 90-day outcomes in patients undergoing radical cystectomy \\
\hline Methods & Randomised double-blind placebo-controlled phase IV trial with 2 parallel treatment groups \\
\hline Participants & $\begin{array}{l}\text { Adults aged } \geq 18 \text { years diagnosed with bladder cancer eligible for radical cystectomy and urinary } \\
\text { diversions. Estimated enrolment } 100 \text { participants. }\end{array}$ \\
\hline Interventions & $\begin{array}{l}\text { Group 1: Bio-tech and omega-3 plus Bio-tech (Biopharm pharmaceutical) powder } 30 \text { mg } 3 \text { times } \\
\text { daily (contains multivitamins and essential amino acids) plus omega-3 plus (SEDICO pharmaceuti- } \\
\text { cal) capsules } 3 \text { times daily (source for omega-3 fatty acids) } 1 \text { week before and } 2 \text { weeks after surgery }\end{array}$ \\
Group 2: placebo powder 30 mg 3 times daily plus placebo capsules 3 times daily for 1 week before \\
and 2 weeks after surgery
\end{tabular}

Outcomes Primary outcome: overall 90-day postoperative complication between groups measured by modi-
fied Dindo-Clavien system (Dindo 2004)

Secondary outcomes: validated nutritional assessment scores at 90 days and anthropometric measures measured by skinfold thickness at 90 days

\begin{tabular}{ll}
\hline Starting date & March 2017 \\
\hline Contact information & Abdelwahab R Hashem, MSc \\
& Mansoura, Aldakahlia, Egypt, 35516 \\
\hline Notes & Above details extracted from www.clinicaltrials.gov. Data collection completed in October 2017. \\
\hline
\end{tabular}

\section{NCT03204266}

\begin{tabular}{ll}
\hline Trial name or title & Oral supplementation to enhance recovery pilot study \\
\hline Methods & Randomised parallel assignment interventional clinical trial \\
\hline Participants & Radical cystectomy for bladder cancer with urinary diversion, aged $\geq 18$ years, 46 participants \\
\hline Interventions & $\begin{array}{l}\text { Goup } 1: \text { immunonutrition: arginine + omega-3 fatty acids. Participants take } 30 \mathrm{~mL} \text { of arginine re- } \\
\text { covery supplement } 4 \text { times daily } 5 \text { days preoperatively and } 14 \text { days postoperatively. }\end{array}$ \\
\hline
\end{tabular}


NCT03204266 (Continued)

Participants also given omega-3 fatty acids, $1 \mathrm{~g} 4$ times daily, $4 \mathrm{~g}$ total daily. This will be started 7 days preoperatively and continued 14 days postoperatively.

Group 2: no immunonutrition

\begin{tabular}{ll}
\hline Outcomes & $\begin{array}{l}\text { Primary outcome: participant compliance at } 21 \text { days after starting immunonutrition regimen. De- } \\
\text { fined as 'Yes' if a participant completes } \geq 16 \text { out of the total } 21 \text { days' treatment. } \\
\text { Secondary outcomes: length of hospital stay }>7 \text { days, postoperative infections, hospital readmis- } \\
\text { sions, deaths within } 90 \text { days of cystectomy all at } 90 \text { days after surgery; decrease in inflammatory re- } \\
\text { sponse of serum interleukin-6 levels after radical cystectomy postoperative day } 1\end{array}$ \\
\hline Starting date & 17 January 2018 \\
\hline Contact information & Neema Navai, MD Anderson Cancer Center National Cancer Institute (NCI) \\
\hline Notes & Estimated completion August 2019 \\
\hline
\end{tabular}

\section{DATA AND ANALYSES}

\section{Comparison 1. Postoperative parenteral nutrition compared to standard care}

\begin{tabular}{lllll}
\hline $\begin{array}{l}\text { Outcome or subgroup } \\
\text { title }\end{array}$ & No. of studies & $\begin{array}{l}\text { No. of partici- } \\
\text { pants }\end{array}$ & Statistical method & Effect size \\
\hline 1 Complications & 1 & 157 & Risk Ratio (M-H, Random, 95\% Cl) & $1.40[1.07,1.82]$ \\
\hline 2 Mortality & 1 & 157 & Risk Ratio (M-H, Random, 95\% Cl) & $1.12[0.07,17.62]$ \\
\hline
\end{tabular}

\section{Analysis 1.1. Comparison 1 Postoperative parenteral nutrition compared to standard care, Outcome 1 Complications.}

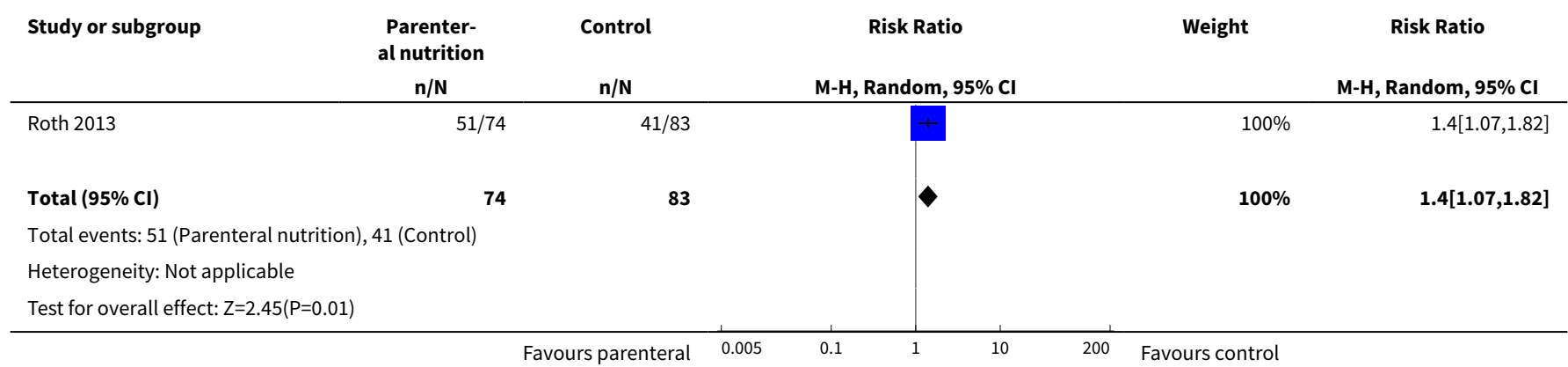


Analysis 1.2. Comparison 1 Postoperative parenteral nutrition compared to standard care, Outcome 2 Mortality.

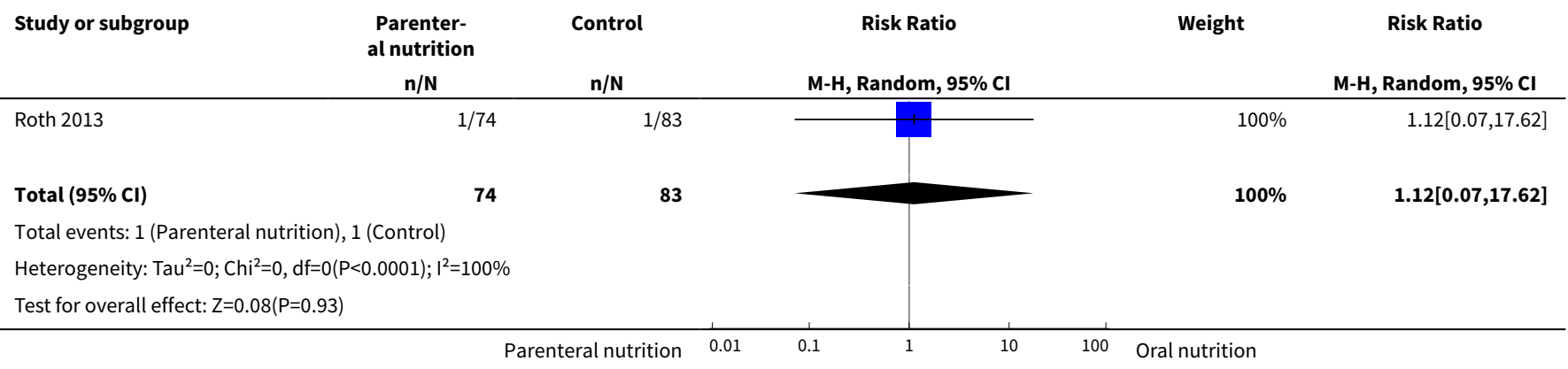

\section{Comparison 2. Immunonutrition compared to standard oral nutritional supplements}

\begin{tabular}{llllll}
\hline Outcome or subgroup title & No. of studies & $\begin{array}{l}\text { No. of partici- } \\
\text { pants }\end{array}$ & Statistical method & Effect size \\
\hline 1 Complications at 90 days & 1 & 29 & Risk Ratio (M-H, Random, 95\% Cl) & $0.31[0.08,1.23]$ \\
\hline 2 Complications at 30 days & 1 & 29 & Risk Ratio (M-H, Random, 95\% Cl) & $0.97[0.62,1.53]$ \\
\hline 3 Length of hospital stay & 1 & 29 & $\begin{array}{l}\text { Mean Difference (IV, Random, 95\% } \\
\text { Cl) }\end{array}$ & $0.20[-1.69,2.09]$ \\
\hline
\end{tabular}

Analysis 2.1. Comparison 2 Immunonutrition compared to standard oral nutritional supplements, Outcome 1 Complications at 90 days.

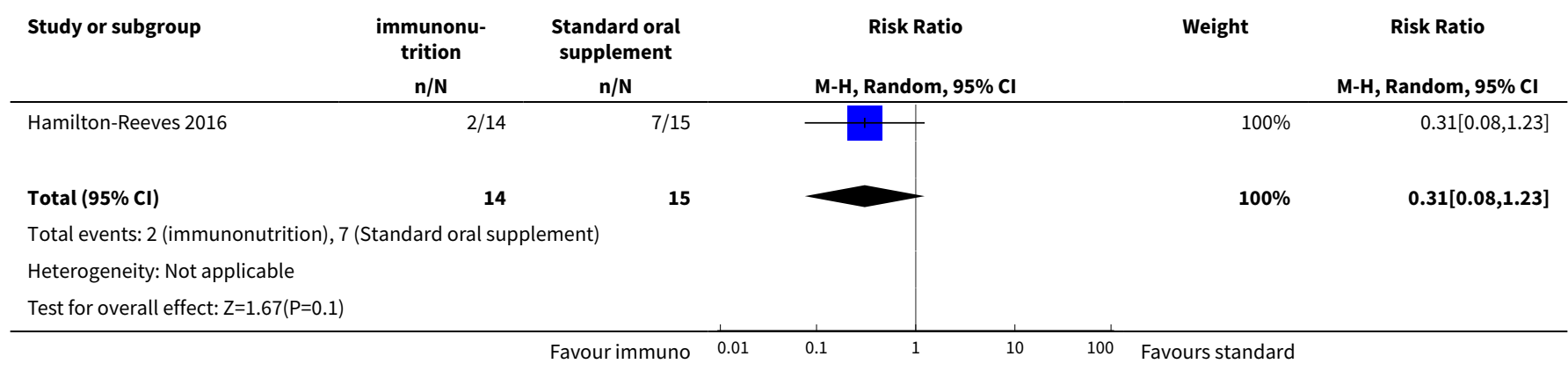

Analysis 2.2. Comparison 2 Immunonutrition compared to standard oral nutritional supplements, Outcome 2 Complications at 30 days.

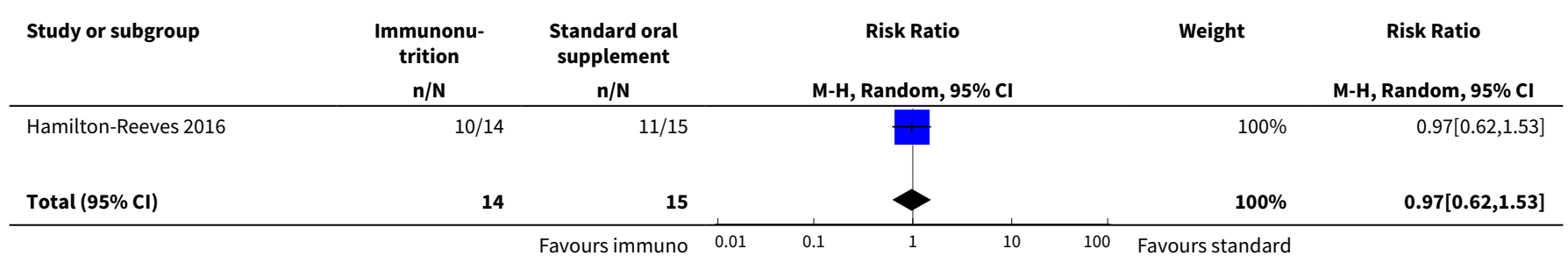




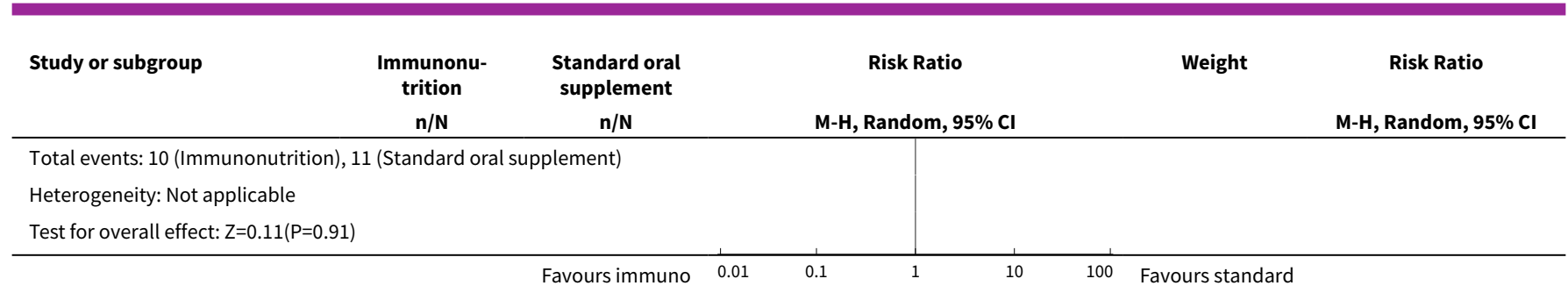

\section{Analysis 2.3. Comparison 2 Immunonutrition compared to standard} oral nutritional supplements, Outcome 3 Length of hospital stay.

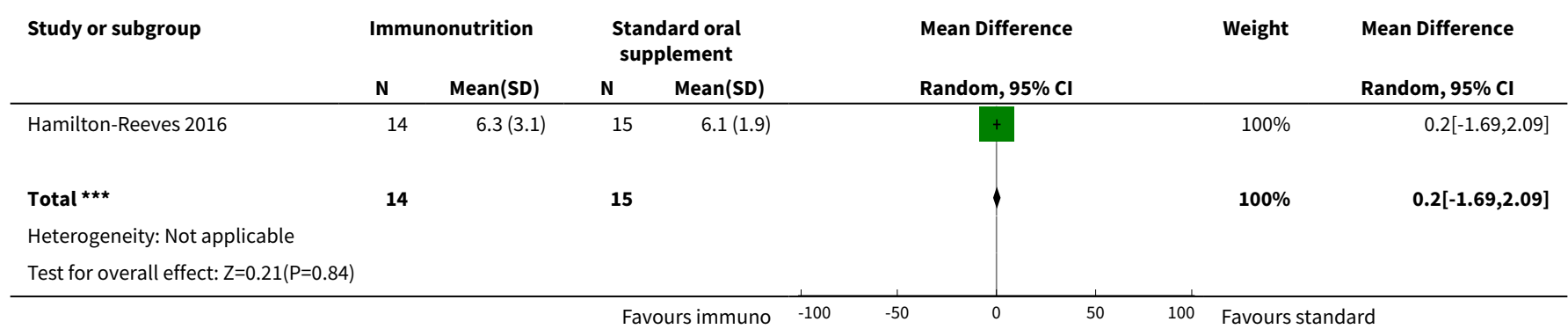

\section{Comparison 3. Preoperative oral nutritional support compared to normal diet}

\begin{tabular}{llllll}
\hline Outcome or subgroup title & No. of studies & $\begin{array}{l}\text { No. of partici- } \\
\text { pants }\end{array}$ & Statistical method & Effect size \\
\hline 1 Complications & 1 & 28 & Risk Ratio (M-H, Random, 95\% Cl) & $0.89[0.18,4.51]$ \\
\hline
\end{tabular}

Analysis 3.1. Comparison 3 Preoperative oral nutritional support compared to normal diet, Outcome 1 Complications.

\begin{tabular}{|c|c|c|c|c|c|}
\hline Study or subgroup & $\begin{array}{c}\text { Supplements } \\
n / N\end{array}$ & $\begin{array}{c}\text { Control } \\
n / N\end{array}$ & $\begin{array}{c}\text { Risk Ratio } \\
\text { M-H, Random, } 95 \% \mathrm{CI}\end{array}$ & Weight & $\begin{array}{c}\text { Risk Ratio } \\
\text { M-H, Random, } 95 \% \mathrm{CI}\end{array}$ \\
\hline Rovera 1989 & $2 / 12$ & $3 / 16$ & - & $100 \%$ & $0.89[0.18,4.51]$ \\
\hline Total $(95 \% \mathrm{Cl})$ & 12 & 16 & & $100 \%$ & $0.89[0.18,4.51]$ \\
\hline \multicolumn{6}{|c|}{ Total events: 2 (Supplements), 3 (Control) } \\
\hline \multicolumn{6}{|c|}{ Heterogeneity: $\operatorname{Tau}^{2}=0 ; \mathrm{Chi}^{2}=0, \mathrm{df}=0(\mathrm{P}<0.0001) ; \mathrm{I}^{2}=100 \%$} \\
\hline Test for overall effect & & & & & \\
\hline
\end{tabular}


Comparison 4. Early postoperative feeding compared to standard postoperative management

\begin{tabular}{lllll}
\hline $\begin{array}{l}\text { Outcome or subgroup } \\
\text { title }\end{array}$ & No. of studies & $\begin{array}{l}\text { No. of partici- } \\
\text { pants }\end{array}$ & Statistical method & Effect size \\
\hline 1 Complications & 1 & 102 & Risk Ratio (M-H, Random, 95\% Cl) & $1.14[0.85,1.53]$ \\
\hline 2 Mortality & 1 & 102 & Risk Ratio (M-H, Random, 95\% Cl) & $0.52[0.10,2.71]$ \\
\hline
\end{tabular}

Analysis 4.1. Comparison 4 Early postoperative feeding compared to standard postoperative management, Outcome 1 Complications.

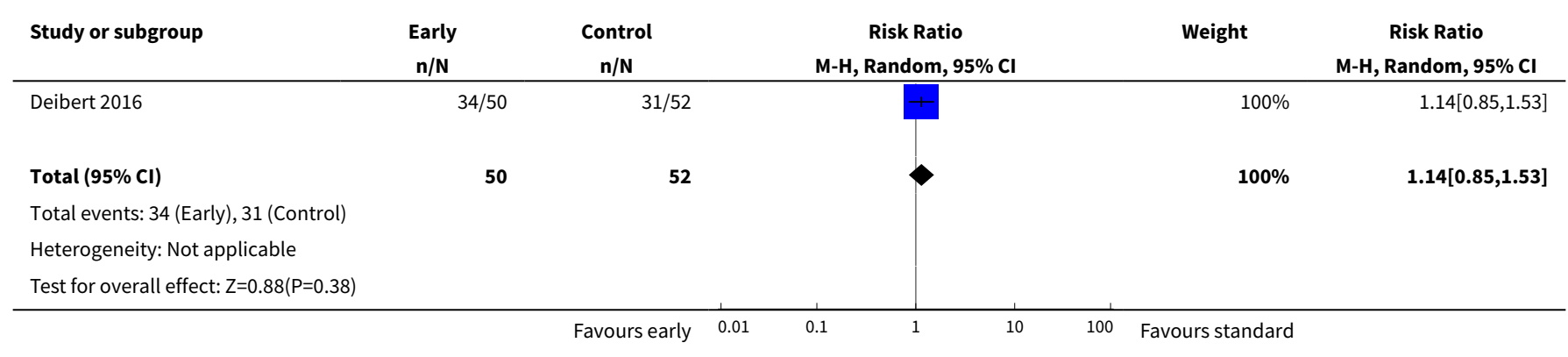

Analysis 4.2. Comparison 4 Early postoperative feeding compared to standard postoperative management, Outcome 2 Mortality.

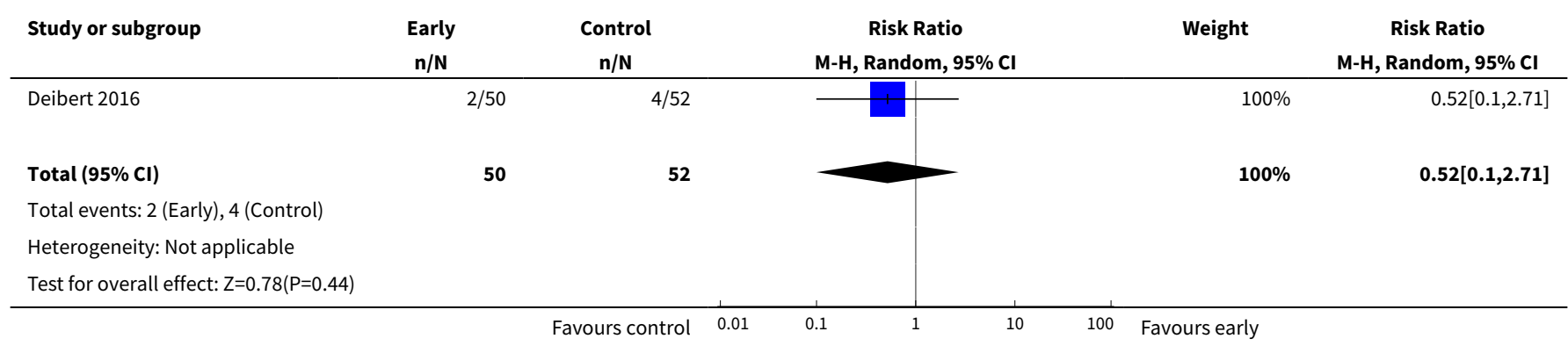

Comparison 5. Amino acid solution, alone or in combination with dextrose, compared to dextrose solution

\begin{tabular}{llllll}
\hline $\begin{array}{l}\text { Outcome or subgroup } \\
\text { title }\end{array}$ & No. of studies & $\begin{array}{l}\text { No. of partici- } \\
\text { pants }\end{array}$ & Statistical method & Effect size \\
\hline 1 Complications & 2 & 104 & Risk Ratio (M-H, Random, 95\% Cl) & $0.77[0.32,1.82]$ \\
\hline 2 Length of hospital stay & 2 & 104 & Mean Difference (IV, Random, 95\% Cl) & $0.0[0.0,0.0]$ \\
\hline 3 Mortality & 1 & 60 & Risk Ratio (M-H, Random, 95\% Cl) & $0.0[0.0,0.0]$ \\
\hline
\end{tabular}


Analysis 5.1. Comparison 5 Amino acid solution, alone or in combination with dextrose, compared to dextrose solution, Outcome 1 Complications.

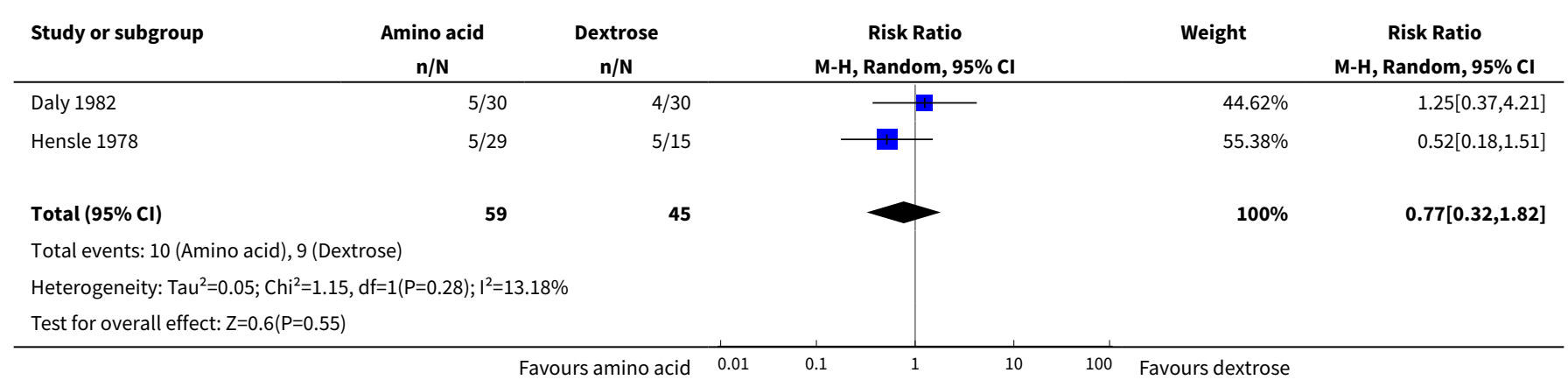

Analysis 5.2. Comparison 5 Amino acid solution, alone or in combination with dextrose, compared to dextrose solution, Outcome 2 Length of hospital stay.

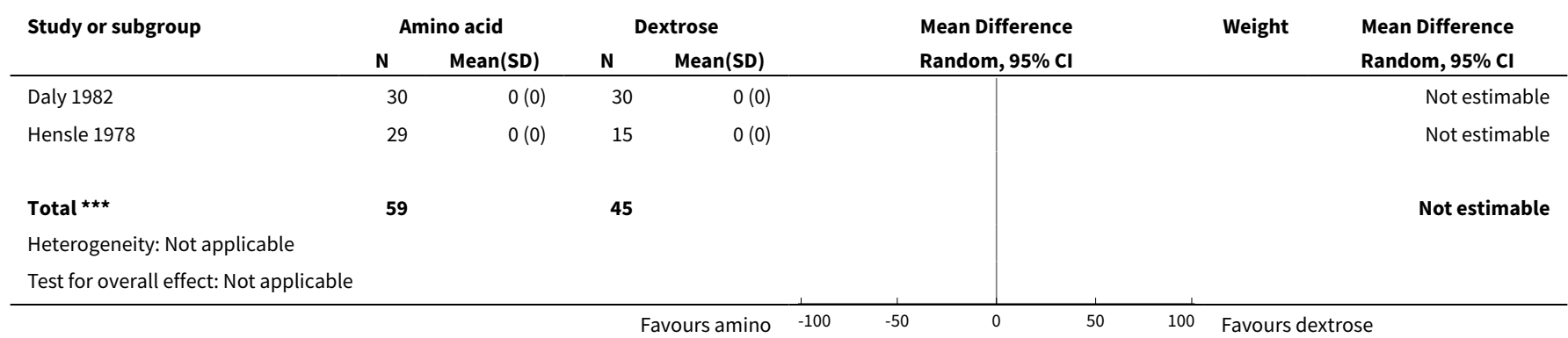

Analysis 5.3. Comparison 5 Amino acid solution, alone or in combination with dextrose, compared to dextrose solution, Outcome 3 Mortality.

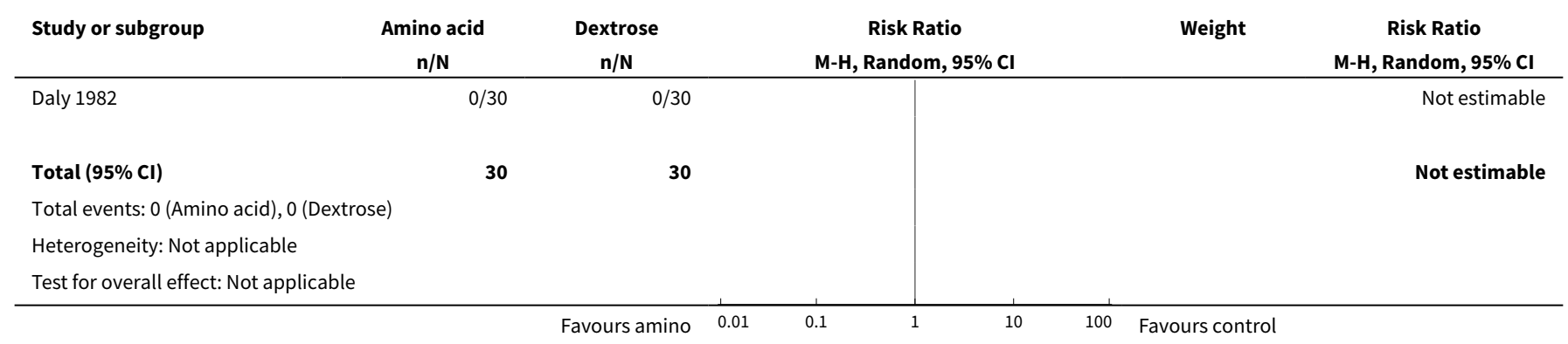

Comparison 6. Perioperative oral nutritional supplements compared to oral multivitamin and mineral supplement

\begin{tabular}{lllll}
\hline $\begin{array}{l}\text { Outcome or subgroup } \\
\text { title }\end{array}$ & No. of studies & $\begin{array}{l}\text { No. of partici- } \\
\text { pants }\end{array}$ & Statistical method & Effect size \\
\hline 1 Complications & 1 & 61 & Risk Ratio (M-H, Random, 95\% Cl) & $0.73[0.47,1.13]$ \\
\hline 2 Length of hospital stay & 1 & 61 & Mean Difference (IV, Random, 95\% Cl) & $-0.30[-3.64,3.04]$ \\
\hline
\end{tabular}




\begin{tabular}{lllll}
\hline $\begin{array}{l}\text { Outcome or subgroup } \\
\text { title }\end{array}$ & No. of studies & $\begin{array}{l}\text { No. of partici- } \\
\text { pants }\end{array}$ & Statistical method & Effect size \\
\hline 3 Mortality & 1 & 61 & Risk Ratio $(\mathrm{M}-\mathrm{H}$, Random, 95\% Cl) & $0.97[0.06,14.78]$ \\
\hline
\end{tabular}

Analysis 6.1. Comparison 6 Perioperative oral nutritional supplements compared to oral multivitamin and mineral supplement, Outcome 1 Complications.

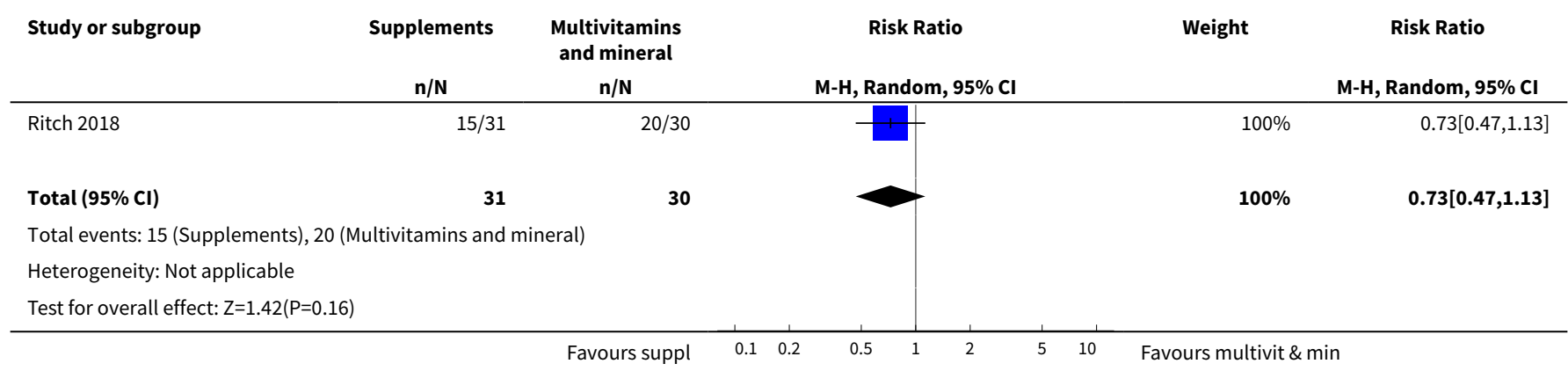

Analysis 6.2. Comparison 6 Perioperative oral nutritional supplements compared to oral multivitamin and mineral supplement, Outcome 2 Length of hospital stay.

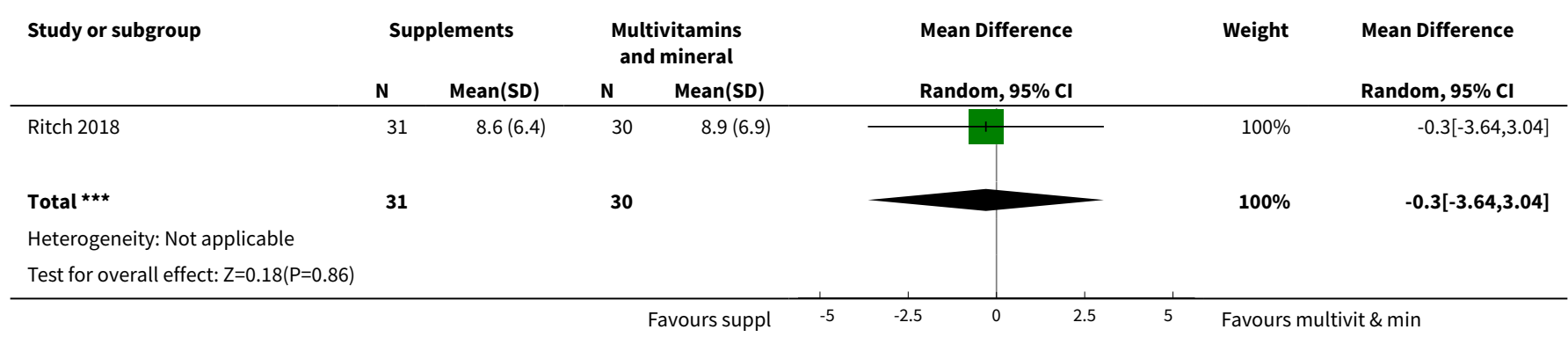

Analysis 6.3. Comparison 6 Perioperative oral nutritional supplements compared to oral multivitamin and mineral supplement, Outcome 3 Mortality.

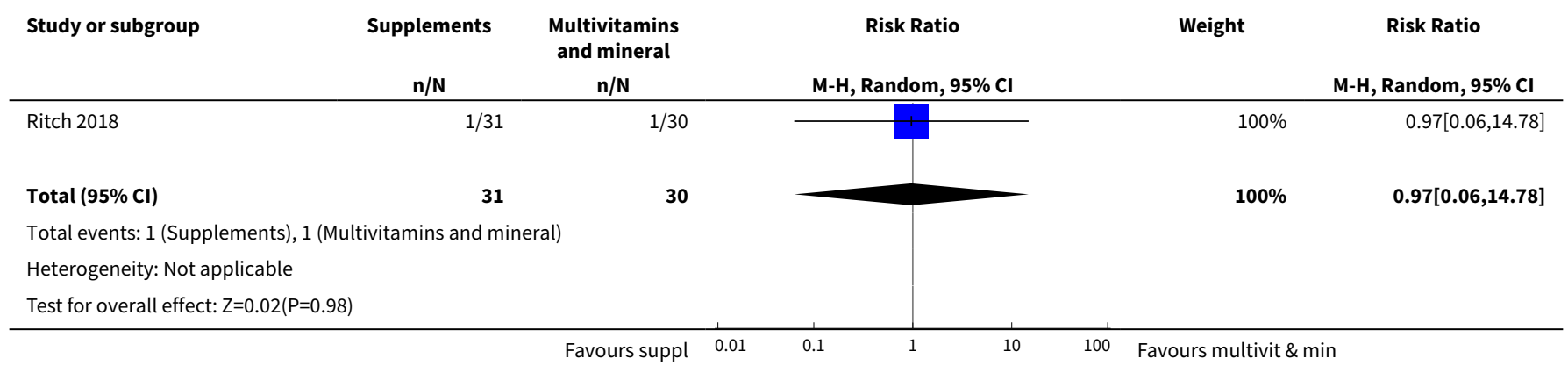




\section{ADDITIONAL TABLES}

Table 1. Description of interventions

\begin{tabular}{|c|c|c|c|c|}
\hline Study & Intervention & $\begin{array}{l}\text { Interventions ap- } \\
\text { propriate as ap- } \\
\text { plied in a clinical } \\
\text { practice settinga }\end{array}$ & Comparator & $\begin{array}{l}\text { Comparator appro- } \\
\text { priate as applied in a } \\
\text { clinical practice set- } \\
\text { tinga }\end{array}$ \\
\hline $\begin{array}{l}\text { Hamil- } \\
\text { ton-Reeves } \\
2016\end{array}$ & $\begin{array}{l}\text { I1: immuno-enhancing nutrition sup- } \\
\text { plement drinks } 3 \text { cartons daily }\end{array}$ & $\begin{array}{l}\text { Pre- and postop- } \\
\text { eratively }\end{array}$ & $\begin{array}{l}\text { C1: oral nutrition sup- } \\
\text { plement drink } 3 \text { car- } \\
\text { tons a day }\end{array}$ & $\begin{array}{l}5 \text { days pre- and } 5 \text { days } \\
\text { postoperatively }\end{array}$ \\
\hline Deibert 2016 & $\begin{array}{l}\text { I1: clear fluid diet and access to full di- } \\
\text { et on day } 2\end{array}$ & Postoperatively & $\begin{array}{l}\text { C1: standard postop- } \\
\text { erative care }\end{array}$ & $\begin{array}{l}\text { From day } 1 \text { postopera- } \\
\text { tively }\end{array}$ \\
\hline Ritch 2018 & $\begin{array}{l}\text { I1: oral nutritional supplements (En- } \\
\text { sure Clinical Strength) }\end{array}$ & $\begin{array}{l}\text { Pre and postoper- } \\
\text { atively }\end{array}$ & $\begin{array}{l}\text { C1: oral multivitamin } \\
\text { and mineral supple- } \\
\text { ment }\end{array}$ & $\begin{array}{l}3-4 \text { weeks pre- and } 4 \\
\text { weeks postoperative }\end{array}$ \\
\hline Roth 2013 & $\begin{array}{l}\text { I1: parenteral nutrition } 1500 \mathrm{~mL} / \text { day } \\
\text { (1860 kcal, } 150 \mathrm{~g} \mathrm{AA}, 360 \mathrm{~g} \text { glucose) }\end{array}$ & Postoperatively & $\begin{array}{l}\text { C1: oral nutrition with } \\
\text { Ringer's lactate solu- } \\
\text { tion with additional } \\
\text { potassium } 1500 \mathrm{~mL} / 24 \\
\text { hours }\end{array}$ & $\begin{array}{l}\text { For } 5 \text { days postopera- } \\
\text { tively }\end{array}$ \\
\hline Rovera 1989 & $\begin{array}{l}\text { I1: oral nutritional supplements (Pre- } \\
\text { cision } \mathrm{N}, 30 \mathrm{kcal} / \mathrm{kg} / \text { day, } 1.5 \mathrm{~g} \text { pro- } \\
\text { tein } / \mathrm{kg} / \text { day) }\end{array}$ & $\begin{array}{l}10 \text { days preopera- } \\
\text { tively }\end{array}$ & $\begin{array}{l}\text { C1: normal diet up to } \\
\text { surgery }\end{array}$ & $\begin{array}{l}\text { Normal diet up to } \\
\text { surgery }\end{array}$ \\
\hline \multirow[t]{2}{*}{ Bonau 1984} & $\begin{array}{l}\text { I1: AA solution containing } 25 \% \text { branch } \\
\text { chain }(30 \mathrm{kcal} / \mathrm{kg} / \text { day, } 1.5 \mathrm{~g} \text { of pro- } \\
\text { tein } / \mathrm{kg} / \text { day) }\end{array}$ & \multirow[t]{2}{*}{$\begin{array}{l}\text { Started postop- } \\
\text { erative day } 1 \text { and } \\
\text { stopped postoper- } \\
\text { ative day } 8\end{array}$} & \multirow[t]{2}{*}{$\begin{array}{l}\text { C1: dextrose } 150 \mathrm{~g} \\
\text { in } 3 \mathrm{~L} \text { of water (intra- } \\
\text { venously adminis- } \\
\text { tered over } 24 \text { hours) }\end{array}$} & \multirow[t]{2}{*}{$\begin{array}{l}\text { Infusions started at } \\
\text { postoperative day } 1 \\
\text { and stopped at post- } \\
\text { operative day } 8\end{array}$} \\
\hline & $\begin{array}{l}\text { I2: AA solution with } 45 \% \text { branch chain } \\
\text { AA ( } 30 \mathrm{kcal} / \mathrm{kg} / \mathrm{day}, 1.5 \mathrm{~g} \text { of protein } / \mathrm{kg} / \\
\text { day) }\end{array}$ & & & \\
\hline \multirow[t]{2}{*}{ Daly 1982} & $\begin{array}{l}\text { I1: AA solution containing (1.3-1.5 g/ } \\
\text { kg/day) }\end{array}$ & \multirow{2}{*}{$\begin{array}{l}3 \text { days preopera- } \\
\text { tively until a min- } \\
\text { imum of } 7 \text { days } \\
\text { postoperatively }\end{array}$} & \multirow[t]{2}{*}{$\begin{array}{l}\text { C1: dextrose (intra- } \\
\text { venously adminis- } \\
\text { tered) }\end{array}$} & \multirow[t]{2}{*}{$\begin{array}{l}3 \text { days preoperatively } \\
\text { until a minimum of } 7 \\
\text { days postoperatively }\end{array}$} \\
\hline & $\begin{array}{l}\text { 12: intravenous fluids containing dex- } \\
\text { trose and AA (1.3-1.5 g/kg/day) }\end{array}$ & & & \\
\hline \multirow[t]{2}{*}{ Hensle 1978} & $\begin{array}{l}\text { I1: AA } 0.7-1.0 \mathrm{~g} / \mathrm{kg} / \text { day and calories } \\
240 \mathrm{kcal} / \text { day }\end{array}$ & & C1: $5 \%$ dextrose & Postoperative \\
\hline & & Duration NR & & Duration NR \\
\hline
\end{tabular}

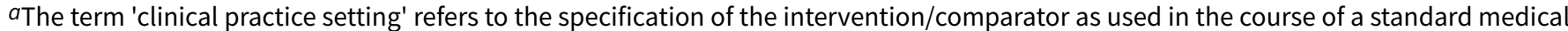
treatment (such as dose, dose escalation, dosing scheme, provision for contraindications and other important features). AA: amino acid; C: comparator; I: intervention; N/CPS: no specification of clinical practice setting possible; NR: not reported.

Table 2. Baseline characteristics

\begin{tabular}{|c|c|c|c|c|c|c|}
\hline Study & Intervention and comparator & $\begin{array}{l}\text { Duration of interven- } \\
\text { tion and follow-up }\end{array}$ & $\begin{array}{l}\text { Trial peri- } \\
\text { od }\end{array}$ & Country & Setting & $\begin{array}{l}\text { Ethnic } \\
\text { groups }\end{array}$ \\
\hline
\end{tabular}


Table 2. Baseline characteristics (Continued)

\begin{tabular}{|c|c|c|c|c|c|c|}
\hline \multirow{2}{*}{$\begin{array}{l}\text { Hamil- } \\
\text { ton-Reeves } \\
2016\end{array}$} & $\begin{array}{l}\text { I1: immuno-enhancing nutri- } \\
\text { tion supplement }\end{array}$ & \multirow{2}{*}{$\begin{array}{l}5 \text { days pre- and } 5 \text { days } \\
\text { postoperatively } \\
\text { Follow-up for } 90 \text { days } \\
\text { postoperatively }\end{array}$} & \multirow[t]{2}{*}{ 2013-2015 } & \multirow[t]{2}{*}{ USA } & \multirow[t]{2}{*}{$\begin{array}{l}\text { Home and } \\
\text { hospital }\end{array}$} & \multirow{2}{*}{$\begin{array}{l}- \\
-\end{array}$} \\
\hline & C1: oral nutrition supplement & & & & & \\
\hline \multirow[t]{2}{*}{ Ritch 2018} & $\begin{array}{l}\text { I1: oral nutritional supple- } \\
\text { ments }\end{array}$ & \multirow[t]{2}{*}{$\begin{array}{l}\text { Follow-up for } 30 \text { days } \\
\text { postoperatively }\end{array}$} & \multirow[t]{2}{*}{$\begin{array}{l}\text { April 2014- } \\
\text { December } \\
2016\end{array}$} & \multirow[t]{2}{*}{ USA } & \multirow[t]{2}{*}{$\begin{array}{l}\text { Home and } \\
\text { hospital }\end{array}$} & \multirow[t]{2}{*}{-} \\
\hline & $\begin{array}{l}\text { C1: multivitamin and mineral } \\
\text { supplements }\end{array}$ & & & & & \\
\hline \multirow{3}{*}{$\begin{array}{l}\text { Deibert } \\
2016\end{array}$} & C1: normal diet & \multirow{3}{*}{$\begin{array}{l}\text { Duration NR } \\
\text { Follow-up for } 90 \text { day } \\
\text { postoperative }\end{array}$} & \multirow[t]{3}{*}{ 2011-2014 } & \multirow[t]{3}{*}{ USA } & \multirow[t]{3}{*}{ Hospital } & $74 \%$ white, \\
\hline & & & & & & $\begin{array}{l}4 \% \text { Hispan- } \\
\text { ic, } 8 \% \text { other }\end{array}$ \\
\hline & $\begin{array}{l}\text { C1: standard postoperative } \\
\text { care }\end{array}$ & & & & & $\begin{array}{l}76 \% \text { white, } \\
9.8 \% \text { black } \\
6 \% \text { Hispan- } \\
\text { ic, } 8 \% \text { other }\end{array}$ \\
\hline \multirow[t]{2}{*}{ Roth 2013} & I1: parenteral nutrition & \multirow{2}{*}{$\begin{array}{l}5 \text { days postoperatively } \\
\text { Follow-up for } 30 \text { days } \\
\text { postoperatively }\end{array}$} & \multirow[t]{2}{*}{ 2008-2011 } & \multirow[t]{2}{*}{ Switzerland } & \multirow[t]{2}{*}{ Hospital } & - \\
\hline & $\begin{array}{l}\text { C1: oral nutrition with Ringer's } \\
\text { lactate solution }\end{array}$ & & & & & - \\
\hline \multirow[t]{2}{*}{$\begin{array}{l}\text { Rovera } \\
1989\end{array}$} & $\begin{array}{l}\text { I1: oral nutritional supple- } \\
\text { ments }\end{array}$ & \multirow{2}{*}{$\begin{array}{l}10 \text { days preoperatively } \\
\text { Follow-up } 30 \text { days post- } \\
\text { operatively }\end{array}$} & \multirow[t]{2}{*}{-} & \multirow[t]{2}{*}{ Italy } & \multirow[t]{2}{*}{-} & - \\
\hline & C1: normal diet & & & & & - \\
\hline \multirow[t]{3}{*}{$\begin{array}{l}\text { Bonau } \\
1984\end{array}$} & $\begin{array}{l}\text { I1: AA solution with } 25 \% \\
\text { branch chain AA }\end{array}$ & \multirow{3}{*}{$\begin{array}{l}\text { From postoperative } \\
\text { days 1-8 } \\
\text { Follow-up NR }\end{array}$} & \multirow[t]{3}{*}{-} & \multirow[t]{3}{*}{ USA } & \multirow[t]{3}{*}{ Hospital } & - \\
\hline & $\begin{array}{l}\text { 12: AA solution with } 45 \% \\
\text { branch chain AA }\end{array}$ & & & & & - \\
\hline & C1: dextrose & & & & & - \\
\hline \multirow[t]{2}{*}{$\begin{array}{l}\text { Hensle } \\
1978\end{array}$} & $\begin{array}{l}\text { I1: intravenous fluids contain- } \\
\text { ing dextrose and } A A\end{array}$ & \multirow{2}{*}{$\begin{array}{l}\text { Duration NR } \\
\text { Follow-up } 60 \text { days }\end{array}$} & \multirow[t]{2}{*}{-} & \multirow[t]{2}{*}{ USA } & \multirow[t]{2}{*}{ Hospital } & - \\
\hline & C1: $5 \%$ dextrose & & & & & - \\
\hline
\end{tabular}

AA: amino acid; C: comparator; I: intervention; NR: not reported.

\section{APPENDICES}

\section{Appendix 1. Evidence Based Medicine Reviews (Ovid) search strategy}

1. bladder cancer.mp. [mp=ti, ot, ab, tx, kw, ct, sh, hw]

2. (bladder cancer $^{\star}$ or tumor ${ }^{\star}$ or tumour ${ }^{\star}$ or neoplas ${ }^{\star}$ or malignan ${ }^{\star}$ or carcinoma*).mp. [mp=ti, ot, ab, tx, kw, ct, sh, hw]

3. cystectomy.mp. [mp=ti, ot, ab, tx, kw, ct, sh, hw] 
4. NURITIONAL STATUS.mp. [mp=ti, ot, ab, tx, kw, ct, sh, hw]

5. Food.mp. [mp=ti, ot, ab, tx, kw, ct, sh, hw]

6. immune enhancing nutrition.mp. [mp=ti, ot, ab, tx, kw, ct, sh, hw]

7. NUTRITIONAL SUPPORT.mp. [mp=ti, ot, ab, tx, kw, ct, sh, hw]

8. 1 or 2

9. 4 or 5 or 6 or 7

10. 3 and 8 and 9

\section{Appendix 2. MEDLINE (Ovid) search strategy}

1. $\exp$ BLADDER NEOPLASMS/

2. ((bladder $\left.{ }^{\star}\right) \operatorname{adj5}\left(\right.$ cancer $^{\star}$ OR tumour ${ }^{\star}$ OR tumour ${ }^{\star}$ OR neoplas ${ }^{\star}$ OR malignant ${ }^{\star}$ OR carcinoma*)).mp

3. 1 OR 2

4. $\exp$ PERIOPERATIVE CARE/

5. exp PERIOPERATIVE PERIOD/

6. (peri-operative OR perioperative).mp

7. ((cystect*) $\operatorname{adj5}\left(\operatorname{rad}^{\star}\right.$ OR total $\left.\left.{ }^{\star}\right)\right) \cdot m p$

8. $\exp$ CYSTECTOMY/

9. 4 OR 5 OR 6 OR 7 OR 8

10. exp NUTRITIONAL SUPPORT/

11 exp NUTRITIONAL STATUS/

12 exp NUTRITION THERAPY/

$13 \exp$ NUTRITION ASSESSMENT/

14 exp CACHEXIA/

15 exp MALNUTRITION/

16 exp BODY WEIGHT/

17 exp WEIGHT LOSS/

18 exp THINNESS/

19 (weight OR underweight OR weight loss OR thinness OR cachexia OR malnutrition).mp

2010 OR 11 OR 12 OR 13 OR 14 OR 15 OR 16 OR 17 OR 18 OR 19

$21 \exp$ FOOD/

22 exp FOOD, FORMULATED/

23 exp VITAMINS/

24 exp MICRONUTRIENTS/

25 (nutrition* OR nutrient* OR macronutrient* OR micronutrient* OR immuno nutrition OR immuno-nutrition).mp

26 exp DIET/

27 diet.mp

Perioperative nutrition for the treatment of bladder cancer by radical cystectomy (Review) 
28 exp DIET THERAPY/

29 exp AMINO ACIDS/

30 exp FATTY ACIDS/

31 exp FATTY ACIDS, Omega-3/

32 exp FISH OILS

33 exp GLUTAMINE

34 exp ARGININE/

35 exp NITROGEN

36 novel AND substrate ${ }^{\star} . \mathrm{mp}$

37 (diet therap ${ }^{\star}$ OR amino acid ${ }^{\star}$ OR fatty acid* OR fish oil ${ }^{\star}$ OR glutamine ${ }^{\star}$ ).mp

3821 OR 22 OR 23 OR 24 OR 25 OR 26 OR 27 OR 28 OR 29 OR 30 OR 31 OR 32 OR 33 OR 34 OR 35 OR

36 OR 37

39 exp FEEDING METHODS/

40 exp ENTERAL NUTRITION/

41 exp PARENTERAL NUTRITION/

42 exp PARENTERAL NUTRITION, TOTAL/

43 exp GASTROSTOMY/

44 exp JEJUNOSTOMY/

45 (enteral OR parenteral OR TPN OR naso-gastric OR nasogastric OR gastrostomy OR jejunostomy OR hyperalimentation).mp

4639 OR 40 OR 41 OR 42 OR 43 OR 44 OR 45

4720 OR 38 OR 46

48 randomized AND controlled AND trial.pt.

49. controlled AND clinical AND trial.pt.

50. randomized.ab.

51 placebo.ab.

52 clinical AND trials AND as AND topic.sh.

53. trial.ti.

5448 OR 49 OR 50 OR 51 OR 52 OR 53

553 AND 9 AND 47 AND 54

56 exp ANIMALS/ NOT humans.sh

55 NOT 56

\section{Appendix 3. Embase (Ovid) search strategy}

1 EXP BLADDER TUMOR/

2 (bladder* adj3 (cancer* or tumo?r* or neoplas* or malignan* or carcinoma*)).mp

31 or 2

Perioperative nutrition for the treatment of bladder cancer by radical cystectomy (Review) 
4 PERIOPERATIVE PERIOD/

5 (peri-operative or perioperative).mp.

6 EXP BLADDER SURGERY/

7 EXP CYSTECTOMY/

8 (cystectom ${ }^{\star}$ or cystostom ${ }^{\star}$ or cytostom ${ }^{\star}$ or ureteroneocystectom $\left.{ }^{\star}\right) \cdot \mathrm{mp}$.

9 or/4-8

10 EXP NUTRITIONAL SUPPORT/

11 EXP NUTRITIONAL STATUS/

12 EXP DIET THERAPY/

13 EXP NUTRITIONAL ASSESSMENT/

14 EXP MALNUTRITION/

15 EXP CACHEXIA/

16 EXP BODY WEIGHT/

17 / EXP WEIGHT REDUCTION

18 EXP FOOD/

19 EXP FOOD INTAKE/

20 EXP NUTRITION/

21 EXP PARENTERAL NUTRITION/

22 EXP ENTERIC FEEDING/

23 EXP NOSE FEEDING/

24 EXP GASTROSTOMY/

25 EXP JEJUNOSTOMY/

26 EXP FISH OIL/

27 EXP AMINO ACID/

28 EXP FATTY ACIDS/

29 EXP OMEGA 3 FATTY ACID/

30 EXP GLUTAMINE/

31 EXP ARGININE/

32 EXP NITROGEN/

33 EXP TRACE ELEMENTS/

34 EXP VITAMIN/

35 (weight or underweight or thinness or cachexia or malnutrition).mp.

36 (nutrition ${ }^{\star}$ or nutrient ${ }^{\star}$ or macronutrient ${ }^{\star}$ or micronutrient ${ }^{\star}$ or immunonutrition or immuno-nutrition).mp.

37 (food $^{\star}$ or feed $^{\star}$ or supplement ${ }^{\star}$ or vitamin $^{\star}$ or mineral ${ }^{\star}$ or protein ${ }^{\star}$ or fat $^{\star}$ or carbohydrate $^{\star}$ or calorie $\left.{ }^{\star}\right) . \mathrm{mp}$.

38 (amino acid* or fatty acid* or fish oil ${ }^{\star}$ or "omega 3 " or glutamin* or arginine).mp.

Perioperative nutrition for the treatment of bladder cancer by radical cystectomy (Review) 
39 (enteral or parenteral or TPN or naso-gastric or nasogastric or gastrostomy or jejunostomy).mp.

40 (novel adj2 substrat $\left.{ }^{\star}\right)$.tw.

41 or $/ 10-40$

423 and 9 and 41

43 CROSSOVER PROCEDURE/

44 DOUBLE-BLIND PROCEDURE/

45 RANDOMIZED CONTROLLED TRIAL/

46 SINGLE-BLIND PROCEDURE/

47 (random or factorial\$ or crossover\$ or cross over\$ or placebo $\$$ or assign\$ or allocat\$ or volunteer\$).mp.

48 ((doubl\$ or singl\$) adj blind\$).mp.

49 or $/ 43-48$

5042 and 49

\section{Appendix 4. AMED (Ovid) search strategy}

1 exp BLADDER NEOPLASMS/

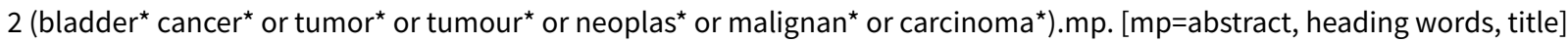

31 or 2

4 exp humans/ or exp Surgery/ or surgical ${ }^{\star} . \mathrm{mp}$.

53 and 4

6 exp Nutritional status/ or exp Therapy/ or exp Nutrition/ or NUTRITIONAL SUPPORT.mp. or Neoplasms/

7 Nutrition therapy/ or NUTRITION THERAPY.mp.

8 Diet/ or Nutrition/ or Metabolism/ or NUTRITION ASSESSMENT.mp. or Diet therapy/

9 exp cachexia/ or CACHEXIA.mp.

10 Body weight/ or BODY WEIGHT.mp.

11 Weight loss/ or WEIGHT LOSS.mp.

12 THINNESS.mp. or Body image/

136 or 7 or 8 or 9 or 10 or 11 or 12

14 Dietary supplements/ or Food/ or Diet/ or Food.mp.

15 FOOD, FORMULATED.mp. or Food/

16 exp Nutrition/ or exp Vitamins/ or VITAMINS.mp.

17 Nutrition/ or exp Vitamins/ or MICRONUTRIENTS.mp. or exp Minerals/ or Diet/

18 DIET.mp. or exp Diet/ or exp Vitamins/

19 exp Nutrition/ or exp Diet therapy/ or DIET THERAPY.mp.

20 Dietary supplements/ or exp Amino acids/ or exp Nutrition/ or AMINO ACIDS.mp.

21 FATTY ACIDS/

22 humans/ or Fatty acids/ or FATTY ACIDS, Omega-3.mp. 
23 exp Fish oils/ or Diet therapy/ or FISH OILS.mp.

24 Metabolism/ or exp Amino acids/ or GLUTAMINE.mp.

25 Postoperative complications/ or Surgery operative/ or exp Enteral feeding/ or Nutrition disorders/ or JEJUNOSTOMY.mp.

26 humans/ or Amino acids/ or ARGININE.mp. or exp Dietary supplements/

27 exp Nitrogen/ or exp Muscle physiology/or nitrogen.mp.

2814 or 15 or 16 or 17 or 18 or 19 or 20 or 21 or 22 or 23 or 24 or 25 or 26 or 27

29 Gastrostomy/ or exp Feeding methods/ or FEEDING METHODS.mp.

$30 \mathrm{Food} /$ or Enteral feeding/ or enteral.mp.

31 Parenteral feeding/ or Therapy/ or parenteral.mp.

32 Gastrostomy/ or GASTROSTOMY.mp. or Enteral feeding/

33 exp Enteral feeding/ or JEJUNOSTOMY.mp.

3429 or 30 or 31 or 32 or 33

3528 or 34

36 randomised controlled trial.mp. or exp Randomized controlled trials/

37 trial.mp. or exp Clinical trials/ or exp Randomized controlled trials/

3836 or 37

3913 or 35

403 and 5 and 38 and 39

41 limit 40 to $y r=" 2012$-Current"

\section{Appendix 5. CINAHL (Ebsco) search strategy}

Search terms used were 'cystectomy', 'nutrition', 'diet'; these were combined to run the search.

Appendix 6. mRCT search strategy

Search terms: bladder cancer, nutrition

\section{Appendix 7. $\mathrm{NCl}$ search strategy}

Search terms: bladder cancer, supportive therapy, nutrition all stages of trials.

\section{Appendix 8. ClinicalTrials.gov search strategy}

Search terms: bladder cancer, nutrition

\section{Appendix 9. WHO ICTRP search strategy}

Search terms: bladder cancer, nutrition

\section{Appendix 10. Zetoc search strategy}

Search terms: bladder cancer, nutrition

\section{Appendix 11. WorldCatDissertations search strategy}

Search terms: bladder cancer and nutrition

\section{CONTRIBUTIONS OF AUTHORS}

$\mathrm{HAB}$ and SB wrote the protocol. 
SB and $\mathrm{HAB}$ wrote the review.

SB and HAB completed the analysis and the 'Summary of findings' tables.

KO, HAB and SB reviewed titles for included studies.

AM provided expert surgical knowledge regarding the interpreting of the studies.

SL provided expert knowledge on clinical nutrition and all authors contributed to the script.

\section{DECLARATIONSOF INTEREST}

SB: received a Macmillan Post Doctoral Fellowship Award for postdoctoral research, which was paid to her institution and unrelated to this work.

HAB: the author's institution, Central Manchester University Hospitals NHS Foundation Trust (CMFT) receives some funds in association with enteral feed procurement from Nutricia Ltd who have had no involvement with this Review.

SL: received honoraria and educational support from Baxter, B Braun and Fresenius Kabi which was unrelated to this work.

KAO: the author's institution, Central Manchester University Hospitals NHS Foundation Trust (CMFT) receives some funds in association with enteral feed procurement from Nutricia Ltd who have had no involvement with this review.

AM: received honoraria and educational support from Eli Lilly and Bayer.

\section{SOURCES OF SUPPORT}

\section{Internal sources}

- National Health Service (NHS), UK.

All authors work in the NHS and receive salaries from the NHS

\section{External sources}

- Macmillan Cancer Care, UK.

SB is supported by a Post Doctoral Fellowship from Macmillan Cancer Care

\section{DIFFERENCES BETWEEN PROTOCOLANDREVIEW}

This review was based on a published protocol (Burden 2012b), with differences as described here.

- Nutrition measures and biochemistry markers were listed as a secondary outcome but were excluded from the review based on guidance from the editorial group to focus on patient-important outcomes.

- In the protocol, searches were to include CRG's Specialised Register, CENTRAL, BNI, DARE and Physicians Data Query; however, instead we searched Evidence Based Medicine. This change was due to the availability of databases changing over time and the Evidence Based Medicine became available and was considered a more appropriate option for this topic. We were unable to access the OCLC WorldCat Dissertations and Theses website after December 2014 due to changes in the website. We did not search the CRG's Specialised Register due to the transfer of this review from the Renal to the Urology Group.

- In the Methods section 'Types of studies', we clarified that quasi-RCTs were eligible for inclusion, for consistency with the 'Unit of analysis issues' section.

- We added for clarification, "studies where a nutritional intervention was included in a package of care have been excluded" to methods section.

- In the Methods section 'Search methods for identification of studies', we clarified that the search methods did not utilise restrictions based on language of publication or publication status.

- We updated methods to correspond to current MECIR and editorial group standards at the time of publication. This included the use of GRADE on a per-outcome basis (Schünemann 2011).

\section{NOTES}

Parts of the Methods section of this review were based on a standard template developed by the Cochrane Metabolic and Endocrine Disorders Group that has been modified and adapted for use by the Cochrane Urology Group. 


\section{N D EX TERMS}

\section{Medical Subject Headings (MeSH)}

${ }^{\star}$ Perioperative Care; Cystectomy [ ${ }^{*}$ methods]; Length of Stay; Nutritional Status; Postoperative Complications [ ${ }^{*}$ epidemiology]; Urinary Bladder Neoplasms [*surgery]; Wound Healing

\section{MeSH check words}

Humans 